\title{
Rede de apoio social dos idosos no município de São Paulo: Estudo SABE
}

\author{
Soraya Martins de Alencar
}

Dissertação apresentada ao Programa de PósGraduação em Saúde Pública para obtenção do título de Mestre em Saúde Pública.

Área de Concentração: Epidemiologia

Orientadora: Prof ${ }^{\mathrm{a}}$ Titular Maria Lúcia Lebrão

\section{São Paulo}


É expressamente proibida a comercialização deste documento, tanto na sua forma impressa como eletrônica. Sua reprodução total ou parcial é permitida exclusivamente para fins acadêmicos e científicos, desde que na reprodução figure a identificação do autor, título, instituição $e$ ano da tese/dissertação. 
Financiamento da Fundação de Amparo à Pesquisa do Estado de São Paulo - FAPESP.

Bolsa de Mestrado: Processo 2007/53121-9 Bolsa de Auxilio à Pesquisa: Processo 2005/54947-2 


\section{AGRADECIMENTOS}

O sentimento de gratidão é profundo e não se expressa somente nessas palavras...

Inicio meus agradecimentos ao universo, pois todas as ações fazem parte dessa rede.

Agradeço aos idosos que foram entrevistados, por acreditarem que suas respostas têm força para mudar a situação de vida do nosso país.

À professora Maria Lúcia Lebrão por ter aceitado me orientar e pela oportunidade que tive de poder pesquisar esse universo tão complexo e interessante que é o envelhecimento em São Paulo.

À professora Yeda Duarte por ter aceitado fazer parte da minha banca de qualificação e defesa e pelas suas sugestões em meu trabalho.

À Ursula Karsch, pelo exemplo de pesquisadora e humanidade, que me iniciou na pesquisa acadêmica e agora por ter aceitado fazer parte da minha banca de qualificação e defesa.

Ao grupo de pesquisa Epidemiologia do Cuidador, em especial à Arlete Salimene, por todos os ensinamentos e experiências adquiridas com pesquisa em envelhecimento.

Ao professor José Maria Pacheco de Souza por ser um grande professor e pela sabedoria e paciência para me ensinar os conceitos de análises estatísticas.

Ao professor Jair Licio Ferreira Santos pela sua disposição em responder as minhas questões sobre análises estatísticas.

A todos os professores da Faculdade de Saúde Pública, com quem eu tive a oportunidade e honra de poder aprender, tanto nas disciplinas quanto no convívio diário.

Aos funcionários da Faculdade de Saúde Pública, pela simpatia e disposição no trabalho diário.

Aos funcionários do Estudo SABE que se dedicam e acreditam nessa pesquisa, com merecido respeito pela Angela e Nazaré.

Aos amigos da faculdade que tornaram o cotidiano e as disciplinas cursadas mais interessantes, com carinho especial para Eliane Golfieri, Elizabeth Hernandes, Karen Tokuhashi, Karina Paiva, Michelle Torres e Tatiana Toporcov. 
À Norma Farias, companheira das tardes no Departamento de Estatística, repletas de cinema, viagens e modelos estatísticos.

Ao meu pai por me incentivar a ter ideais. À minha mãe por me acolher com seu amor e carinho. Aos meus irmãos por acreditam em mim.

Aos amigos do coração, em diversos oceanos... Que me inspiram a ter dignidade e seguir o meu caminho.

Enfim, a todos os que nos ensinam e nos movimentam em cada momento da nossa vida. 


\section{RESUMO}

Alencar SM. Rede de apoio social dos idosos no município de São Paulo: Estudo SABE. [Dissertação de Mestrado]. São Paulo: Faculdade de Saúde Pública da USP; 2009.

Introdução - O processo de envelhecimento acarreta ao indivíduo o convívio com limitações físicas e funcionais e o acúmulo de doenças crônicas, aliado aos aspectos emocionais mais evidentes nesse período da vida que geram maior demanda por parte do idoso da sua rede de apoio formal e informal. Objetivos - Investigar os fatores associados às mudanças ocorridas, no período de 2000 a 2006, no apoio social recebido pelos idosos residentes no município de São Paulo. Métodos - Este trabalho é um recorte do Estudo Saúde, Bem-estar e Envelhecimento (SABE), estudo longitudinal de base populacional realizado, desde 2000, com 1115 idosos residentes na área urbana do município de São Paulo. $O$ instrumento utilizado foi um questionário estruturado em dez seções que versavam sobre as condições de vida e de saúde dos idosos. Para verificar os fatores associados às mudanças no apoio recebido, foram feitas análises de regressão logística multinomial. Resultados - Os idosos identificam mais apoio no seu domicílio e entre seus filhos, sendo esses apoios de caráter instrumental. A rede de apoio extradomiciliar dos familiares e amigos demonstrou-se presente, porém oscila ao longo do tempo do estudo. As condições de saúde física, comprometimento funcional e bemestar dos idosos foram indicadores da manutenção das trocas de apoio com toda a sua rede ao longo do tempo, entretanto a piora nessas condições foi acompanhada de mais apoio disponibilizado aos idosos. Conclusões $-A$ rede informal vem sendo demandada somente para as questões instrumentais de apoio por não ser acompanhada do suporte da rede formal, sendo os aspectos emocionais que o processo de envelhecimento acarreta aos idosos, que podem incidir na piora de suas condições de independência e autonomia não estarem sendo supridos pela rede.

Descritores: Idoso; Apoio social; Rede de apoio; Envelhecimento; Estudo longitudinal. 


\section{ABSTRACT}

Alencar SM. Social support network of the elderly in São Paulo: SABE Project. [Master Dissertation]. São Paulo: Faculdade de Saúde Pública da USP; 2009.

Introduction - The aging process brings the individual living with the physical and functional limitations and accumulation of chronic diseases, added to the emotional aspects more apparent during this period of life that generate increased demand by the elderly of their network of formal and informal support. Objectives - To investigate the factors associated with changes, in the period 2000 to 2006, the social support received by elderly residents in the city of São Paulo. Methods - This is a part of Study Health, Welfare and Aging (SABE), population-based longitudinal study conducted since 2000, with 1,115 elderly residents in the urban area of São Paulo. The instrument used was a questionnaire structured in ten sections that deals with the conditions of life and health of the elderly. To determine the factors associated with changes in support received, were analyzed in multinomial logistic regression. Results Older people identify more support at home and among their children, and support those that are instrumental. The extra home support network of family and friends showed present, but fluctuates over time of the study. The physical conditions, functional and well-being of the elderly were indicators of maintaining the exchange of support with all their network over time, but the worsening in these conditions was accompanied by more support available for the elderly. Conclusions - The network is being demanded only for instrumental support issues for not being accompanied by the formal support network, and the emotional aspects to the aging process involves the elderly, which may relate to worsening of their conditions of independence and autonomy not being supplied by the network.

Keywords: Elderly; Social support; Network support; Aging; Longitudinal study. 


\section{SUMÁRIO}

1. INTRODUÇÃO 12

1.1 ENVELHECIMENTO E CONDIÇŌES DE SAÚDE___ 14

1.2 REDE SOCIAL 16

1.3 APOIO SOCIAL 19

1.4 TROCA SOCIAL 25

1.5 APOIO INTERGERACIONAL__ 26

2. OBJETIVOS 30

2.1 OBJETIVO GERAL 30

2.2 OBJETIVOS ESPECÍFICOS 30

3. MATERIAIS E MÉTODOS — 31

3.1 O ESTUDO SABE 31

3.1.1 O ESTUDO SABE 2000 - COORTE A $A_{00}$

3.1.2 INSTRUMENTO _ 32

3.1.3 AMOSTRA 35

3.1.4 PROCEDIMENTO DE COLETA DE DADOS __ 36

3.1.5 O ESTUDO SABE 2006 - COORTE $A_{06} \longrightarrow 36$

3.2 VARIÁVEIS DE ESTUDO 37

3.2.1 VARIÁVEL DEPENDENTE_ 37

3.2.2 VARIÁVEIS INDEPENDENTES_ 38

3.3 ANÁLISE ESTATÍSTICA

3.4 PARECER DO COMITÉ DE ÉTICA___ 42

4. RESULTADOS E DISCUSSÃO 43

4.1 CARACTERÍSTICAS SOCIODEMOGRÁFICAS E DE SAÚDE DOS IDOSOS 43

4.2 REDE DE APOIO SOCIAL DOS IDOSOS 48

4.3 MUDANÇAS NO APOIO SOCIAL RECEBIDO PELOS IDOSOS _ 56

TABELA EM PAISAGEM

4.4 FATORES ASSOCIADOS ÁS MUDANÇAS NO APOIO RECEBIDO

PELOS IDOSOS 77

5. CONCLUSÕES 88

6. REFERÊNCIAS BIBLIOGRÁFICAS __ 91

ANEXOS 100

ANEXO 1 TERMO DE APROVAÇÃO DO COMITÉ DE ÉTICA EM PESQUISA

DA FACULDADE DE SAÚDE PÚBLICA

ANEXO 2 TERMO DE APROVAÇÃO DA COMISSÃO NACIONAL DE ÉTICA

EM PESQUISA

ANEXO 3 TERMO DE APROVAÇÃO DO COMITÉ DE ÉTICA EM PESQUISA DA FACULDADE DE SAÚDE PÚBLICA 104

ANEXO 4 QUESTIONÁRIOS DO ESTUDO SABE 2000 E 2006 106 


\section{LISTA DE TABELAS}

Tabela 1 - Características sociodemográficas dos idosos, Município de São Paulo, 2000 e $2006(n=1115)$.

Tabela 2 - Características de saúde dos idosos, município de São Paulo, SP, 2000 e $2006(n=1115)$. 48

Tabela 3 - Disponibilidade da rede de apoio domiciliar e extradomiciliar (filhos) dos idosos, Município de São Paulo, 2000 e 2006 ( $n=1115$ ). 52

Tabela 4 - Características estruturais da rede de apoio domiciliar e extradomiciliar (filhos, outros familiares e amigos) dos idosos, Município de São Paulo, 2000 e 2006 ( $n=1115)$.

Tabela 5 - Características funcionais da rede de apoio domiciliar e extradomiciliar (filhos, outros familiares e amigos) dos idosos, Município de São Paulo, 2000 e 2006 ( $n=1115)$.

Tabela 6 - Mudança no apoio social dos idosos nos dois momentos, segundo sexo e fluxo dos apoios domiciliar e extradomiciliar (filhos, outros familiares e amigos), Município de São Paulo, 2000 e 2006 ( $n=1115)$. 59

Tabela 7 - Mudança no apoio recebido pelos idosos nos dois momentos, segundo características sociodemográficas, Município de São Paulo, 2000 e $2006(n=1.115)$.

Tabela 8 - Mudança no apoio recebido pelos idosos nos dois momentos, segundo características de saúde, Município de São Paulo, 2000 e 2006 $(n=1115)$.

Tabela 9 - Mudança no apoio recebido pelos idosos nos dois momentos, segundo disponibilidade da rede de apoio domiciliar e extradomiciliar (filhos), Município de São Paulo, 2000 e 2006 ( $n=1115)$.

Tabela 10 - Mudança no apoio recebido pelos idosos nos dois momentos, segundo características estruturais da rede de apoio domiciliar e extradomiciliar (filhos, outros familiares e amigos), Município de São Paulo, 2000 e 2006 $(n=1115)$.

Tabela 11 - Mudança no apoio recebido pelos idosos nos dois momentos, segundo características funcionais da rede de apoio domiciliar e extradomiciliar (filhos, outros familiares e amigos), Município de São Paulo, 2000 e 2006 $(n=1115)$.

Tabela 12 - Resultados da análise de regressão logística multinomial univariada das mudanças no apoio recebido pelos idosos e características sociodemográficas e de saúde, Município de São Paulo, 2000 e $2006(n=1115)$. 
Tabela 13 - Resultados da análise de regressão logística multinomial univariada das mudanças no apoio recebido pelos idosos e características da rede de apoio domiciliar e extradomiciliar, Município de São Paulo, 2000 e 2006 $(n=1115)$.

Tabela 14 - Modelo de regressão logística multinomial multivariada dos fatores associados às mudanças no apoio recebido pelos idosos, Município de São Paulo, $2000(n=1115)$. 86

Tabela 15 - Modelo de regressão logística multinomial multivariada dos fatores associados às mudanças no apoio recebido pelos idosos, Município de São Paulo, 2000 e 2006 ( $n=1115)$. 


\section{INTRODUÇÃO}

A questão do envelhecimento tem aparecido em diversas discussões públicas tanto no mundo como no Brasil, devido ao processo rápido de envelhecimento das populações nos países em desenvolvimento como também à forma como está se dando o envelhecimento nesses países. As projeções da Organização das Nações Unidas (ONU) apontam que, em 2050, os paises em desenvolvimento, dos quais o Brasil faz parte, terão $80 \%$ da população de idosos ${ }^{1}$ do mundo.

As mudanças na estrutura etária da população afetam não só os indivíduos, como também suas famílias e a sociedade. Nesse contexto, a ONU realizou duas assembléias mundiais para discutir as questões relacionadas ao envelhecimento, a primeira em 1982, em Viena, Áustria, e a segunda, em 2002, em Madri, Espanha. O objetivo dessas assembléias foi traçar recomendações para que os países pudessem se organizar para suprir as demandas advindas desse grupo populacional, além de trazer a questão do idoso não como um segmento vulnerável, mas como um indivíduo com características particulares, porém ativo socialmente (TORNEL, 2002; CAMARANO e PASINATO, 2004; KALACHE, 2008).

Uma das principais preocupações da ONU é tentar sensibilizar os países para estas questões por meio de pactos globais, firmados de tempos em tempos, visando seu comprometimento com a questão do envelhecimento e o cumprimento de metas para o seu enfrentamento (ANTONUCCI et al., 2002).

A preocupação em torno do processo acelerado de envelhecimento das populações dos países em desenvolvimento é devido ao fato de os governos e sociedades desses países terem, como conseqüência da economia capitalista globalizada, grande desigualdade social, refletida na elevada proporção de suas populações vivendo em condições de pobreza e vulnerabilidade social. Aliado ao contexto histórico e econômico desses governos que,

\footnotetext{
${ }^{1}$ A Organização Mundial de Saúde - OMS define idoso como o indivíduo com idade a partir de 60 anos, para os países em desenvolvimento, e a partir de 65 anos, para os países desenvolvidos.
} 
gradativamente, se desresponsabilizam em implantar e gerir políticas sociais (SOARES, 2000).

O processo de envelhecimento dos países em desenvolvimento ocorreu devido à melhoria das condições de vida de sua população associada às intervenções da tecnologia médica que permitiram maior controle das mortes prematuras, a prevenção e/ou tratamento de grande parte das enfermidades infecciosas que, no passado tinham elevada letalidade. Entretanto essa melhora, nesses países, não na população como um todo.

Aliado ao aumento da estrutura etária da população, nesses países, tem-se a precariedade nas relações sociais e de trabalho, que se manifestam, no campo da saúde, através da complexidade do quadro epidemiológico, ocorrendo o aumento das doenças crônico-degenerativas e os agravos de natureza social, como também, o recrudescimento de doenças transmissíveis até então controladas (dengue, febre amarela etc).

Nesse contexto, os sistemas de proteção social, principalmente aqueles ligados às necessidades de saúde da população idosa, são ainda aquém da necessiadade fazendo com que as redes de apoio familiar e outras redes pessoais ou comunitárias, constituam-se como importantes fontes de apoio aos idosos (SOSA e HUENCHUAN, 2002). A Organização Mundial da Saúde (OMS) destaca que entre a população idosa, "quando não há provisão de cuidados formais adequados, a assistência informal permanece como o principal aliado (OMS, $2000^{2}$ apud OMS, 2005, p. 38).

Com o avançar da idade, os recursos provenientes de aposentadoria e pensão não suprem as demandas requeridas pelos idosos. Em estudo com a população idosa do município de São Paulo verificou-se que $66,7 \%$ dos homens e $68,0 \%$ das mulheres, em 2000 , e $51,0 \%$ dos homens e $49,5 \%$ das mulheres, em 2006, consideravam sua renda insuficiente para suprir suas necessidades (LEBRÃO e DUARTE, 2008).

$O$ apoio familiar adquire assim, um significado diferente quando comparado às outras etapas da vida. Isso é mais evidente nos países em desenvolvimento onde os idosos contam com um sistema de proteção social

${ }^{2} \mathrm{OMS}$. Long-term care laws in five developed countries: a review. OMS/NMH/CCl/002. Genebra: OMS, 2000. 
disponível e preparado para lidar com suas crescentes demandas específicas (HUENCHUAN, 2004).

Guzmán, Huenchuan e Montes de Oca (2002) ressaltam ser impensável ao Estado garantir à população condições de vida favoráveis para alcançar uma velhice com independência econômica e boas condições de saúde, sem levar em conta uma estrutura social que permita, facilite e potencialize as redes de apoio e as trocas informais existentes na sociedade e que se estruturam em torno do apoio familiar.

Os problemas que os idosos enfrentam afetam suas famílias e a sociedade, pois envolvem não somente a forma como as políticas sociais são direcionadas, mas também as mudanças que implicam nas relações sociais e familiares.

É importante destacar as mudanças na estrutura familiar decorrentes da vida no contexto urbano, como a diminuição do tamanho das famílias, a crescente incorporação da mulher no mercado de trabalho e as alterações nos padrões de uniões conjugais pois essas interferem na rede de relações sociais e familiares que cercam os idosos (LOWENSTEIN, 1999; KOMTER e VOLLEBERGH, 2002; MONTES DE OCA, 2002; ATTIAS-DONFUT et al., 2005).

\subsection{ENVELHECIMENTO E CONDIÇÕES DE SAÚDE}

O avanço da medicina moderna, a industrialização e a urbanização estão entre os principais fatores que possibilitaram o crescente processo de envelhecimento da população mundial e, conseqüentemente, acarretaram mudanças no seu perfil epidemiológico, passando de doenças infectocontagiosas para doenças crônico-degenerativas.

As principais doenças crônicas que acometem os idosos no mundo são: doenças cardiovasculares, hipertensão, Acidente Vascular Cerebral (AVC), diabetes, câncer, Doença Pulmonar Obstrutiva Crônica (DPOC), doenças músculo-esqueléticas, doenças mentais, comprometimento parcial ou total da acuidade visual (OMS, 2005). 
Quando tais condições não são adequadamente acompanhadas e controladas podem surgir, como consequência, o comprometimento funcional que resulta em limitação na execução de determinadas atividades cotidianas, denominadas atividades de vida diária (AVDs). Tais atividades envolvem tanto as relacionadas ao autocuidado quanto as necessárias para a manutenção da participação e do convívio social. Porém, Veras $(2003$, p.13) destaca que

[...] de acordo com os mais modernos conceitos gerontológicos, esse idoso que mantém sua autodeterminação, e prescinde de qualquer ajuda ou supervisão para realizar-se no dia-a-dia, deve ser considerado um idoso saudável, ainda que seja portador de uma ou mais doenças crônicas.

A OMS (2005, p.45) salienta que as ações de saúde devem ser direcionadas no sentido de possibilitarem que os fatores de risco comportamentais e ambientais para as doenças crônicas e declínio da capacidade funcional sejam mantidos baixos, pois dessa forma "as pessoas desfrutam maior quantidade e maior qualidade de vida, permanecem sadias $e$ capazes de cuidar de sua própria vida à medida que envelhecem, e poucos idosos precisam constantemente de tratamentos médicos e serviços assistenciais onerosos".

Os organismos internacionais e conferências de saúde pública apontam a saúde como sendo o bem-estar físico, mental e social. As condições e recursos fundamentais para a saúde abrangem a paz, habitação, educação, alimentação, renda, ecossistema estável, recursos sustentáveis, justiça social e equidade. A falta de controle das pessoas em algum destes fatores incide na não realização total de seus potenciais de saúde (WHO, 1986).

Nesse sentido, outras dimensões passam a integrar a promoção da saúde como o apoio social, o autocuidado e um ambiente saudável. A OMS (2005, p. 13) ressalta que "as políticas e programas que promovem a saúde mental e relações sociais são tão importantes quanto aquelas que melhoram as condições físicas de saúde".

A promoção da saúde é entendida como o processo de capacitação da comunidade para atuar na melhoria de sua qualidade de vida e saúde, incluindo uma maior participação no controle desse processo (WHO, 1986). 
Visa trabalhar através de ações comunitárias que possibilitem maior empoderamento (empowerment) do indivíduo, entendido como um processo pelo qual este passa a ter mais controle sobre o seu destino (MINKLER, 1992; ISRAEL et al., 1994; LABONTE, 1994).

Através dessa concepção, as relações informais, como família e amigos, a disponibilidade de apoio que o idoso tem para executar suas AVDs, como também os sentimentos em que esta relação de apoio ocorre, são fatores extremamente importantes para promover e manter a sua saúde, pois influenciam na sua capacidade de se manter ativo, com autonomia e em convívio social. Dessa forma, o envelhecimento abrange não só o idoso, como também toda a sua rede social, que é composta por amigos, vizinhos, colegas de trabalho e familiares.

\subsection{REDE SOCIAL}

A partir dos anos 50, no campo das ciências sociais, o termo rede social passa a ser utilizado de forma analítica para dar significado às causas complexas que envolvem os relacionamentos entre os membros de um sistema social, ou seja, os sentimentos que abrangem vários grupos pequenos, como a família, e as categorias sociais, como gênero e classe social (WELLMAN, 1983; HALL e WELLMAN, 1985).

A rede social pode ser definida como um conjunto de nós interligados que são ligados por um ou mais tipos específicos de relações. Esses nós podem ser caracterizados pelos indivíduos, grupos, famílias ou outras coletividades e os laços podem ser definidos pela qualidade do fluxo de recursos de um nó (ou membro da rede) para outro. Esses recursos podem variar pelo tipo de característica do laço e da rede (WELLMAN, 1983; HALL e WELLMAN, 1985).

Segundo Hall e Wellman (1985) os pioneiros em utilizaro conceito de rede social de forma analítica foram Barnes (1972) e Bott (1971) e sistematizaram a variedade de medidas que vem sendo utilizadas desde Barnes e Bott para caracterizar os laços e as redes sociais. 
As medidas dos laços sociais incluem as situações que caracterizam cada relação individual dentro das possíveis redes sociais que o indivíduo mantém. Essas medidas podem ser caracterizadas como:

- Força - quantidade de recursos que caracterizam a relação;

- Freqüência - quantidade de contato entre dois dos membros da rede;

- Multiplexidade - número de recursos diferentes trocados em um laço por dois membros da rede;

- Duração - período de tempo existente em um laço ou relação;

- Simetria ou reciprocidade - extensão na qual os recursos são trocados;

- Intimidade - proximidade percebida de um membro da rede por outro.

As medidas das redes sociais abrangem a composição de todos os agrupamentos de relações que um indivíduo pode manter e distinguem-se em:

- Tamanho - número de membros da rede;

- Densidade - extensão na qual a rede é interconectada por todos através de vínculos diretos e é mensurado ao comparar o membro atual do vínculo direto pelos membros da rede, com o número de laços que poderia existir se todos os membros fossem diretamente ligados;

- Grau - extensão na qual o membro da rede é ligado diretamente por outros membros da rede;

- Limitação - proporção de todos os laços dos membros da rede que estão dentro dos limites da rede;

- Acessibilidade - número médio de laços requerido para ligar um dos dois membros da rede;

- Homogeneidade - extensão na qual os membros da rede têm atributos pessoais similares;

- Círculos - porções de rede na qual todos os membros são ligados diretamente;

- Grupos ou agrupamentos - porções de redes com alta densidade, mas definida por critérios de conectividade menos rigorosa que os círculos; 
- Componentes - porções de redes na qual todos os membros são ligados diretamente ou indiretamente.

A abordagem de rede social tem se tornado especialmente importante para os pesquisadores que querem predizer as circunstâncias nas quais os apoios ocorrem. Sluzki (1997, p. 41) define rede social pessoal como "a soma de todas as relações que um indivíduo percebe como significativas ou define como diferenciadas da massa anônima da sociedade", e distingue a análise da rede a partir de suas características estruturais, funcionais de cada relação, como também os atributos de cada vínculo.

A rede social de um indivíduo envolve uma conexão de relacionamentos, nos quais interage direta ou indiretamente e assim, se relaciona com diversos tipos de apoio social, envolvendo também os recursos institucionais e organizacionais que têm disponíveis em sua rede social.

A análise da rede social vem sendo empregada no campo científico, cada vez mais, como instrumento de avaliação da influência que o apoio social exerce na saúde do indivíduo (GOTTLIEB, 1985; HALL e WELLMAN, 1985; HOUSE e KAHN, 1985). As redes sociais constituem a base sobre a qual se dão as ajudas que os indivíduos requerem, são as instâncias em que os papéis sociais se estruturam e tomam sentido, promovendo a sensação de pertencimento na estrutura social, gerando assim, a integração social do indivíduo (GUZMÁN et al., 2002).

Durante o curso de vida, o indivíduo passa por diferentes períodos e situações estressantes, sendo a sua rede social que disponibiliza os recursos de apoio social que o ajudam a lidar com esses eventos (HALL e WELLMAN, 1985; PEARLIN, 1985). Na idade avançada, o idoso está mais sujeito ao estreitamento de sua rede social, devido à maior perda de parentes e amigos, como também ao declínio de sua capacidade funcional, que pode vir a resultar em maior limitação para manter o convívio social. A rede de apoio permite a integração social do idoso, evitando assim seu isolamento (GUZMÁN et al., 2002).

A composição da rede é um indicador confiável das fontes de apoio social, da quantidade, qualidade e dos tipos de apoio a que os idosos têm acesso. As relações tendem a ser especializadas em suas provisões de apoio. 
O conhecimento sobre os diferentes tipos de relações que compõem a rede fornece subsídios a respeito do apoio disponível. Dessa forma, os diferentes tipos de relações fornecem melhor apoio de acordo com as suas estruturas. Os vizinhos podem melhor ajudar com as questões imediatas por causa de sua proximidade geográfica, os familiares podem executar melhor as tarefas que requerem comprometimento ao longo do tempo e aos amigos, com quem têm similaridade de interesses e valores, podem ser confiada tarefas particulares, no decorrer da vida.

A análise e detecção da rede social do idoso se mostram como um instrumento imprescindível para a implantação de políticas públicas de saúde, no sentido de que se pode constatar se está mais vulnerável ou protegido das situações estressantes da vida, que repercutem diretamente em seu status de saúde (DYKSTRA, 2006).

\subsection{APOIO SOCIAL}

O apoio social refere-se às trocas sociais (dar e receber) positivas entre os membros da rede social que ajudam os indivíduos a permanecerem saudáveis ou a lidarem com os eventos adversos, sendo essas trocas de caráter funcional (HOUSE e KAHN, 1985; COHEN, 2004; DYKSTRA, 2006).

Durkheim foi o primeiro a problematizar as relações sociais influenciando no estado de saúde dos indivíduos, ao notar que, quando os trabalhadores migravam para as áreas industriais, seu ambiente social se alterava através da desagregação de suas famílias, comunidade e laços de trabalho. A modificação de seus ambientes poderia ser prejudicial para o bem-estar psicológico desses indivíduos. Verificou, também, que os suicídios eram mais prevalentes entre aqueles com menos laços sociais, propondo que uma estrutura social estável e normas sociais amplamente realizadas eram protetoras e serviam para regular o comportamento desses indivíduos. (BRISSETTE et al., 2000; COHEN et al., 2000; ROOK e UNDERWOOD, 2000; COHEN, 2004).

Nas décadas de 70 e 80 começaram a ser freqüentes os estudos que abordaram a questão dos laços sociais e do bem-estar psicológico devido à 
diferente forma de reação que os indivíduos apresentavam frente à enfermidade física, como também sua recuperação e sofrimento psíquico, sendo criadas diversas medidas de integração social para avaliar essas questões (BERKMAN, 1985; COHEN e SYME, 1985; COHEN e WILLS, 1985; BRISSETTE et al., 2000).

Nesse mesmo período, no campo da epidemiologia social, essas medidas de integração social foram incorporadas nos estudos sobre o papel dos laços sociais na morbidade e mortalidade dos indivíduos. O estudo pioneiro que examinou a associação entre integração social e mortalidade foi desenvolvido por Berkman e Syme (1979), utilizando uma coorte prospectiva de nove anos, com 6928 adultos residentes no condado de Alameda, Estados Unidos. Esses autores verificaram que os indivíduos que estavam mais socialmente integrados, ou seja, tinham uma rede social maior, como também maior freqüência de contatos, viviam mais tempo, em relação àqueles com laços sociais menores (BERKMAN, 1985).

Outros estudos que foram importantes por começarem a desenvolver medidas de redes sociais para verificar a relação entre os laços sociais e mortalidade são o estudo realizado por House, Robbins e Metzner (1982) utilizando uma coorte prospectiva de dez anos, com 2754 adultos, em Tecumseh, Michigan, Estados Unidos; e o estudo realizado por Blazer (1982) com 331 idosos de uma coorte prospectiva de 30 meses, no condado de Durham, Carolina do Norte, Estados Unidos (BERKMAN, 1985).

Entretanto, a relação entre apoio social e o sistema imunológico. do indivíduo foi percebida por Cassel e Cobb. Cassel (1976) verificou que os estressores que colocavam os indivíduos em risco de adoecimento eram freqüentemente caracterizados por confusão ou ausência de resposta do ambiente social, ou seja, os indivíduos que estabeleciam uma comunicação com sua rede conforme suas expectativas, auxiliando-os com os apoios que eles requeriam, estavam mais protegidos do impacto desses estressores. Cobb (1976) notou que as transições da vida e crises, que colocavam os indivíduos em risco, ocorriam de forma diferenciada entre aqueles que se sentiam pertencentes a uma rede que os estimava e cuidava, facilitando assim o enfrentamento e a adaptação a essas transições e crises (COHEN et al., 2000). 
Embora o mecanismo preciso sobre como o apoio social influencia no status de saúde permaneça desconhecido, diversas hipóteses e estudos realizados nesse período, mostraram que a disponibilidade de apoio social refletia diretamente no sistema imunológico do indivíduo, tornando-o menos suscetível ao estresse, como também a níveis mais baixos de morbidade física (BERKMAN, 1985). Outra questão levantada é de que a relação de reciprocidade estabelecida entre os sujeitos, através do apoio social, proporcionava-Ihes maior autonomia diante da vida, relacionando-se com a noção de empoderamento (empowerment).

Para Valla (1998, p.156) apoio social pode ser compreendido como:

Qualquer informação, falada ou não, e/ou auxilio material, oferecidos por grupos e/ou pessoas, com os quais teriamos contatos sistemáticos, que resultam em efeitos emocionais e/ou comportamentos positivos. Trata-se de um processo recíproco, que gera efeitos positivos para o sujeito que recebe, como também para quem oferece 0 apoio, permitindo que ambos tenham mais sentido de controle sobre suas vidas.

As relações sociais fornecem diferentes funções de apoio social, que podem ser caracterizados como: apoio emocional, apoio material ou instrumental, apoio educacional ou informativo e apoio de companhia (WILLS, 1985; WILLS e SHINAR, 1985).

O apoio emocional inclui situações em que as pessoas precisam conversar ou serem ouvidas por outras pessoas, envolvendo a necessidade de aceitação, pertencimento ou de cuidado.

O apoio material ou instrumental está relacionado à prestação de qualquer tipo de ajuda prática, como tarefas de casa, transporte, ou serviços tangíveis, como dar ou emprestar dinheiro, roupas etc.

O apoio educacional ou informativo enfoca situações de informação, educação ou esclarecimento sobre vários assuntos que são úteis para resolver problemas, como por exemplo, o fornecimento de informações sobre recursos da comunidade, conselhos e orientações sobre quaisquer acontecimentos ou problemas. 
O apoio de companhia abrange a disponibilidade de pessoas com quem se pode estar junto em determinadas ocasiões, desde atividades sociais, de lazer, como também, somente companhia.

As redes sociais dos indivíduos fornecem diferentes tipos de apoio, regulam o comportamento dos seus membros e oferecem oportunidades de engajamento social. Para a rede fornecer apoio, os membros dessa rede devem possuir habilidade, conhecimento e motivação para atuar quando necessário. As condições de apoio variam conforme o evento experenciado pelo indivíduo em seu curso de vida (SCHULZ e RAU, 1985; COHEN, 2004)

O maior foco da pesquisa em apoio social tem sido a questão de como e porque o apoio social tem esse efeito benéfico. Dois modelos teóricos têm sido dominantes na literatura, o modelo do efeito direto (main effect) e o modelo que amortece o estresse (stress-buffering) (COHEN et al., 2000).

O modelo do efeito direto (main effect) sustenta que o apoio social opera em todos os tempos, ajudando os indivíduos a manterem o senso de controle diante da vida e enfatiza sua análise nos recursos sociais.

Esse modelo discute as relações sociais como exercendo efeitos diretos na saúde física e psicológica do indivíduo, por meio da rede social, que atua no controle social dos seus sujeitos, através da influência que exercem entre si para comportamentos normativos de saúde, como dietas adequadas, exercícios físicos e costumes saudáveis. A rede social possibilita também o aumento das fontes de informação e a probabilidade de acesso a uma informação apropriada, como acesso a serviços de saúde ou comportamentos que são influências positivas para a saúde e o bem-estar. Pode também operar na prevenção de uma enfermidade, através do fornecimento de ajuda material e econômica, que teriam possibilidade de resultar na melhora da saúde e na disponibilidade de cuidado de saúde pelos membros da rede (COHEN et al., 2000; COHEN, 2004).

O modelo que amortece o estresse (stress-buffering) centra sua análise no fluxo de apoio social, ao referir que o apoio social opera nos períodos de estresse dos indivíduos, ajudando-os a lidar com os retrocessos, servindo como uma barreira protetora contra as ameaças ao bem-estar.

De acordo com esse modelo, os papéis do apoio social atuam como determinadas respostas individuais para eventos potencialmente estressantes, 
através de mecanismos que atuam na percepção da disponibilidade, estima e pertencimento de sua rede social. $O$ apoio opera através do fornecimento de recursos necessários a não permitir que determinada situação possa prejudicar, potencializando os indivíduos a lidarem de maneira favorável com as demandas impostas. $O$ apoio também pode reduzir ou eliminar a reação ao evento estressante, amortecer respostas psicológicas ao evento, como prevenir ou alterar respostas comportamentais mal adaptadas (COHEN e MCKAY, 1984; COHEN e SYME, 1985; COHEN et al., 1985, 2000; COHEN, 2004).

A percepção da disponibilidade de apoio pelo indivíduo tem sido associada com ambos os modelos, devido ao conhecimento e segurança de que existe a disponibilidade de pessoas para ajudar em tempos de necessidade poder gerar efeitos positivos na saúde.

Tais modelos não são quadros teóricos competitivos, cada um é redigido na sua própria tradição empírica (COHEN e WILLS, 1985; LAKEY et al., 2000).

$O$ apoio social pode também ter conseqüências negativas, que podem ser devido à natureza, ao significado atribuído ou à motivação dessas trocas de apoio. As conseqüências negativas podem ocorrer quando as trocas influenciam na piora da percepção de autonomia e independência do indivíduo, ao não identificar a troca de apoio, como também à transmissão de doenças, relações de conflito, exploração, estresse, ajuda desorientada e sentimentos de perda e solidão provenientes da rede social. Essas relações tendem a tornarem-se mais evidentes com o envelhecimento, devido à maior necessidade física e mental de apoio que o idoso passa a ter de sua rede. Os potenciais aspectos negativos da rede social podem atuar como estressores psicológicos, resultando em respostas emocionais e físicas que se configuram como risco para a piora da saúde do indivíduo. (ANTONUCCl et al., 1998; ROOK e UNDERWOOD, 2000; COHEN, 1992, 2004; DYKSTRA, 2006).

No campo da gerontologia social, o apoio social tem sido analisado através da explicação das diferenças na disponibilidade de apoio pelo idoso. Considerando que o processo de envelhecimento acarreta ao indivíduo a diminuição do número de relações sociais, o declínio da capacidade funcional e assim, levando-o ao aumento do apoio requerido pelos outros, sugere maior relevância verificar como os idosos negociam as transições em suas relações (SCHULZ e RAU, 1985; DYKSTRA, 2006). 
Khan e Antonucci (1980) propuseram o modelo protetor de apoio social (convoy model) sugerindo que as reservas de apoio de que os indivíduos dispõem na idade avançada, são aquelas que eles forneceram ao longo da vida, apresentando mudanças e estabilidade de acordo com as situações, sendo essas relações de apoio também construídas ao longo do tempo (MINKLER, 1985; SCHULZ e RAU, 1985; ANTONUCCI e AKIYAMA, 1987; DYKSTRA, 2006).

Dessa maneira, a disponibilidade de familiares, amigos e vizinhos para a ocorrência de apoio depende do desenvolvimento de reciprocidade decorrente das interações durante o curso da vida. As relações vão se construindo dentro das famílias e fora destas. Familiares e não familiares geralmente diferem no apoio que fornecem. Os membros da família são mais suscetiveis que os amigos a fornecer apoio instrumental e os amigos tendem a fornecer apoio emocional.

Essa relação pode se mostrar inversa, quando as principais fontes de apoio não estão disponiveis, verificada na ausência de cônjuge e/ou filho no envelhecimento, fazendo com que os outros membros da família e amigos se mobilizem para preencher $o$ apoio demandado.

No sentido inverso, os pais idosos tendem a fornecer apoio aos seus descendentes sempre que requerido, esse papel se reverte somente quando começam a encontrar dificuldade de independência funcional.

Existe uma hierarquia de apoio social a respeito de quem poderia fornecer ajuda, o cônjuge é geralmente o primeiro a fornecer assistência, quando os idosos necessitam de auxílio com as ABVDs. Na ausência deste ou quando não tem condições de ajudar, o filho adulto é freqüentemente o substituto. Na ausência de filhos ou quando estes moram distantes, os apoios freqüentemente vêm de outros familiares, amigos e/ou vizinhos.

Contudo, essa hierarquia pode se mostrar diferenciada devido aos recasamentos, que podem ocorrer principalmente entre os homens idosos, com formações de novas configurações familiares.

O apoio social também sofre influencia do gênero. Os homens são mais engajados nos apoios de característica instrumental, enquanto as mulheres executam freqüentemente as tarefas de casa e o cuidado pessoal. Entretanto, a maior presença da mulher no mercado de trabalho vem modificando 0 
provimento desse apoio pela menor disponibilidade de tempo para ajudar. $O$ acúmulo de papéis sociais (mãe, filha, esposa e trabalhadora), tem levado as mulheres a maior negociação para o fornecimento de apoio (HILLCOATNALLÉTAMBY e DHARMALINGAM, 2003; DYKSTRA, 2006).

O apoio social atua de forma mediadora no processo de envelhecimento, como potencial que contribui para a manutenção da saúde e enfrentamento das fases de tensão e mudanças no curso de vida, como o luto e perda de familiares e amigos do idoso, ressaltando que "o apoio social inadequado está associado não apenas a um aumento em mortalidade, morbidade e problemas psicológicos, mas também a uma diminuição na saúde e bem-estar em geral" (GIRONDA e LUBBEN, 2002, apud OMS, 2005, p. 28).

\subsection{TROCA SOCIAL}

Ao se tratar de apoio social, está se fazendo referência as trocas de recursos que ocorrem nas relações sociais, sendo delegado papel importante em como essas relações podem influenciar os indivíduos. Portanto, mostra-se importante entender o que são as funções específicas de apoio fornecidas pelas relações sociais e qual o processo psicológico através do qual essas funções têm seus efeitos (WILLS, 1985).

No campo da psicologia, Wills (1985) destaca três teóricos que contribuíram para a discussão do conceito de troca social. Homans (1961) que incluiu o princípio da equidade e justiça distributiva, especificando que as recompensas ganhas nas relações deveriam ser proporcionais aos seus investimentos. Foa (1971) que investigou os tipos de trocas ocorridas nas relações, sugerindo que estas podem ser desde emocionais, como afeto, até materiais, como dinheiro e serviços. Clark e Mills (1979) que propuseram uma distinção teórica entre as relações de troca, percebendo aquelas que eram estabelecidas nas relações rotineiras, como transações econômicas, e as relações comunais, como casamentos e amizades, assinalando que essa 
última relação de troca é regida mais pelo sentimento de desejar uma resposta para a necessidade dos outros do que pelos princípios de troca.

A partir das teorias da troca social foram estabelecidas várias suposições a respeito das relações sociais, algumas sugerem que as trocas aumentam com o desenvolvimento das relações, outras que as trocas determinariam o progresso do relacionamento. Tais teorias foram importantes no sentido de sugerirem que as trocas entre o relacionamento eram apoiadas não somente para o aumento de recompensas, mas também porque a reciprocidade das trocas tornaria os indivíduos mais confiantes, ao perceberem teriam alguma ajuda proporcionada quando necessitassem.

No campo da teoria sociológica, Blau (2006) trouxe para discussão da teoria da troca social que esta é inerente da vida social, pois as associações entre as pessoas, como na família, trabalho e lazer, são os espaços em que os indivíduos estabelecem suas relações e manifestam seus sentimentos.

A maioria dos desejos e sofrimentos humanos tem suas origens na vida social, por meio das trocas estabelecidas nas relações sociais. A recompensa básica procurada nas relações é a aprovação social e a desconsideração com os outros, tornam-nas impossíveis de obter essa recompensa.

Dessa maneira, a coesão do grupo demonstra ser uma importante fonte de apoio social e de controle normativo entre seus membros. As implicações dessa coesão estão relacionadas, uma vez que, a ameaça da perda de apoio social, pode servir como um mecanismo de controle efetivo nos grupos. Nesse sentido, o controle social fortalece o grupo como um todo, enquanto o apoio social fortalece os membros individualmente, particularmente na relação com pessoas estranhas.

\subsection{APOIO INTERGERACIONAL}

No âmbito da gerontologia e da sociologia da família, desde a década de 70 , principalmente nos EUA e Europa, têm aumentado o número de estudos sobre as relações familiares intergeracionais. $O$ interesse pelas relações 
familiares entre as gerações deve-se ao aumento das demandas trazidas pelas famílias, em vista da mudança na estrutura etária da população que verticaliza e aumenta o tempo de convívio e trocas de apoio entre as gerações no ambiente familiar. Aliado ao gasto público em garantir serviços de saúde para essa população mais envelhecida (LOWENSTEIN, 1999; BENGTSON e MARTIN, 2001; HAMMARSTRÖM, 2004).

Historicamente os filhos têm sido a principal referência de apoio aos idosos quando necessitam de cuidado. Mesmo nos paises desenvolvidos em que existe maior estrutura para que os idosos vivam independentemente, os filhos continuam a representar suas principais fontes de apoio social, através da co-residência e transferência de apoio (CAMARANO et al., 2005; SILVERSTEIN et al., 2006).

As relações entre pais e filhos são regidas por normas de responsabilidade filial, em que existe uma expectativa entre ambos de ocorrer apoio quando precisarem. No entanto, são conceitualmente distintas entre as intenções para fornecer apoio e os comportamentos de apoio existentes.

O conceito de capital social familiar surge como um recurso importante na discussão das relações intergeracionais, que seria um estoque de afeição social, criado através do cultivo de relações sociais em torno de normas compartilhadas e senso de pertencimento comum, que geraria uma relação de troca entre os membros da família (FURSTENBERG, 2005; SILVERSTEIN et al., 2006)

Bengtson et al. elaboraram um modelo multidimensional de solidariedade intergeracional para caracterizar os comportamentos e sentimentos que permeiam as relações intergeracionais ao longo da vida. $O$ termo solidariedade refere-se a um conceito que incorpora as múltiplas, complexas e contraditórias relações sociais intergeracionais. (LAWTON et al., 1994; SILVERSTEIN e BENGTSON, 1997; HAMMARSTRÖM, 2004).

Nesse modelo, a solidariedade apresenta seis dimensões:

- estrutural: caracterizada pela estrutura das relações intergeracionais, que são traduzidas no número, tipo e proximidade geográfica dos membros da família; 
- associativa: verifica a intensidade com que os membros de uma linhagem estão em contato entre si, através da freqüência de interações formais e informais;

- afetiva: refere-se ao grau de sentimentos positivos presentes nas relações intergeracionais, estimado pelos sentimentos de proximidade, entendimento e comunicação;

- consensual: definida pelo grau de consenso ou conflito nas atitudes, valores e expectativas entre os membros familiares; funcional: manifesta-se pela intensidade com que as trocas de apoio ocorrem no espaço familiar;

- normativa: demonstra o compromisso no desempenho dos papéis familiares.

Porém identificaram três componentes centrais - afetivo, cognitivo e comportamental - da solidariedade intergeracional, traduzidos na solidariedade afetiva, consensual e associativa. Esse modelo propõe que as famílias se estruturam em diferentes tipos de solidariedade em sua extensão multigeracional, com recursos latentes que podem ser ativados quando necessário (BENGTSON e ROBERTS, 1991; SILVERSTEIN e BENGTSON, 1997; HAMMARSTRÖM, 2004).

Existem dois domínios gerais de coesão intergeracional, a solidariedade latente e manifesta. A solidariedade latente representa os fatores cognitivos e emocionais, como sentimentos de obrigação e proximidade emocional. A solidariedade manifesta trata dos aspectos funcionais da vida familiar, como trocas de apoio social. Formas latentes de solidariedade têm a capacidade de provocar formas manifestas de solidariedade, porém a ligação que ocorre entre essas relações ainda não foi identificada empiricamente (SILVERSTEIN e BENGTSON, 1997; SILVERSTEIN et al., 2006).

Entretanto as relações intergeracionais podem atuar no outro extremo da solidariedade, o do conflito, gerado pelas diferenças e discordâncias entre as gerações familiares (BENGTSON e MARTIN, 2001)

As configurações familiares dos idosos têm uma determinação importante através do estado conjugal, bem como a independência financeira dos filhos. Quando o idoso é o chefe da família, pressupõe-se que tenha 
autonomia física, mental e financeira. Se isso não acontece, a estratégia familiar utilizada pode ser a ampliação da família, para suprir essa demanda.

Os homens idosos podem assumir papéis importantes de apoio intergeracional devido à manutenção do papel tradicional de chefe e provedor da família pela permanência no mercado de trabalho e/ou recebimento do benefício previdenciário, como também pela posse de domicílio próprio. No caso das mulheres idosas o apoio intergeracional deve-se em maior parte pelo papel tradicional de cuidadoras da família, mas também, pode ocorrer através de transferências de apoio material devido á maior renda proveniente de pensão e/ou benefício previdenciário. 


\section{OBJETIVOS}

\subsection{OBJETIVO GERAL}

Investigar os fatores associados às mudanças ocorridas, no período de 2000 a 2006, no apoio social recebido pelos idosos residentes no município de São Paulo.

\subsection{OBJETIVOS ESPECÍFICOS}

- Caracterizar a rede de apoio social dos idosos através das características estruturais, funcionais e a disponibilidade de apoio social;

- Determinar a associação entre os fatores sociodemográficos e as mudanças no apoio social recebido pelos idosos;

- Verificar a associação entre as características da rede de apoio social e as mudanças no apoio social recebido pelos idosos;

- Avaliar a associação entre as características de saúde e as mudanças no apoio social recebido pelos idosos. 


\section{MATERIAIS E MÉTODOS}

\subsection{O ESTUDO SABE}

O presente estudo é parte do Estudo Saúde, Bem-Estar e Envelhecimento (SABE), estudo longitudinal de base populacional, realizado com os idosos residentes no município de São Paulo. A coleta de dados foi realizada por meio de entrevistas no domicílio, em dois períodos: 2000 (coorte $A_{00}$ ) e 2006 (coorte $A_{06}$ ).

O Estudo SABE é coordenado pela Faculdade de Saúde Pública da Universidade de São Paulo (FSP-USP), com financiamento do Ministério da Saúde e da Fundação de Amparo a Pesquisa do Estado de São Paulo (FAPESP).

\subsubsection{O Estudo SABE 2000 - Coorte $A_{00}$}

Entre os anos de 1997 e 2003, a Organização Panamericana da Saúde (OPAS) coordenou um estudo multicêntrico denominado SABE, para traçar o perfil dos idosos na América Latina e no Caribe. Esse estudo foi planejado para colocar luz nas demandas de saúde que poderão emergir de uma população que se tornou rapidamente idosa e pela necessidade de antecipar o que se encontrará adiante, de modo que os países possam se planejar adequadamente para prevenir as conseqüências mais negativas do processo de envelhecimento na região (PALLONI e PELÁEZ, 2003).

No Estudo SABE foram incluídos: Argentina, Barbados, Brasil, Chile, Cuba, México e Uruguai. Esses países representavam uma combinação daqueles que trazem uma boa representação dos vários estágios do envelhecimento na região. Argentina, Barbados, Cuba e Uruguai estão em 
estágios muito avançados do processo de envelhecimento, enquanto Chile, México e Brasil estão ligeiramente atrás, mas a velocidade com que esse processo ocorre em tais países pode fazê-los, muito em breve, superar os primeiros (PALLONI e PELÁEZ, 2003).

Esse estudo foi proposto para ser longitudinal, sendo construído de forma a ser rigorosamente comparável, com a finalidade de recolher uma ampla quantidade de informações cujos resultados pudessem subsidiar tanto o desenvolvimento de estudos complementares, quanto à organização das políticas públicas destinadas a esse grupo etário na região. Entretanto, somente no Brasil, a partir de 2006 , tornou-se um estudo longitudinal.

\subsubsection{Instrumento}

Os dados para o Estudo SABE foram obtidos em entrevista domiciliar, por meio de um questionário, elaborado por um comitê regional, composto pelos principais pesquisadores de cada país e por especialistas em temas específicos da pesquisa. $O$ instrumento inicial foi submetido a dois pré-testes até a obtenção de sua forma final ${ }^{3}$ (Anexo 4), composta por onze seções, a saber:

Seção A - Dados pessoais

Ano e país de nascimento; local de residência durante os primeiros quinze anos de vida; local de residência durante os últimos cinco anos de vida e, onde fosse aplicável, razões para a mudança de residência; história e estado marital; número de filhos; sobrevivência dos pais e, se não, a idade em que faleceram; escolaridade.

Seção B - Avaliação cognitiva

\footnotetext{
${ }^{3}$ Disponivel em http://www.fsp.usp.br/sabe
} 
Auto-avaliação da memória; avaliação da memória pelo teste minimental modificado e validado no Chile para realização do estudo. Para os que obtivessem escore igual ou inferior a 12 pontos, uma escala de desempenho funcional era administrada a um proxi-respondente (informante substituto) a partir da questão "é capaz de...."

Seção C - Estado de saúde

Auto-avaliação de saúde atual e comparativa ao ano anterior, bem como da saúde na infância; doenças referidas, considerando nove das condições crônicas mais prevalentes na população idosa e incluindo seu tratamento; hábitos, condições sensoriais; saúde reprodutiva; saúde bucal; ocorrência de quedas; escala de avaliação de depressão geriátrica e mini screening nutricional.

Seção D - Estado funcional

Avaliação do desempenho funcional e da ajuda recebida, quando necessário, nas atividades básicas e instrumentais da vida diária e identificação e caracterização do(s) cuidadores principais.

\section{Seção E-Medicamentos}

Terapêutica medicamentosa utilizada, incluindo indicação, tempo de uso, forma de utilização, obtenção e pagamento; gastos mensais com medicamentos e motivos referidos para a não utilização dos medicamentos prescritos.

Seção F-Uso e acesso a serviços

Serviços de saúde utilizados, públicos ou privados, nos últimos 12 meses e ocorrência de hospitalização, atendimento ambulatorial, exames nos 
últimos quatro meses, bem como tempo de espera para atendimento, terapêutica prescrita e gastos relacionados.

Seção G - Rede de apoio familiar e social

Número e características de pessoas que vivem com o idoso no mesmo domicílio (sexo, parentesco, estado marital, idade, escolaridade e condição de trabalho); assistência prestada ao idoso e fornecida por ele referente a cada membro citado; tempo gasto na ajuda ao idoso. As mesmas perguntas foram feitas em relação aos irmãos e filhos que não vivem no mesmo domicílio, bem como a outros familiares e que, de alguma forma, fornecem ou recebem ajuda do/ao idoso; assistência recebida ou fornecida nos últimos 12 meses de alguma instituição ou organização; participação do idoso em algum serviço voluntário ou organização comunitária.

Seção H - História laboral e fontes de renda

Trabalho atual (tipo, renda, razões para continuar trabalhando); caso não trabalhasse mais, por quê não o fazia, ocupação que teve durante o maior período de sua vida, horas trabalhadas, razões para mudar de atividade, aposentadoria, pensões, benefícios, outras fontes de renda, renda total pessoal e número de dependentes dessa renda; gastos pessoais (moradia, transporte, alimentação, vestimenta, saúde) e auto-avaliação de seu bem estar econômico.

Seção J-Características da moradia

Tipo e propriedade da moradia, condições de habitação (saneamento básico, luz, número de cômodos, bens presentes).

\section{Seção K-Antropometria}

Altura do joelho, circunferência do braço, cintura, quadril, prega triciptal, peso, circunferência da panturrilha, largura do punho e força da mão. 


\section{Seção L - Flexibilidade e Mobilidade}

Provas de equilíbrio, mobilidade e flexibilidade.

\subsubsection{Amostra}

A amostra foi composta por idosos residentes, em 2000, na área urbana do município de São Paulo e foi calculada a partir da contagem populacional da Fundação Instituto Brasileiro de Geografia e Estatística (IBGE), de 1996. A amostra foi probabilística e utilizou-se o método de amostragem por conglomerados polietápicos, com estratificação das unidades primárias da amostra. O processo de amostragem contou com três etapas, sendo considerados os estratos socioeconômicos.

A distribuição da amostra foi realizada pelo método de fixação proporcional ao tamanho, sendo aplicado também um procedimento para sobredimensionar a seleção de idosos com 75 anos e mais de idade.

Os métodos de estimação e ponderação aplicados correspondiam à utilização de estimadores simples, não viesados e estimadores de razão que consideram, em todos os casos, o cálculo dos fatores de expansão do desenho amostral empregado, ou seja, as probabilidades de seleção aplicadas em cada etapa e as não-respostas. Foram também consideradas as variáveis sexo e

grupos etários, dadas as diferenças de mortalidade entre sexos e o sobredimensionamento da população igual e superior a 75 anos. Ao final, obteve-se um fator para cada indivíduo da amostra, que resumia todos os elementos mencionados no desenho amostral e os estratos considerados.

Para realização da amostra probabilística, foi utilizado o cadastro permanente de 72 setores censitários existentes na FSP-USP selecionados sob o critério de probabilidade proporcional ao número de domicílios do cadastro da Pesquisa Nacional por Amostra de Domicílios (PNAD), de 1995. Em seguida, foram sorteados sistematicamente os domicílios a serem visitados. A complementação da amostra de pessoas de 75 anos e mais foi realizada pela localização de moradias próximas aos setores selecionados ou, 
no máximo, dentro dos limites dos distritos aos quais pertenciam os setores sorteados.

Para a análise dos resultados, foi atribuído a cada questionário um peso relativo a sua representatividade na população. A amostra final foi composta de 2143 idosos.

\subsubsection{Procedimento de coleta de dados}

Após a seleção da amostra, os idosos foram entrevistados em seus domicílios. A maior parte das entrevistas (88\%) foi feita de forma direta. Em algumas ocasiōes, utilizou-se um proxi-respondente quando havia impossibilidade do idoso para responder às questões (problemas físicos ou cognitivos).

A coleta de dados ocorreu em duas etapas. Na primeira, foram preenchidas as seções de $\mathrm{A}$ a $\mathrm{J}$, e na segunda, que ocorreu de um a seis meses após a primeira, as seções L e K. Isso ocorreu, em parte, pela extensão do questionário e, por outro lado, as seções $L$ e $K$ exigiam maior disponibilidade do idoso para a realização de alguns testes, além de material específico.

\subsubsection{O Estudo SABE 2006 - Coorte $A_{06}$}

No Brasil, o Estudo SABE, a partir de $2006\left(A_{06}\right)$, transformou-se em um estudo longitudinal que busca estudar as alterações, com o passar do tempo, das condições de vida e de saúde dos idosos do município de São Paulo e seus fatores determinantes. Para tanto, os idosos que fizeram parte da primeira coleta de dados $\left(A_{00}\right)$ foram revisitados e reavaliados. $O$ questionário base foi mantido e foram acrescentados alguns instrumentos complementares, com 
ênfase em fatores de risco para mortalidade, institucionalização, alterações da funcionalidade e fragilidade.

Dos 2.143 indivíduos entrevistados no ano de $2000\left(A_{00}\right)$, após extensa busca, foram entrevistados $1.115(52 \%)$ idosos em $2006\left(A_{06}\right)$. A diferença entre os dois momentos é composta por 649 (30,3\%) óbitos, $139(6,5 \%)$ mudanças não localizadas, 51 (2,4\%) mudanças localizadas, $11 \quad(0,5 \%)$ institucionalizados e $178(8,3 \%)$ recusas.

\subsection{VARIÁVEIS DE ESTUDO}

Para responder as questões propostas foram utilizados os dados da seção A (informações pessoais), seção $C$ (estado de saúde), seção $D$ (estado funcional) e seção $\mathrm{G}$ (rede de apoio familiar e social) dos questionários do Estudo SABE de 2000 e 2006.

\subsubsection{Variável Dependente}

Mudança no apoio social recebido pelo idoso de sua rede de apoio domiciliar e extradomiciliar (familiares e amigos).

A variável "mudança no apoio social recebido pelo idoso" foi construída através do número de ajudas recebidas nos dois períodos do estudo, $A_{00}$ e $A_{06}$, sendo as alterações nessas ajudas, do primeiro para o segundo período, foram categorizadas em apoio recebido que aumentou, ficou igual e diminuiu. A categoria "ficou igual" foi utilizada como referência; 
3.2.2 Variáveis Independentes

- Características sociodemográficas dos idosos:

- Sexo: masculino e feminino;

- Idade: em anos (quantitativa) e faixa etária (60 a 69,70 a 79,80 anos e mais);

- Escolaridade: em anos de estudo (quantitativa) e categorias (até 1, 1 a 3, 4 a 7,8 e mais);

- Estado civil: casado/amasiado, divorciado/separado, solteiro e viúvo;

- Mudança no estado civil: sim e não.

- Rede de apoio domiciliar:

1. Disponibilidade:

- Número de co-residentes;

- Número de filhos co-residentes;

2. Características estruturais:

- Número de ajudas recebidas pelo idoso;

- Número de ajudas fornecidas pelo idoso;

3. Características funcionais:

- Tipo de apoio social recebido pelo idoso: número de apoios material/instrumental e outro tipo de apoio;

- Tipo de apoio social fornecido pelo idoso: número de apoios material/instrumental e outro tipo de apoio;

- Rede de apoio extradomiciliar (filhos):

1. Disponibilidade:

- Número de filhos; 
- Local de residência dos filhos: em categorias (mesmo bairro, outro bairro, outra cidade e outro país) e escala (de 1 a 4 , conforme aumenta o valor, aumenta a proximidade da residência);

- Freqüência do contato com os filhos: em categorias (diário, semanal, mensal, anual, nunca) e escala (de 1 a 5 , conforme aumenta o valor, aumenta a freqüência do contato).

2. Características estruturais:

- Número de ajudas recebidas pelo idoso;

- Número de ajudas fornecidas pelo idoso;

3. Características funcionais:

- Tipo de apoio social recebido pelo idoso: número de apoios material/instrumental, companhia e outro tipo de apoio;

- Tipo de apoio social fornecido pelo idoso: número de apoios material/instrumental e outro tipo de apoio;

- Rede de apoio extradomiciliar (irmãos, outros familiares e amigos):

1. Características estruturais:

- Número de ajudas recebidas pelo idoso;

- Número de ajudas fornecidas pelo idoso;

2. Características funcionais:

- Tipo de apoio social recebido pelo idoso: número de apoios material/instrumental, companhia e outro tipo de apoio;

- Tipo de apoio social fornecido pelo idoso: número de apoios material/instrumental e outro tipo de apoio;

- Características de saúde dos idosos:

- Auto-avaliação da saúde: em categorias (muito boa, boa, regular, ruim) e escala (de 1 a 4, conforme aumenta o valor, piora a autoavaliação da saúde);

- Doenças referidas (hipertensão, diabetes, câncer, doença cardíaca, pulmonar, cerebrovascular e artrite/reumatismo/artrose): 
em número de doenças (quantitativa) e categorias (nenhuma, uma, 2 e mais);

- Atividades Básicas da Vida Diária (ABVDs) comprometidas (deambular, mobilizar-se, alimentar-se, vestir-se, banhar-se e manter o controle sobre suas eliminações): em número de ABVDs (quantitativa) e categorias (nenhuma, 1 a 2, 3 e mais);

- Número de Atividades Instrumentais da Vida Diária (AIVDs) comprometidas (fazer compras, manejar dinheiro, usar telefone, tomar medicamentos, ir a outros lugares sozinho): em número de AIVDs (quantitativa) e categorias (nenhuma, 1 a 2 e 3 e mais).

\subsection{ANÁLISE ESTATÍSTICA}

Foram feitas análises descritivas para caracterizar a população de estudo nos dois períodos da coorte $\left(A_{00}\right.$ e $\left.A_{06}\right)$ através das características sociodemográficas, de saúde e da rede de apoio social domiciliar e extradomiciliar dos idosos. Para a caracterização da rede de apoio social, nos dois períodos, foram selecionadas algumas características que compõem a rede de apoio, a partir da literatura e da disponibilidade de variáveis presentes no Estudo SABE.

$\mathrm{Na}$ análise descritiva foram realizados os testes de associação RaoScott (1984), para amostra complexa, com o intuito de verificar se houve comportamento diferenciado entre os sexos para as mudanças nas trocas de apoio social entre os idosos e a rede de apoio.

O Teste " $t$ " de Student pareado, utilizado para variáveis quantitativas com medidas repetidas, foi empregado para analisar se ocorreram diferenças nas médias das variáveis entre os dois períodos do estudo.

O Teste de McNemar, empregado para variáveis categóricas com medidas repetidas, foi usado para investigar se as proporções das variáveis nos dois períodos mudaram. 
Foram realizadas as análises de regressão logística multinomial univariada e multivariada para verificar os fatores associados às mudanças no apoio social recebido pelos idosos. A análise univariada foi utilizada para verificar o efeito isolado de cada variável e a multivariada para o efeito conjunto das características sociodemográficas, de saúde e da rede de apoio social dos idosos. (KLEINBAUM et al., 1997; HOSMER e LEMESHOW, 2000; SZKLO, 2000).

A identificação da associação entre cada variável de estudo e as mudanças no apoio social recebido pelos idosos foi realizada através da análise de regressão logística multinomial univariada, em que foram testadas todas as variáveis independentes, sendo selecionadas aquelas que apresentaram valor de $p \leq 0,20$, para as análises multivariadas.

As análises univariadas foram realizadas para as variáveis do primeiro período $\left(A_{00}\right)$ e para a diferença proporcional das variáveis nos dois períodos $\left(A_{00}\right.$ e $\left.A_{06}\right)$. Dessa forma, foi possível verificar o quanto as variáveis do primeiro período predizem as mudanças no apoio social, como também a associação entre o comportamento das alterações dessas variáveis com as mudanças no apoio social recebido pelos idosos.

Para as análises de regressão logística multinomial multivariada das mudanças no apoio recebido pelos idosos foram feitos também modelos de regressão para as variáveis do primeiro período e para as alterações proporcionais dessas variáveis nos dois períodos.

No modelo de regressão multivariada do primeiro período foi possível verificar o conjunto das variáveis independentes que predisseram as mudanças no apoio social recebido pelos idosos. Enquanto no modelo de regressão multivariada das diferenças das variáveis nos dois períodos foi analisado o comportamento do conjunto dessas variáveis que estiveram associados às mudanças no apoio social recebido pelos idosos.

As variáveis que permaneceram nos modelos de regressão multinomial multivariada finais das mudanças no apoio recebido pelos idosos foram as que apresentaram significância estatística de $p \leq 0,05$ ou que ajustaram esses modelos. O Teste de Wald foi usado para verificar o ajuste das variáveis independentes no modelo (KLEINBAUM et al., 1997; SZKLO, 2000) e o teste de Hosmer-Lemeshow foi empregado para a análise de resíduos dos modelos 
finais (HOSMER e LEMESHOW, 2000). A variável sexo foi utilizada para comparar o seu efeito de ajuste nos modelos finais.

Os programas utilizados para as análises estatísticas foram o SPSS 16.0 for Windows (SPSS Inc., Chicago, IL, EUA) e o STATA 10 for Windows (STATA CORPORATION, College Station, TX, EUA).

\subsection{PARECER DO COMITÊ DE ÉTICA}

O estudo foi aprovado pelo Comitê de Ética em Pesquisa da Faculdade de Saúde Pública (FSP-COEP), na qual pertencem os principais investigadores do estudo e pelo Conselho Nacional de Ética em Pesquisa (CONEP). (Anexos 1 a 3) 


\section{RESULTADOS E DISCUSSÃO}

\subsection{CARACTERÍSTICAS SOCIODEMOGRÁFICAS E DE SAÚDE DOS IDOSOS}

As características sociodemográficas dos idosos que permaneceram na coorte durante os dois períodos do estudo mostraram que o sexo feminino foi predominante $(61,1 \%)$ e a escolaridade média permaneceu em 3,9 anos de estudo. A idade média passou de 64,3 para 74,6 anos, o que é verificado no incremento das faixas etárias de 70 a $79(31,1 \% ; 52,2 \%)$ e 80 anos e mais $(6,1 \% ; 21,5 \%),(p=0,000)$. (Tabela 1$)$

A sobrevida das mulheres já é um fato verificado nos países desenvolvidos, entretanto, o componente de gênero na longevidade acarreta diferenças sociais e culturais que são refletidas em situações como as mulheres sendo "vítimas mais freqüentes da violência doméstica e de discriminação no acesso à educação, salário, alimentação, trabalho significativo, assistência a saúde, heranças, medidas de seguro social e poder político" (OMS, 2005, p. 39).

Esse fato, aliado ao aumento expressivo do contingente de idosos, na coorte, com 80 anos e mais de idade, reforça a necessidade de uma rede de apoio informal, que possa fornecer os recursos necessários para a manutenção da independencia e autonomia desse idoso, no sentido mais amplo. No sistema formal de apoio, há uma heterogeneidade nas demandas desse grupo etário, tornando mais complexa a formulação de políticas públicas direcionadas à população idosa (CAMARANO et al., 2004).

Segundo a OMS (2005) o envelhecimento não sobrecarrega o sistema de saúde, pois os maiores gastos são provenientes da medicina curativa. A OMS aponta ainda, a necessidade da atuação do sistema de saúde na prevenção das doenças crônicas, possibilitando, por mais tempo, uma vida independente e, ainda, a atuação conjunta com a família do idoso no fornecimento dos cuidados de longo prazo, por meio da implantação de políticas e programas que capacitem e potencializem os cuidadores. 
As principais alterações nos padrões conjugais dos idosos ocorreram entre os casados ou amasiados, que embora tenham diminuído, continuam predominantes $(59,5 \% ; 50,6 \%)$. Observa-se ainda o aumento dos viúvos (de $28,2 \%$ para $39,7 \%$ ). Nas demais condições não houve modificações expressivas $(p=0,000)$. Os recasamentos não foram tão evidentes possivelmente devido ao número mais elevado de mulheres na coorte, que culturalmente tendem a permanecer solteiras ou viúvas nas idades mais avançadas, em conformidade com os dados do IBGE, apresentados por Camarano, Kanso e Leitão e Mello (2004). (Tabela 1)

O aumento da viuvez, mais expressivo entre as mulheres, também é freqüente nos países europeus. KOHLI et al.(2005) verificaram que a proporção dessa condição em idosos, de doze países da Europa, com 80 anos e mais foi de $30 \%$ para os homens e $69 \%$ para as mulheres, sendo mais expressivo na Grécia, onde atingiu $80 \%$ das mulheres. )

No mesmo estudo, Buber e Engelhardt (2008b), encontraram que a presença de sintomas depressivos nos idosos foram altamente correlacionados com o contexto associado ao envelhecimento, como a maior perda do cônjuge. 
Tabela 1 - Características sociodemográficas dos idosos, Município de São Paulo, 2000 e 2006 ( $n=1115$ ).

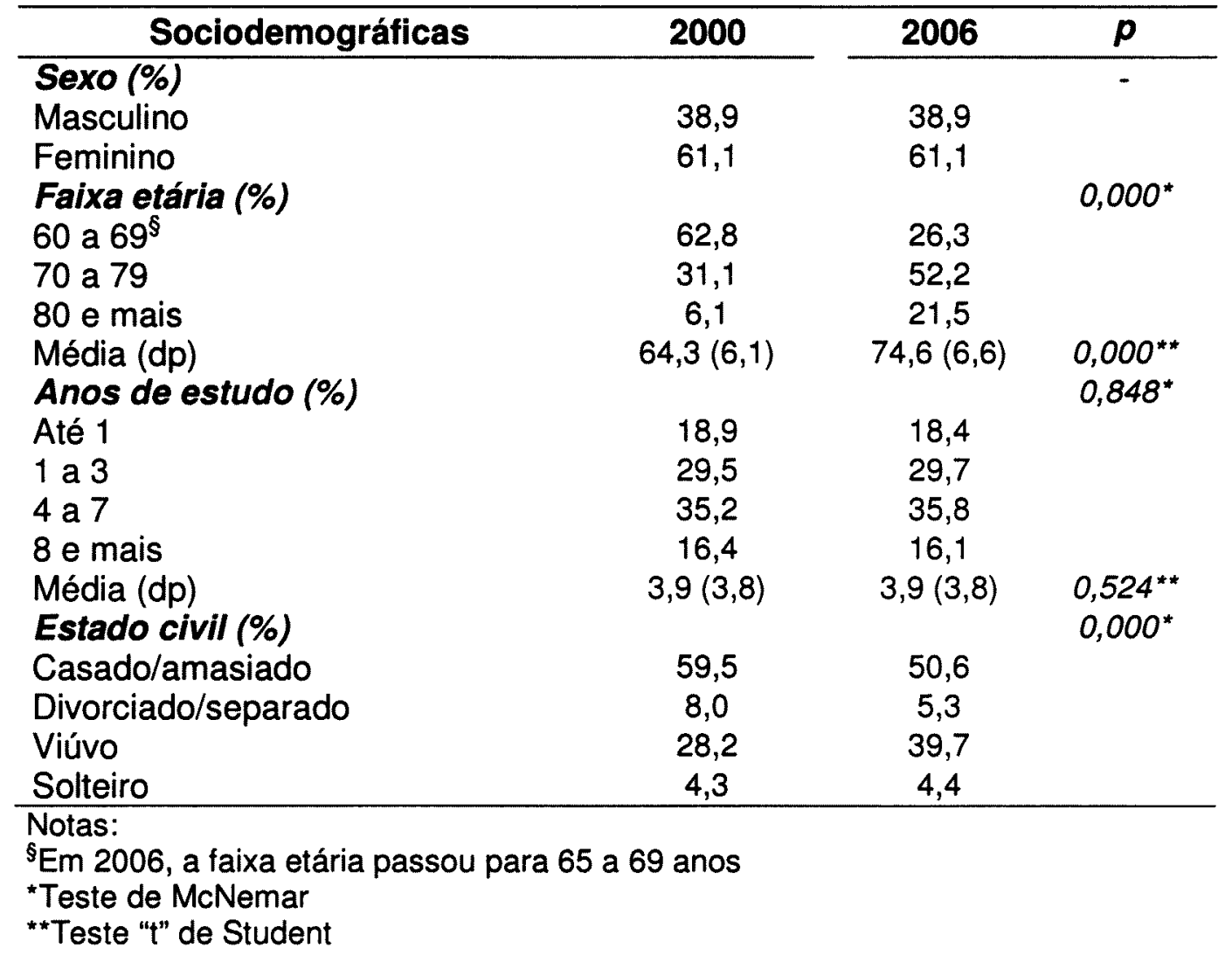

A auto-avaliação da saúde do idoso é um importante indicador subjetivo de bem-estar, pois traduz a percepção de suas condições físicas de saúde e de seu ambiente social. De maneira geral, a maioria dos idosos não apresentou modificações evidentes nas suas percepções de saúde, permanecendo mais freqüentes os que a avaliavam como boa $(37,6 \% ; 38,7 \%)$ e regular $(45,8 \%$; $46,4 \%$ ). Contudo, ocorreram pioras nas auto-avaliações, observada entre os que deixaram de percebê-la como muito boa $(10,4 \% ; 5,9 \%)$ e aumento das percepções ruins $(6,2 \% ; 9,0 \%),(p=0,001)$. A piora tornou-se evidente na escala da auto-avaliação da saúde, que está tendendo para regular, $(p=0,001)$. Merece ressaltar que a pergunta sobre a saúde referida no instrumento do presente estudo mudou, de 2000 para 2006. Em 2000 a escala da autoavaliação da saúde era de muito boa até muito ruim, enquanto em 2006, era de excelente a ruim.(Tabela 2) 
Estudos populacionais realizados em países desenvolvidos, como Áustria (BUBER, 2007), Inglaterra (BOWLING et al., 2007), Suécia (BORGLIN et al., 2006) e Israel (LITWIN, 2006) confirmam que o avançar da idade repercute na piora da percepção de saúde do idoso.

Com o envelhecimento há um aumento na prevalência de doenças crônicas, o que pode ser percebido pela referencia, em 2006, da presença de doença(s) entre aqueles que, anteriormente (2000), não referiram nenhuma $(26,4 \% ; 17,9 \%$ respectivamente), a permanência dos que referiram apenas uma doença $(30,9 \% ; 30,4 \%)$ e aumento dos que referiram duas e mais doenças de $42,7 \%$ para $51,7 \%,(p=0,000)$. As médias das doenças referidas pelos idosos confirmam esse aumento ao longo do tempo, passando de 1,4 para 1,6 doenças, $(p=0,000)$. (Tabela 2$)$

Em relação ao comprometimento funcional, a maioria dos idosos não referiu, nos dois períodos, nenhuma dificuldade no desempenho das Atividades Básicas da Vida Diária (ABVDs) e das Atividades Instrumentais da Vida Diária (AIVDs). Entretanto, observa-se expressivo aumento entre os que referiram três e mais ABVDs (2,9\%; 11,6\%) e AIVDs comprometidas (10,6\%; 20,9\%), $(p=0,000)$. A média das dificuldades em ABVDs passou de 0,3 para 0,7 e entre AIVDs de 0,7 para 1,2, $(p=0,000)$. (Tabela 2)

Os dados apontam para dois grupos de idosos, os que não têm declínio funcional e mantêm condições de viver ativamente sem necessidade de ajuda para executar suas Atividades da Vida Diária (AVDs) e dos idosos que estão necessitando cada vez mais de sua rede de apoio para exercer suas atividades de vida diária.

Buber e Engelhardt (2008b) analisaram a relação entre os sintomas depressivos e a idade dos idosos em 12 países da Europa que fazem parte de um estudo multicêntrico e verificaram que as limitações nas atividades da vida diária, declínio cognitivo e saúde física ruim foram os principais fatores de risco associados à depressão nos idosos.

Dados similares foram encontrados em estudo populacional realizado na Coréia, que mostrou a relação negativa entre o declínio funcional e qualidade de vida do idoso (IK KI KIM e CHEONG-SEOK KIM, 2003)

As doenças crônicas e declínio da capacidade funcional não precisam, necessariamente, culminar com deficiência, perda de autonomia e 
comprometimento da qualidade de vida dos idosos. Segundo a OMS (2005, p. 36) é necessária a adoção de "políticas e programas que ajudem a prevenir e reduzir a carga de deficiência na velhice", tratando essa questão não como incapacidade, mas capacidade, potencializando que os idosos possam ter condições de participar e permanecer ativos na sociedade, tanto com medidas de melhora na infra-estrutura, como iluminação, pavimentação, transporte etc., até programas de educação em saúde e fornecimento de recursos e programas sociais.

Bonsang (2006) comparando os padrões de apoio formal e informal nos países europeus mostrou que nos países escandinavos cujo sistema de saúde é universal os idosos mais dependentes são cuidados, principalmente, por serviços de cuidados domiciliares ou são instituicionalizados. Nos países mediterrâneos, que contam com um sistema de saúde misto, o papel da família como cuidadora do idoso é mais valorizado.

Glaser, Tomassini e Grundy (2004) investigaram os diferentes padrões de apoio formal e informal existentes em 13 países da Europa e concluíram que as atitudes que envolvem as normas de responsabilidade filial de apoio são prováveis de ocorrerem diferenciadamente de acordo com as políticas sociais existentes em cada país, através da disponibilidade, custo e qualidade na provisão dos serviços.

Attias-Donfut (2001) verificou que, na França, a presença do cuidador profissional não altera o tempo de ajuda despendido pelos filhos, ao contrário, o tempo de ajuda familiar é comparativamente mais significativo quando é complementado pelo sistema público.

Se a rede formal começar a se estruturar, as demandas para a familia não serão de sobrecarga, podendo prevenir relações de troca de apoio que gerariam impacto negativo, em vez de protetor, na saúde do idoso. Estudo realizado em Israel (LITWIN, 2006) analisando a influência da rede social dos idosos em suas percepções de saúde mostrou que o idoso ser capaz de fornecer ajuda reflete em um bom estado de saúde, enquanto precisar de ajuda é interpretado como reflexo de uma saúde pior. 
Tabela 2 - Condições de saúde dos idosos, município de São Paulo, SP, 2000 e $2006(n=1115)$.

\begin{tabular}{|c|c|c|c|}
\hline Condições de saúde & 2000 & 2006 & $p$ \\
\hline Auto-avaliação da saúde (\%) & & & $0,001^{*}$ \\
\hline Muito boa & 10,4 & 5,9 & \\
\hline Boa & 37,6 & 38,7 & \\
\hline Regular & 45,8 & 46,4 & \\
\hline Ruim & 6,2 & 9,0 & \\
\hline Média $(d p)^{(1)}$ & $2,5(0,7)$ & $2,6(0,7)$ & $0,001 * *$ \\
\hline $\begin{array}{l}N^{\circ} \text { dificuldades referidas no } \\
\text { desempenho das ABVDs (\%) }\end{array}$ & & & $0,000^{*}$ \\
\hline Nenhuma & 84,0 & 79,3 & \\
\hline $1 \mathrm{a} 2$ & 13,1 & 15,1 & \\
\hline 3 e mais & 2,9 & 11,6 & \\
\hline Média (dp) & $0,3(0,9)$ & $0,7(1,6)$ & $0,000^{* *}$ \\
\hline $\begin{array}{l}N^{\circ} \text { dificuldades referidas no } \\
\text { desempenho das AIVDs (\%) }\end{array}$ & & & $0,000^{*}$ \\
\hline Nenhuma & 61,9 & 52,3 & \\
\hline 1 a 2 & 27,5 & 26,8 & \\
\hline 3 e mais & 10,6 & 20,9 & \\
\hline Média (dp) & $0,7(1,2)$ & $1,2(1,6)$ & $0,000^{* *}$ \\
\hline$N^{\circ}$ doenças referidas (\%) & & & $0,000^{*}$ \\
\hline Nenhuma & 26,4 & 17,9 & \\
\hline 1 & 30,9 & 30,4 & \\
\hline 2 e mais & 42,7 & 51,7 & \\
\hline Média (dp) & $1,4(1,1)$ & $1,6(1,2)$ & $0,000^{* *}$ \\
\hline
\end{tabular}

\subsection{REDE DE APOIO SOCIAL DOS IDOSOS}

A disponibilidade da rede de apoio domiciliar dos idosos é atribuída ao número de pessoas com quem eles podem contar quando necessitam e são procuradas, primeiramente, no domicilio, entre seus co-residentes e filhos e, extradomicilio, principalmente entre os filhos, que representam suas principais fontes de apoio extradomiciliar.

A média de co-residentes revelou uma diminuição de 3,2 para 2,8 , no período estudado, $(p=0,000)$; enquanto a de filhos co-residentes aumentou de 
1,8 para 2,5, refletindo alteração do arranjo familiar, $(p=0,000)$. Essa situação é confirmada pelo aumento do número de filhos não co-residentes, de 3,7 para $3,8,(p=0,042)$. Os dados apontam que os idosos contam com uma extensa rede de apoio dos filhos, tanto no domicílio quanto fora deste, indicando que estão residindo mais com seus filhos, mas estes também estão saindo de casa. (Tabela 3)

A extensa disponibilidade de apoio verificada no presente estudo difere da dos paises europeus, em que os idosos já vivem o declínio da fecundidade anterior, com médias entre dois e três filhos, como demonstrado no estudo de Buber e Engelhardt (2006). Por outro lado, Hank (2007), relatou que a probabilidade de os idosos residirem com seus filhos, nesse mesmo estudo, aumenta com o número de filhos, sendo ainda maior entre os idosos com 70 anos e mais de idade.

Já em países como o México (WONG, 2002) e China (ZIMMER e KWONG, 2003) o número de filhos foi expressivo como no Brasil. No México, $59,2 \%$ das pessoas com 50 anos e mais tinham entre quatro e dez filhos vivos, enquanto na China, $42,3 \%$ dos idosos que residiam nas áreas rurais e $33,5 \%$ dos que viviam nas áreas urbanas tinham pelo menos cinco filhos vivos.

Um estudo populacional realizado na China sobre as alterações nas estruturas familiares demonstrou ser o número de filhos uma importante fonte de apoio, pois enquanto um filho fornece a ajuda necessária instrumental, os outros filhos complementam com a ajuda financeira. Esse mesmo estudo encontrou também que a co-residência com os filhos aumenta a probabilidade dos idosos em receber apoio (ZIMMER e KWONG, 2003).

Attias-Donfut (2001) encontrou resultados similares na França; apontando que quando os idosos possuem vários filhos, estes dividem as ajudas, onerando menos o tempo por cada filho. Esses dados foram confirmados por Bonsang (2006) em estudo multicêntrico realizado na Europa.O autor relatou, no entanto, que o aumento da idade dos pais requer, dos filhos, mais tempo de ajuda para o fornecimento de apoio. A mesma relação foi encontrada por Gierveld e Dykstra (2006) em estudo na Holanda, onde o número de filhos é importante preditor para o idoso receber mais ajuda.

No caso dos idosos mais longevos residentes em São Paulo (80 anos e mais de idade), observa-se uma rede de apoio mais extensa, que pode 
compartilhar a atenção à ajuda demandada diminuindo a probabilidade de sobrecarga de um único filho..

Gierveld e Dykstra (2006) verificaram que os idosos holandeses com 80 anos e mais de idade são os que têm mais filhos fornecendo ajuda. Na Coréia do Sul, Ik Ki Kim e Cheong-Seok Kim (2003) observaram que a qualidade de vida dos idosos esteve positivamente associada tanto com o número de filhos quanto com a coresidencia com eles.

No arranjo domiciliar verifica-se mais nitidamente os movimentos ocorridos no intervalo de cinco anos, entre os idosos que deixaram de residir com seus cônjuges $(58,6 \%, 24,0 \%$, em 2000 e 2006, respectivamente), aqueles que continuaram a morar com seus filhos $(22,6 \% ; 21,7 \%)$, aqueles que passaram a morar sozinhos $(11,4 \% ; 16,2 \%)$ e aqueles que passaram a morar com outras pessoas $(7,4 \% ; 38,1 \%),(p=0,000)$. (Tabela 3$)$

Os padrões de arranjos domiciliares apresentam diferenças de acordo com os contextos culturais. No estudo de Buber e Engelhardt (2006) com famílias européias, verifica-se que somente nos países do sul, como Grécia, Itália e Espanha, foi referida maior freqüência de co-residência com os filhos.

Attias-Donfut, Ogg e Wolff (2005) nesse mesmo estudo, observaram que o desemprego dos mais jovens, verificado em países como Espanha e Itália ocasiona o adiamento da saída da casa dos pais, confirmando que o uso da coabitação nesses países está relacionado mais como um mecanismo de proteção social se comparado com os outros países europeus. Os autores destacam que a disponibilidade de recursos sociais verificado nos países centrais e do norte da Europa substitui a assistência intensiva e mais árdua dada pelos filhos nos outros países, mantendo uma relação de apoio entre pais e filhos de outras formas menos sobrecarregadas. Encontraram ainda a proporção de $21 \%$ a $37 \%$ de idosos morando sozinhos, o que novamente deixa evidente, ao comparar com os dados da coorte estudada, que morar sozinho pode envolver ter os recursos necessários para não precisar residir com os filhos ou outras pessoas, na perda do cônjuge ou familiares com quem habitavam.

Diante disso pode-se inferir que o contexto de instabilidade econômica atual, mais evidente nos países em desenvolvimento, como o Brasil, reflete nas configurações domiciliares dos idosos, através da independência financeira dos 
filhos, sua inconstância no mercado de trabalho, que resulta em diversas famílias residindo no mesmo teto ou a volta dos filhos a morar com seus pais. Outra situação que pode ocorrer no aumento da co-residência dos idosos com os filhos deve-se à perda da independência ou autonomia desses idosos, que passam a ter que residir com seus filhos, pois o sistema formal não fornece a estrutura adequada para que vivam sós (CAMARANO et al., 2004).

Entretanto, merece atenção os estudos citados por Komter e Vollebergh (2002) sobre os aspectos negativos que envolvem as relações de troca de apoio entre os idosos e seus filhos. Na percepção dos idosos se verifica na piora de suas saúdes, ocasionada pelos sentimentos de dependência de seus filhos ou quando sentem que estes utilizam o apoio fornecido como forma de controle. Nos filhos foram notados sentimentos de obrigação em fornecer apoio aos pais quando estes precisavam, por dependerem mais tempo financeiramente de seus pais.

Hank (2007), analisando os mesmos dados do estudo multicêntrico realizado na Europa, verificou que a piora na percepção de saúde dos idosos estava associada com a presença de sintomas depressivos, quando residiam com seus filhos.

A disponibilidade de apoio é também verificada pela proximidade da residência dos filhos e freqüência do contato com eles. O local de residência dos filhos não mudou durante o intervalo de cinco anos do estudo. Aproximadamente $53 \%$ dos idosos continuam a ter filhos residindo no mesmo bairro ou em outro bairro, e por volta de $40 \%$ em outra cidade. No entanto, a freqüência do contato aumentou demonstrada pelo aumento do contato semanal (36,6\% e 46,8\% em 2000 e 2006, respectivamente) e diário (23,9\%; $28,2 \%$ ), enquanto o mensal manteve-se em torno de $20 \%$ e os contatos que nunca ocorriam ou eram anuais diminuíram visivelmente $(19,2 \% ; 8,1 \%)$, $(p=0,000)$. (Tabela 3)

Como já vem sendo destacado, o avanço da idade dos idosos gera mais demandas de suas redes de apoio, sendo possível verificar na coorte que os filhos se mantiveram próximos geográfica e presencialmente, podendo representar uma forma de monitoramento da saúde e do bem-estar dos idosos.

Estudo realizado em Israel (LITWIN, 2006) também encontrou que a proximidade de residência dos filhos não se relacionava com a freqüência do 
contato com eles, entretanto o contato por si só foi suficiente para não piorar a percepção de saúde dos idosos. Buber e Engelhardt (2006) verificaram em 12 países europeus, que a frequência do contato entre os idosos e seus filhos também foi independente da distância geográfica entre eles. Outra abordagem desse estudo por esses autores (2008) revelou que o pouco contato dos idosos com seus filhos esteve associado com o aumento dos sintomas depressivos dos idosos. Entretanto, os autores destacam que o contato diário entre os idosos e seus filhos também pode ser um indicador de saúde física e/ou mental ruim dos idosos.

Tabela 3 - Disponibilidade da rede de apoio domiciliar e extradomiciliar (filhos) dos idosos, Município de São Paulo, 2000 e 2006 ( $n=1115)$.

\begin{tabular}{|c|c|c|c|}
\hline Disponibilidade & 2000 & 2006 & $\bar{p}$ \\
\hline \multicolumn{4}{|l|}{ Domiciliar } \\
\hline $\mathrm{N}^{\circ}$ médio de co-residentes ${ }^{\S}$ & $3,2(1,7)$ & $2,8(1,6)$ & $0,000 * *$ \\
\hline $\mathrm{N} \circ$ médio de filhos co-residentes $\$$ & $1,8(1,0)$ & $2,5(1,0)$ & $0,000 *$ \\
\hline Arranjo domiciliar (\%) & & & $0,000^{*}$ \\
\hline Sozinho & 11,4 & 16,2 & \\
\hline Com cônjuge & 58,6 & 24,0 & \\
\hline Com filho & 22,6 & 21,7 & \\
\hline Com outros & 7,4 & 38,1 & \\
\hline \multicolumn{4}{|l|}{ Extradomiciliar (filhos) } \\
\hline $\begin{array}{l}N \circ \text { médio de filhos } \\
\S \\
\text { Local de residência dos filhos(\%) }\end{array}$ & $3,7(2,4)$ & $3,8(2,3)$ & $0,042^{\star *}$ \\
\hline Mesmo bairro & 16,9 & 16,4 & \\
\hline Outro bairro & 37,7 & 37,4 & \\
\hline Outra cidade & 40,7 & 40,3 & \\
\hline Outro país & 4,7 & 5,9 & \\
\hline Média $(\mathrm{dp})^{(1)}$ & $2,6(0,8)$ & $2,6(0,8)$ & $0,123^{* *}$ \\
\hline Freq. contato com os filhos(\%) & & & $0,000^{*}$ \\
\hline Diário & 23,9 & 28,2 & \\
\hline Semanal & 36,6 & 43,8 & \\
\hline Mensal & 20,4 & 19,9 & \\
\hline Anual & 15,4 & 6,2 & \\
\hline Nunca & 3,8 & 1,9 & \\
\hline Média (dp) $)^{(2)}$ & $3,6(1,1)$ & $3,9(0,9)$ & $0,000^{* *}$ \\
\hline
\end{tabular}

Notas:

§Variáveis expressas em média e desvio-padrão

(1) Escala de 1 a 4, conforme aumenta o valor, aumenta a proximidade da residência

${ }^{(2)}$ Escala de 1 a 5, conforme aumenta o valor, aumenta a freqüência do contato

*Teste de McNemar

"*Teste " $\mathrm{t}$ " de Student 
As características estruturais da rede de apoio dos idosos confirmam ser a principal fonte de apoio proveniente do domicilio e a rede extradomiciliar apresenta ser secundária e mais presente entre os filhos. Porém, com o passar do tempo, a média das ajudas recebidas no domicílio permaneceu em torno de três ajudas, enquanto a extradomiciliar aumentou tanto entre os filhos - de 1,7 para 2,4 - quanto entre os outros familiares e amigos - com 0,5 para 0,7durante o período estudado, $(p<0,05)$. Dessa forma, a rede domiciliar se mantém organizada com as demandas já existentes. Todavia, ao longo do tempo, a extradomiciliar tem se mobilizado para suprir as que vão surgindo, ou a domiciliar pode ter se tornado insuficiente, exigindo complementação. (Tabela 4)

Gierveld e Dykstra (2006) analisaram um estudo realizado na Holanda sobre as relações intergeracionais dos idosos e verificaram que a dedicação dos filhos em fornecer apoio a seus pais não é influenciada pelos eventos da vida conjugal por que os filhos estão passando, como divórcio e viuvez, não obstante a carga extra que isso possa ocasionar-Ihes.

O fornecimento de apoio pelos idosos também ocorreu principalmente no domicílio e se ampliou, depois, para os filhos não co-residentes. O tempo de estudo mostrou que os idosos passaram a fornecer menos ajuda no domicílio (de 3,6 para 3,3 ajudas em média, $p=0,029$ ) e mantiveram a ajuda extradomiciliar para os filhos (média de 1,1 ) e aos outros familiares e amigos (média de 0,6 ajudas). Aliado ao fato de o número de co-residentes ter diminuído no período do estudo, pode-se supor que as ajudas decresceram no domicílio porque o número de co-residentes com quem os idosos dividiam suas ajudas dadas também diminuiu. Os dados confirmam que, conforme passam os anos, os recursos da rede extradomiciliar são mais requisitados e, dessa forma, ativam o fluxo de apoio. (Tabela 4) 
Tabela 4 - Características estruturais da rede de apoio domiciliar e extradomiciliar (filhos, outros familiares e amigos) dos idosos, Municipio de São Paulo, 2000 e 2006 ( $n=1115)$.

\begin{tabular}{|c|c|c|c|}
\hline Características estruturais $^{\S}$ & 2000 & 2006 & $p^{*}$ \\
\hline \multicolumn{4}{|l|}{ Domiciliar } \\
\hline$N^{\circ}$ médio de ajudas recebidas & $3,0(2,7)$ & $3,3(2,8)$ & 0,099 \\
\hline $\begin{array}{l}\text { No médio de ajudas fornecidas } \\
\text { Extradomiciliar }\end{array}$ & $3,6(3,3)$ & $3,3(3,1)$ & 0,029 \\
\hline \multicolumn{4}{|l|}{$\begin{array}{l}\text { Extradomiciliar } \\
\text { Filhos }\end{array}$} \\
\hline$N^{\circ}$ médio de ajudas recebidas & $1,7(2,7)$ & $2,4(3,2)$ & 0,000 \\
\hline$N^{\circ}$ médio de ajudas fornecidas & $1,1(1,8)$ & $1,1(2,1)$ & 0,693 \\
\hline \multicolumn{4}{|l|}{ Outros familiares/amigos } \\
\hline$N^{\circ}$ médio de ajudas recebidas & $0,5(1,7)$ & $0,7(1,7)$ & 0,014 \\
\hline$N^{\circ}$ médio de ajudas fornecidas & $0,6(1,8)$ & $0,6(1,4)$ & 0,885 \\
\hline
\end{tabular}

As características funcionais da rede de apoio foram verificadas por meio dos tipos de apoio social instrumental, de companhia e outro tipo de apoio. Na rede domiciliar, o fluxo (dar e receber) de apoio instrumental foi o mais freqüente, entretanto, as trocas desse apoio diminuíram tanto para receber - de 2,6, em 2000, para 2,3, em 2006 - quanto para fornecer - de 3,2 para 2,3. Também para o outro tipo de apoio, tanto para receber - de 0,4 apoios para 0,2 - quanto para dar - de 0,5 para $0,2-,(p<0,05)$ ocorreu uma diminuição. (Tabela 5)

$\mathrm{Na}$ rede de apoio extradomiciliar dos filhos, o fluxo de apoio instrumental também foi o mais freqüente. Entretanto, no apoio recebido, aumentaram o apoio instrumental - de 1,0 para 1,3 ajudas - e companhia - de 0,3 para 0,5 ajudas, $(p<0,05)$, enquanto o outro tipo de apoio se manteve em torno de 0,4 ajudas. No apoio fornecido pelo idoso ocorreu o inverso para o instrumental de 3,2 para 0,5 ajudas - e o outro tipo de apoio também permaneceu em 0,4 ajudas. (Tabela 5)

Os estudos ressaltam que o apoio instrumental é o principal tipo de apoio trocado entre os idosos e seus filhos, através de dinheiro e serviços (KOMTER e VOLLEBERGH, 2002; ZIMMER e KWONG, 2003). Os sentimentos 
acumulados ao longo da relação intergeracional são revelados na identificação do apoio de companhia que os idosos passaram a receber mais de seus filhos.

Estudo realizado na Alemanha (SCHÜTZE e HOLLSTEIN, 1994) examinou a relação da troca de apoio na percepção dos pais e filhos e apontou que os filhos se sentem mais obrigados a fornecer apoio instrumental, independente da qualidade da relação estabelecida. Já, os pais idosos percebem, com menos intensidade, a troca de apoio com os filhos. Dessa forma, os filhos tendem a superestimar a troca enquanto os pais a subestimam.

Kohli (1999), no mesmo estudo, encontrou que $70 \%$ do apoio fornecido pelos pais idosos se direcionam para os filhos e destaca que, quanto mais apoio o idoso recebe de seus filhos, mais ele fornece.

A rede de apoio extradomiciliar de familiares e amigos dos idosos manifestou-se como secundária, dado condizente com o estudo de Litwin (2006) em Israel. No entanto, houve aumento nos apoios instrumentais (de 0,1 para 0,3 ) e de companhia (de 0,1 para 0,2 ) recebidos durante o período de estudo $(p<0,05)$, não ocorrendo o mesmo com o apoio fornecido pelos idosos. (Tabela 5)

As transferências de apoio entre familiares e amigos são construidas pelas afinidades e proximidades estabelecidas ao longo do curso de vida. São firmadas nos vínculos estabelecidos e não nas relações mais concretas como as relações filiais (entre pais e filhos) ou comunais (entre cônjuges). Observase, nesse estudo, que os idosos estão utilizando os recursos dessa fonte de apoio mesmo os dados não sendo tão evidentes.

Komter e Vollebergh (2002) analisaram um estudo na Holanda comparando os sentimentos de amor e obrigação que envolviam o apoio dado pelos filhos adultos aos seus pais idosos, encontraram que a solidariedade com os pais baseia-se em normas de obrigações filiais, sendo o apoio instrumental - mais freqüente enquanto a solidariedade entre amigos é acompanhada principalmente por sentimentos de amor. 
Tabela 5 - Características funcionais da rede de apoio domiciliar e extradomiciliar (filhos, outros familiares e amigos) dos idosos, Município de São Paulo, 2000 e 2006 ( $n=1115)$.

\begin{tabular}{|c|c|c|c|}
\hline Caracteristicas funcionais $^{\mathbf{S}}$ & 2000 & 2006 & $p^{*}$ \\
\hline \multicolumn{4}{|l|}{$\begin{array}{l}\text { Domiciliar } \\
\text { Tipo de apoio recebido }\end{array}$} \\
\hline Instrumental & $2,6(2,5)$ & $2,3(2,1)$ & 0,019 \\
\hline $\begin{array}{l}\text { Outro tipo } \\
\text { Tipo de apoio dado }\end{array}$ & $0,4(0,8)$ & $0,2(0,5)$ & 0,001 \\
\hline Instrumental & $3,2(3,1)$ & $2,3(2,5)$ & 0,000 \\
\hline Outro tipo & $0,5(1,1)$ & $0,2(0,7)$ & 0,002 \\
\hline $\begin{array}{l}\text { Extradomiciliar } \\
\text { Filhos } \\
\text { Tipo de apoio recebido }\end{array}$ & & & \\
\hline Instrumental & $1,0(1,9)$ & $1,3(2,2)$ & 0,003 \\
\hline Companhia & $0,3(1,0)$ & $0,5(1,0)$ & 0,040 \\
\hline $\begin{array}{l}\text { Outro tipo } \\
\text { Tipo de apoio dado }\end{array}$ & $0,3(0,9)$ & $0,4(0,9)$ & 0,325 \\
\hline Instrumental & $3,2(3,1)$ & $0,5(1,0)$ & 0,000 \\
\hline $\begin{array}{l}\text { Outro tipo } \\
\text { Outros familiares/amigos } \\
\text { Tipo de apoio recebido }\end{array}$ & $0,4(1,2)$ & $0,4(1,1)$ & 0,628 \\
\hline Instrumental & $0,1(0,6)$ & $0,3(0,9)$ & 0,000 \\
\hline Companhia & $0,1(0,7)$ & $0,2(0,7)$ & 0,029 \\
\hline $\begin{array}{l}\text { Outro tipo } \\
\text { Tipo de apoio dado }\end{array}$ & $0,2(0,9)$ & $0,2(0,6)$ & 0,614 \\
\hline Instrumental & $0,2(0,8)$ & $0,2(0,6)$ & 0,072 \\
\hline Companhia & $0,1(0,7)$ & $0,2(0,7)$ & 0,067 \\
\hline Outro tipo & $0,2(1,0)$ & $0,1(0,6)$ & 0,316 \\
\hline
\end{tabular}

Notas:

șTodas as variáveis foram expressas em média e desvio-padrão

"Teste " $\mathrm{t}$ " de Student

\subsection{MUDANÇAS NO APOIO SOCIAL RECEBIDO PELOS IDOSOS}

$\mathrm{Na}$ análise que se fará a seguir, ater-se-á ao estudo apenas do apoio recebido, tendo em vista a extensão da análise e discussão dos dois sentidos dos apoios e, também, por este aspecto de apoio ser importante para entender como a rede de apoio se organiza, ao longo do tempo, com as demandas advindas do processo de envelhecimento. 
O comportamento dos idosos, segundo o sexo, para as mudanças no recebimento de apoio ao longo do tempo, de acordo com as trocas de apoio com sua rede domiciliar e extradomiciliar, demonstrou que não houve diferença, entre os sexos, para o apoio fornecido no domicílio e para as trocas entre os filhos não co-residentes. Mas, procederam de maneira diferenciada no apoio recebido no domicílio $(p=0,000)$ e nas trocas de apoio entre familiares e amigos da rede extradomiciliar $(p<0,050)$. (Tabela 6)

No domicílio, verifica-se um aumento do apoio recebido em $51,3 \%$ dos homens e uma diminuição de $43,3 \%$ do apoio fornecido aos seus coresidentes. As mulheres exibiram proporções semelhantes para todas as condições de mudanças no apoio recebido no domicílio; enquanto, no fornecimento de apoio aos seus co-residentes, predominaram as que aumentaram $(35,6 \%)$ e diminuíram $(37,8 \%)$ o apoio dado. (Tabela 6 )

No fluxo de apoio extradomiciliar com os filhos, os homens apresentaram maior freqüência para igualdade $(41,8 \%)$ e aumento $(39,1 \%)$ do apoio recebido pelos filhos. No caso do apoio dado aos filhos, a maioria não alterou o fornecimento $(49,9 \%)$. As mulheres também tiveram as maiores proporções no aumento $(40,7 \%)$ e manutenção $(37,8 \%)$ do apoio recebido pelos filhos, a maior porção também conservou o número de apoio dado aos filhos (48,9\%). (Tabela 6 )

As transferências de apoio entre os idosos e seus familiares e amigos não co-residentes, para ambos os sexos, em sua maioria, não se alterou ao longo do tempo, porém vale ressaltar que esta também aumentou tanto no sexo masculino, totalizando no apoio recebido em $18,3 \%$ e no fornecido $14,0 \%$, quanto no feminino, em $23,7 \%$ e $20,9 \%$, respectivamente. (Tabela 6 )

O comportamento diferenciado de gênero evidenciado no apoio recebido no domicílio e nas trocas de apoio com a rede extradomiciliar dos familiares e amigos é devido às trocas de apoio que os homens estabelecem serem diferenciadas se comparadas às das mulheres, sendo organizadas e menos diversificadas, através da renda, moradia e serviços específicos. Dessa forma, requerem mais apoio da rede domiciliar, enquanto as mulheres, por estabelecerem maiores relações de apoio com os familiares e amigos não coresidentes, buscam recursos também dessa fonte. 
Como já foi mencionado, a rede extradomiciliar dos familiares e amigos é estabelecida através de laços sociais que vão sendo construídos ao longo da vida por meio de afinidades. Antonucci, Akiyama e Lansford (1998) destacam uma série de estudos que apresentam as diferenças de gênero nas relações sociais, demonstrando que as mulheres estabelecem um maior número de relações, que também são mais íntimas. Porém, ressaltam que, mesmo ocorrendo mais interações positivas que negativas nessas ligações, o impacto das interações negativas pode ser considerável. $O$ aspecto negativo pode ser percebido no senso de independência e autonomia das idosas, no recebimento de apoio que não é correspondente à necessidade e os custos psicológicos que a troca de apoio pode ocasionar.

A rede de apoio dos filhos que não residem com os idosos permaneceu ativa ao longo do tempo, para ambos os sexos, como, também, se tornou mais freqüente, verificado pelo aumento no apoio recebido. No entanto, a relação de troca se manteve independente do sexo, confirmada no apoio dado pelos idosos.

Estudo populacional realizado na Coréia verificando os padrões de troca de apoio intergeracional e suas relações na qualidade de vida dos idosos encontraram que os que estavam maior satisfação com a vida eram os que estabeleciam maior relação de troca com seus filhos, enquanto os idosos que só davam apoio a seus filhos estavam menos satisfeitos com suas vidas que os idosos que somente recebiam apoio de seus filhos (IK KI KIM e CHEONGSEOK KIM, 2003) 
Tabela 6 - Mudança no apoio social dos idosos nos dois momentos, segundo sexo e trocas de apoio domiciliar e extradomiciliar (filhos, outros familiares e amigos), Município de São Paulo, 2000 e 2006 ( $n=1115$ ).

\begin{tabular}{|c|c|c|c|c|c|c|c|}
\hline \multirow{3}{*}{ Fluxo do apoio } & \multicolumn{6}{|c|}{ Mudança no apoio social } & \multirow{3}{*}{$\boldsymbol{p}^{*}$} \\
\hline & \multicolumn{3}{|c|}{ Masculino (\%) } & \multicolumn{3}{|c|}{ Feminino (\%) } & \\
\hline & Ficou igual & Aumentou & Diminuiu & Ficou igual & Aumentou & Diminuiu & \\
\hline Domiciliar & & & & & & & \\
\hline $\begin{array}{l}\text { Apoio recebido } \\
\text { Apoio dado }\end{array}$ & $\begin{array}{l}21,3 \\
22,1\end{array}$ & $\begin{array}{l}51,3 \\
34,6\end{array}$ & $\begin{array}{l}27,4 \\
43,3\end{array}$ & $\begin{array}{l}30,2 \\
26,6\end{array}$ & $\begin{array}{l}36,0 \\
35,6\end{array}$ & $\begin{array}{l}33,8 \\
37,8\end{array}$ & $\begin{array}{l}0,000 \\
0,291\end{array}$ \\
\hline $\begin{array}{l}\text { Extradomiciliar } \\
\text { Filhos }\end{array}$ & & & & & & & \\
\hline $\begin{array}{l}\text { Apoio recebido } \\
\text { Apoio dado } \\
\text { Outros familiares/amigos }\end{array}$ & $\begin{array}{l}41,8 \\
49,9\end{array}$ & $\begin{array}{l}39,1 \\
27,4\end{array}$ & $\begin{array}{l}19,1 \\
22,7\end{array}$ & $\begin{array}{l}37,8 \\
48,9\end{array}$ & $\begin{array}{l}40,7 \\
24,7\end{array}$ & $\begin{array}{l}21,5 \\
26,4\end{array}$ & $\begin{array}{l}0,414 \\
0,412\end{array}$ \\
\hline $\begin{array}{l}\text { Apoio recebido } \\
\text { Apoio dado }\end{array}$ & $\begin{array}{l}72,2 \\
73,1\end{array}$ & $\begin{array}{l}18,3 \\
14,0\end{array}$ & $\begin{array}{c}9,5 \\
13,9\end{array}$ & $\begin{array}{l}63,2 \\
62,2\end{array}$ & $\begin{array}{l}23,7 \\
20,9\end{array}$ & $\begin{array}{l}13,1 \\
16,9\end{array}$ & $\begin{array}{l}0,030 \\
0,003\end{array}$ \\
\hline
\end{tabular}

Nota:

"Teste Rao-Scott 
Os dados a seguir foram analisados com o intuito de verificar como se comportaram, ao longo do tempo, as características sociodemográficas, de saúde e da rede de apoio social domiciliar e extradomiciliar dos idosos, segundo as mudanças no apoio social recebido pela rede como um todo. Dessa forma, foi possível perceber as características que os idosos tinham, em 2000 , e que passaram a ter em 2006, de acordo com as mudanças no apoio recebido pela sua rede e verificar se existiram padrões diferenciados de envelhecimento, em 2000, como também, o comportamento nesses padrões, em 2006, conforme as mudanças no apoio recebido pela sua rede. (Tabelas 7 a 11)

Verificam-se maiores mudanças no apoio social recebido pelas mulheres idosas. Entretanto, essas mudanças foram mais presentes no apoio que se manteve ao longo do tempo $(70,5 \%)$, seguido do apoio que diminuiu $(66,1 \%)$ e, por fim, do apoio que aumentou $(56,2 \%)$ no intervalo de seis anos do estudo. (Tabela 7)

A idade dos idosos não apresentou comportamento diferenciado para as categorias de mudanças no apoio recebido, o que se nota que as mudanças no apoio recebido ocorreram de maneira parecida segundo a idade dos idosos. Para todas as condições de mudanças no apoio recebido, a faixa etária mais freqüente, em 2000, foi a de 60 a 69 anos e, em 2006, a de 70 a 79 anos. Enquanto a idade média, para todas as condições de mudanças no apoio recebido, esteve em torno de 68 anos, em 2000, e de 74 anos, em 2006. Os dados apontam que as mudanças no apoio ocorreram com padrões similares de idade. (Tabela 7)

A escolaridade dos idosos não exibiu alterações durante o período estudado, com média aproximada de quatro anos de estudo. No estado civil dos idosos, entre as categorias de mudança no apoio recebido, os casados ou amasiados e viúvos estiveram entre os mais freqüentes, com diminuição da primeira condição e ênfase no aumento da viuvez, para todas as categorias de mudança no apoio recebido, $(p<0,000)$. Entretanto essas mudanças no estado civil foram mais evidentes para os que mantiveram ou reduziram seu apoio recebido ao longo do tempo. (Tabela 7 )

Tendo em vista que o cônjuge se configura como a principal, senão a mais presente, fonte de apoio do idoso, quando este deixa de existir, esse fato 
interfere no apoio que recebe. No entanto, a família e outras fontes de apoio informal podem se organizar para preencher essa lacuna. Caso contrário, esse apoio realmente desaparece.

Um estudo realizado na Holanda (GIERVELD e DYKSTRA, 2006) mostrou que mais de $60 \%$ dos idosos que residiam com seus cônjuges reportaram receber algum tipo de ajuda de seus companheiros, enquanto no grupo dos mais idosos a ajuda do cônjuge foi menos freqüente, devido ao fato de o cônjuge não ser apto para fornecer apoio por causa de suas restrições de saúde. Os autores também encontraram que os idosos viúvos que vivem sozinhos têm maiores chances de receber apoio de seus filhos.

Komter e Vollebergh (2002) citam estudos que verificaram que a viuvez demanda mais ajuda fornecida pelos filhos, que as outras condições conjugais. Dados parecidos foram encontrados em um estudo populacional na China, em que a ausência do cônjuge aumenta a probabilidade de receber apoio dos filhos (ZIMMER e KWONG, 2003). Attias-Donfut (2001) também encontrou associação positiva entre receber ajuda e ser viúvo, principalmente se for mulher.

A perda do cônjuge não aumenta somente as demandas instrumentais da rede de apoio, mas influencia nos aspectos emocionais que essa perda gera. Dykstra, Tilburg e Gierveld (2005) analisaram as mudanças nas percepções de solidão pelos idosos em estudo longitudinal realizado na Holanda, encontrando o cônjuge como protetor dos sentimentos de solidão dos idosos, sendo os mais altos níveis de solidão encontrados entre os que haviam perdido seu cônjuge durante o período estudado. 
Tabela 7 - Mudança no apoio recebido pelos idosos nos dois momentos, segundo características sociodemográficas, Município de São Paulo, 2000 e $2006(n=1.115)$.

\begin{tabular}{|c|c|c|c|c|c|c|}
\hline \multirow{2}{*}{ Sociodemográficas } & \multicolumn{2}{|c|}{ Ficou igual } & \multicolumn{2}{|c|}{ Aumentou } & \multicolumn{2}{|c|}{ Diminuiu } \\
\hline & 2000 & 2006 & 2000 & 2006 & 2000 & 2006 \\
\hline \multicolumn{7}{|l|}{ Sexo (\%) } \\
\hline Masculino & 29,5 & 29,5 & 43,8 & 43,8 & 33,9 & 33,9 \\
\hline Feminino & 70,5 & 70,5 & 56,2 & 56,2 & 66,1 & 66,1 \\
\hline \multicolumn{7}{|l|}{ Faixa etária (\%) } \\
\hline 60 a 69 & 63,0 & 24,4 & 63,5 & 24,9 & 61,5 & 29,3 \\
\hline 70 a 79 & 31,4 & 54,3 & 29,8 & 52,2 & 33,1 & 51,5 \\
\hline \multirow[t]{2}{*}{80 e mais } & 5,6 & 21,3 & 6,7 & 22,9 & 5,4 & 19,2 \\
\hline & \multicolumn{2}{|c|}{$p=0,000^{\star}$} & \multicolumn{2}{|c|}{$p=0,000^{*}$} & \multicolumn{2}{|c|}{$p=0,000^{*}$} \\
\hline \multirow[t]{2}{*}{ Média (dp) } & $\begin{array}{l}68,7 \\
(6,7)\end{array}$ & $\begin{array}{c}74,7 \\
(6,7)\end{array}$ & $\begin{array}{l}68,7 \\
(6,6)\end{array}$ & $\begin{array}{l}74,7 \\
(6,6)\end{array}$ & $\begin{array}{l}68,2 \\
(6,4)\end{array}$ & $\begin{array}{l}74,2 \\
(6,4)\end{array}$ \\
\hline & & \multicolumn{2}{|c|}{-} & \multicolumn{2}{|c|}{$p=0,000^{*}$} \\
\hline \multicolumn{7}{|l|}{ Anos de estudo (\%) } \\
\hline Até 1 & 13,8 & 18,1 & 19,4 & 19,0 & 19,9 & 17,5 \\
\hline 1 a 3 & 36,2 & 29,4 & 28,5 & 29,5 & 28,7 & 30,2 \\
\hline 4 a 7 & 31,6 & 32,6 & 33,3 & 33,0 & 39,6 & 41,7 \\
\hline \multirow[t]{2}{*}{8 e mais } & 18,4 & 19,9 & 18,8 & 18,5 & 11,8 & 10,6 \\
\hline & \multicolumn{2}{|c|}{$p=0,962^{*}$} & \multicolumn{2}{|c|}{$p=0,806^{*}$} & \multicolumn{2}{|c|}{$p=0,504^{*}$} \\
\hline Média (dp) & $\begin{array}{c}4,0 \\
(3,7) \\
p=0,\end{array}$ & $\begin{array}{c}4,1 \\
(3,9) \\
57^{\star *}\end{array}$ & $\begin{array}{c}4,1 \\
(4,0) \\
p=0\end{array}$ & $\begin{array}{c}4,0 \\
(3,9) \\
94^{* *}\end{array}$ & $\begin{array}{r}3,6 \\
(3,5) \\
p=\end{array}$ & $\begin{array}{c}3,7 \\
(3,5) \\
15^{\star \star}\end{array}$ \\
\hline \multicolumn{3}{|l|}{ Estado civil (\%) } & \multicolumn{2}{|c|}{$p=0,094^{* *}$} & $p=0,315^{\star *}$ & \\
\hline Casado/amasiado & 59,6 & 44,4 & 60,6 & 56,5 & 57,7 & 42,9 \\
\hline Divorciado/separado & 6,1 & 6,0 & 8,1 & 5,7 & 8,7 & 4,2 \\
\hline Viúvo & 29,4 & 44,7 & 27,5 & 33,8 & 28,8 & 48,1 \\
\hline \multirow{2}{*}{ Solteiro } & 4,9 & 4,9 & 3,8 & 4,0 & 4,8 & 4,8 \\
\hline & \multicolumn{2}{|c|}{$p=0,007^{*}$} & \multicolumn{2}{|c|}{$p=0,000^{*}$} & \multicolumn{2}{|c|}{$p=0,000^{*}$} \\
\hline
\end{tabular}

Notas:

"Teste de McNemar

**Teste "t" de Student

As mudanças no apoio recebido apresentaram características diferenciadas de acordo com a auto-avaliação de saúde do idoso. Essas mudanças foram mais freqüentes nos idosos com percepção boa e regular. (Tabela 8)

Aqueles que demonstraram piora evidente na sua percepção de saúde foram os que não tiveram modificado o apoio recebido ao longo do tempo, fato esse verificado no aumento das avaliações regular $(45,9 \% ; 50,6 \%)$ e ruim $(6,5 \% ; 10,2 \%)$ e diminuição da muito boa $(9,9 \% ; 1,6 \%)$. (Tabela 8$)$ 
Essa percepção, interpretada na forma de escala, mostrou propensão para auto-avaliação regular, $(p=0,011)$. Entre os que tiveram o apoio recebido aumentado, durante o período estudado, apresentaram alterações visíveis na auto-avaliação de saúde somente os extremos, ou seja, os que deixaram de perceber sua saúde como muito boa $(9,8 \% ; 6,2 \%)$ e os que passaram a senti-la como ruim $(4,6 \% ; 9,3 \%)$. Esse fato, verificado em escala, mostra indicação para regular, $(p=0,001)$. Os idosos que tiveram seu apoio recebido diminuído, não demonstraram alterações nas suas percepções de saúde, com maiores proporções na avaliação boa e regular. (Tabela 8 )

Nesse caso, foram encontrados três grupos distintos na disposição da rede de apoio: os idosos que mantiveram o apoio recebido, os idosos que tiveram apoio aumentado e os idosos que tiveram o apoio diminuído. Os primeiros apresentaram piora na sua percepção de saúde, que pode ser explicada pela ausência de resposta ou falta de disponibilidade da rede. Entre os idosos do segundo grupo, a maioria não modificou sua percepção de saúde. Entretanto, ocorreram modificações nos extremos dessas percepções, mostrando que os que pioraram sua percepção de saúde tiveram, também, o apoio aumentado. Entre os idosos que tiveram o apoio diminuído, não houve piora ou melhora de suas avaliações de saúde, o que pode ser explicado pela real melhora nas condições de saúde desses idosos, que passaram a necessitar de menos apoio da rede, mas sem que tivesse havido fornecimento dos aspectos emocionais que possibilitariam melhor percepção de saúde. Também a rede pode ter diminuido seu apoio, mas mantendo-se organizada a ponto de não influenciar na avaliação de saúde dos idosos.

De maneira geral, os idosos que percebiam sua saúde como boa e regular não mudaram sua percepção ao longo do tempo, independente da mudança no recebimento de apoio da sua rede. Isso pode ser explicado pelo fato de a rede estar presente e se dispor a ajudá-lo quando do agravamento da sua saúde e, dessa forma, não se refletir na piora do seu bem-estar. Ainda, pode se pensar que a rede se manteve organizada e conservou suas condições de saúde, mantém a sua percepção inalterada.

Estudos populacionais (BORGLIN et al., 2006; BOWLING et al., 2006; LITWIN, 2006; BUBER, 2007) referem que o aumento da idade reflete na piora da percepção de saúde dos idosos. No caso dos idosos do município de São 
Paulo, poder-se-ia pensar que sua rede de apoio tem se disposto a ajudar nas questões de saúde e dependência funcional, não permitindo variações em suas avaliações subjetivas de saúde.

Merecem atenção os impactos emocionais das relações estabelecidas pelo idoso, que atuariam indiretamente no seu bem-estar, sendo preenchidas tanto pelos filhos quanto pelos amigos e outros familiares. Entretanto, 0 despreparo da rede formal e informal de apoio em lidar com as demandas do envelhecimento, principalmente aquelas ligadas a fatores emocionais, não repercutem na melhora de suas avaliações de saúde.

Kalache (2008) destaca que os períodos de transição ao longo da vida, que ocorrem mais evidentemente entre os idosos, devido à maior perda de familiares e amigos, saída do mercado de trabalho e reestruturação de suas vidas, quando passam a ser mais dependentes de ajuda de sua rede de apoio. Como esses fatores incidem na saúde mental do idoso, o autor salienta a necessidade de ação através de medidas intersetoriais, inseridas no âmbito da saúde pública, para lidar com essas questões.

Em relação ao comprometimento funcional, verificado pelas ABVDs e AIVDs, os dados apontam que não houve comportamento diferenciado, da rede de apoio dos idosos, no fornecimento de apoio. Os dados apresentaram maiores freqüências de idosos com nenhuma dificuldade nas atividades básicas e instrumentais e aumento mais evidenciado dos idosos que apresentam comprometimento de três e mais dessas atividades (Tabela 8).

Estudo longitudinal realizado na Holanda (DYKSTRA et al., 2005) sobre as mudanças nas percepções de solidão pelos idosos, relatou que o declínio na capacidade funcional, durante o período estudado, aumentou os sentimentos de solidão dos idosos e concluíram que os idosos que tiveram melhor capacidade funcional, ao longo do tempo, tendiam a se tornar menos sozinhos.

Resultado encontrado em um estudo populacional na China mostrou que os idosos que reportaram ao menos uma limitação funcional e auto-avaliaram sua saúde como ruim, aumentaram a probabilidade de receber apoio dos filhos (ZIMMER e KWONG, 2003). Dados de estudo transversal, realizado na Holanda (GIERVELD e DYKSTRA, 2006), encontraram que $34 \%$ dos idosos que tinham alguma limitação funcional mencionaram receber apoio dos filhos. 
Tabela 8 - Mudança no apoio recebido pelos idosos nos dois momentos, segundo características de saúde, Município de São Paulo, 2000 e 2006 ( $n=1115)$.

\begin{tabular}{|c|c|c|c|c|c|c|}
\hline \multirow{2}{*}{ Características de saúde } & \multicolumn{2}{|c|}{ Ficou igual } & \multicolumn{2}{|c|}{ Aumentou } & \multicolumn{2}{|c|}{ Diminuiu } \\
\hline & 2000 & 2006 & 2000 & 2006 & 2000 & 2006 \\
\hline \multicolumn{7}{|l|}{ Auto-avaliação da saúde } \\
\hline Muito boa & 9,9 & 1,6 & 9,8 & 6,2 & 11,6 & 6,9 \\
\hline Boa & 37,7 & 37,6 & 40,1 & 40,0 & 33,2 & 36,9 \\
\hline Regular & 45,9 & 50,6 & 45,5 & 44,4 & 46,3 & 48,1 \\
\hline \multirow[t]{2}{*}{ Ruim } & 6,5 & 10,2 & 4,6 & 9,3 & 8,9 & 8,1 \\
\hline & \multicolumn{2}{|c|}{$p=0,020^{*}$} & \multicolumn{2}{|c|}{$p=0,001^{*}$} & \multicolumn{2}{|c|}{$p=0,358^{*}$} \\
\hline \multirow[t]{2}{*}{ Média (dp) ${ }^{(1)}$} & $2,5(0,7)$ & $2,7(0,7)$ & $2,4(0,7)$ & $2,6(0,7)$ & $2,5(0,8)$ & $2,6(0,7)$ \\
\hline & \multicolumn{2}{|c|}{$p=0,011^{* *}$} & \multicolumn{2}{|c|}{$p=0,001^{\star \star}$} & \multicolumn{2}{|c|}{$p=0,343^{\star *}$} \\
\hline \multicolumn{7}{|l|}{ ABVDs (\%) } \\
\hline Nenhuma & 83,4 & 72,7 & 87,2 & 73,7 & 78,9 & 72,9 \\
\hline 1 a 2 & 12,2 & 12,1 & 10,5 & 14,6 & 17,8 & 17,1 \\
\hline 3 e mais & 4,4 & 15,2 & 2,3 & 11,7 & 3,3 & 10,0 \\
\hline \multirow[t]{2}{*}{ Média (dp) } & $0,3(1,0)$ & $0,9(1,9)$ & $0,2(0,8)$ & $0,8(1,7)$ & $0,3(0,9)$ & $0,7(1,5)$ \\
\hline & \multicolumn{2}{|c|}{$p=0,001^{* *}$} & \multicolumn{2}{|c|}{$p=0,000^{* \star}$} & \multicolumn{2}{|c|}{$p=0,001^{* *}$} \\
\hline \multicolumn{7}{|l|}{ AIVDs (\%) } \\
\hline Nenhuma & 65,7 & 52,5 & 61,2 & 50,2 & 61,9 & 55,9 \\
\hline 1 a 2 & 24,5 & 29,8 & 29,0 & 26,6 & 26,0 & 26,1 \\
\hline 3 e mais & 9,8 & 17,7 & 9,8 & 23,2 & 12,1 & 18,0 \\
\hline \multirow[t]{2}{*}{ Média (dp) } & $0,7(1,2)$ & $1,1(1,5)$ & $0,7(1,2)$ & $1,3(1,6)$ & $0,8(1,3)$ & $1,0(1,5)$ \\
\hline & \multicolumn{2}{|c|}{$p=0,002^{* \star}$} & \multicolumn{2}{|c|}{$p=0,000^{* *}$} & \multicolumn{2}{|c|}{$p=0,000^{* *}$} \\
\hline
\end{tabular}


Tabela 8 - Mudança no apoio recebido pelos idosos segundo características de saúde, São Paulo, SP, 2000 e 2006 $(n=1115)$.

"Continuação"

\begin{tabular}{|c|c|c|c|c|c|c|}
\hline \multirow{2}{*}{ Características de saúde } & \multicolumn{2}{|c|}{ Ficou igual } & \multicolumn{2}{|c|}{ Aumentou } & \multicolumn{2}{|c|}{ Diminuiu } \\
\hline & 2000 & 2006 & 2000 & 2006 & 2000 & 2006 \\
\hline \multicolumn{7}{|l|}{$N^{\circ}$ doencas referidas (\%) } \\
\hline Nenhuma & 25,7 & 17,2 & 28,9 & 19,4 & 22,3 & 15,6 \\
\hline 1 & 27,0 & 30,3 & 30,9 & 28,5 & 32,2 & 33,6 \\
\hline \multirow[t]{2}{*}{2 e mais } & 47,3 & 52,5 & 40,2 & 52,1 & 45,5 & 50,8 \\
\hline & \multicolumn{2}{|c|}{$p=0,010^{*}$} & \multicolumn{2}{|c|}{$p=0,000^{*}$} & \multicolumn{2}{|c|}{$p=0,009^{*}$} \\
\hline \multirow[t]{2}{*}{ Média (dp) } & $1,5(1,2)$ & $1,7(1,2)$ & $1,3(1,1)$ & $1,6(1,2)$ & $1,5(1,2)$ & $2,6(1,1)$ \\
\hline & \multicolumn{2}{|c|}{$p=0,009^{* *}$} & \multicolumn{2}{|c|}{$p=0,000^{* *}$} & \multicolumn{2}{|c|}{$p=0,003^{\star \star}$} \\
\hline
\end{tabular}

(1)Escala de 1 a 4, conforme aumenta o valor, piora a auto-avaliação da saúde

"Teste de McNemar

** Teste " $t$ " de Student 
A disponibilidade da rede de apoio domiciliar, expressa pelo número de co-residentes e de filhos, mostrou que os idosos que passaram a receber mais apoio da rede, continuam morando com o mesmo número total de pessoas, mas com mais filhos. Nas outras condições de mudanças no apoio recebido, os idosos passaram a residir com menos pessoas e mais filhos. (Tabela 9)

O arranjo domiciliar demonstrou modificações aparentes, ao longo do tempo, em todas as categorias de mudança no apoio recebido pelos idosos, apresentando arranjos diferenciados para cada situação de apoio recebido. Independente da mudança no apoio recebido, em 2000, a maioria dos idosos residia com seus cônjuges. (Tabela 9)

Entre os idosos que mantiveram o apoio recebido ao longo do tempo, os arranjos passaram a distribuir-se uniformemente entre: morar sozinhos (19,7\%; $27,6 \%)$, com filhos $(16,0 \% ; 21,1 \%)$, com outras pessoas $(5,9 \% ; 27,2 \%)$ ou continuarem a residir com seus cônjuges $(58,4 \% ; 24,1 \%),(p=0,007)$. (Tabela 9 )

As mudanças nos arranjos dos idosos que passaram a receber mais apoio da rede foram ocorridas, principalmente, para residir com outras pessoas $(4,3 \% ; 42,7 \%)$ e deixarem de morar com seus cônjuges $(59,6 \% ; 25,2 \%)$, 0 restante continuou a morar com seus filhos $(22,6 \% ; 21,7 \%)$ ou sozinhos $(10,5 \% ; 10,4 \%),(p=0,000)$. (Tabela 9$)$

Os idosos que passaram a receber menos apoio da rede foram morar primordialmente com outras pessoas $(8,3 \% ; 34,4 \%)$ e se distribuíram, em proporções parecidas, entre os que deixaram de residir com seus cônjuges $(57 \% ; 21,7 \%)$, continuaram a morar com seus filhos $(24,9 \% ; 22,2 \%)$ e sozinhos $(9,7 \% ; 21,7 \%),(p=0,000)$. (Tabela 9$)$

Conforme a disponibilidade da rede extradomiciliar dos filhos se manteve, ao longo do tempo, o apoio recebido pelo idoso também permaneceu ou aumentou. Mas a reorganização dessa rede, apresentada pelo aumento do número de filhos não co-residentes, em 2006, exprimiu em menos apoio recebido pelo idoso. Isso pode ser devido às alterações na disponibilidade da rede extradomiciliar dos filhos gerarem reorganizações no funcionamento dos recursos dessa rede, ocorrendo modificações nas transferências de apoio. (Tabela 9)

Em relação ao local de residência dos filhos, somente os idosos que passaram a receber menos apoio da rede apresentaram comportamento 
diferenciado em relação às outras situações de mudanças no apoio recebido, verificado, principalmente, entre os que passaram a ter seus filhos morando em outra cidade $(37,0 \% ; 38,8 \%)$ e outro país $(4,8 \% ; 6,2 \%),(p=0,049)$. (Tabela 9$)$

A freqüência do contato com os filhos aumentou somente para os idosos que tiveram mudanças no apoio recebido pela rede. Para os que passaram a receber mais apoio, a freqüência do contato tornou-se, principalmente, diária $(22,4 \% ; 37,4 \%)$ e semanal $(36,4 \% ; 46,0 \%)$. Entre os idosos que passaram a receber menos apoio, esta também se tornou mais diária $(25,9 \% ; 29,7 \%)$ e semanal $(35,9 \% ; 41,6 \%)$, $(p<0,05)$. (Tabela 9$)$

Schütze e Hollstein (1994) fizeram um recorte de um estudo populacional realizado na Alemanha, para analisar qualitativamente as relações de troca de apoio entre os idosos e seus filhos, na perspectiva de ambos. Os autores verificaram ser a qualidade da relação um importante preditor na preferência da distância geográfica da residência dos filhos em relação à dos pais.

Estudo longitudinal realizado na Alemanha sobre a qualidade da relação de troca entre mães e filhas encontrou que a proximidade de residência dos pais e maior intimidade de relação entre mãe e filha refletiam em mais relação de troca de apoio entre elas (SCHWARZ, 2006).

Attias-Donfutt (2001), no estudo populacional ocorrido na França, analisou a reciprocidade nas relações intergeracionais entre avós, filhos e netos e verificou que, quando os idosos ajudaram seus filhos no cuidado de seus netos, as relações tornaram-se mais próximas, mesmo depois que os netos ficam adultos. Nessas famílias também há maior freqüência de contatos e visitas, do que entre as famílias em que não ocorreu esse tipo de apoio intergeracional.

As relações intergeracionais não são fáceis de investigar, pois envolvem aspectos construídos ao longo da vida, podendo ser reveladas de maneiras diferenciadas, pois são permeadas tanto pelo contexto social, que atinge as estruturas familiares e seus papéis sociais, como por aspectos que envolvem a falta ou inabilidade de lidar com os recursos instrumentais e emocionais. Esses aspectos podem gerar ambivalência nas relações, que são difíceis de mensurar, como estresses e enfermidades físicas e mentais. 
Estudos longitudinais realizados nos Estados Unidos, acompanhando diversas fases das relações intergeracionais durante a vida dos indivíduos, mostraram que a forma que as relações se constroem influencia na responsabilidade filial dos filhos, entretanto, não é um modelo fechado, podendo ter nuances. Os autores sugerem um modelo de investimento de transferências intergeracionais em que, de maneira geral, os pais que trocaram mais apoio com seus filhos, no início das relações, receberam mais apoio quando se tornaram idosos. As principais conclusões apontadas nesses estudos foram que as motivações dos filhos em fornecer apoio a seus pais idosos são conduzidas por experiências familiares anteriores, erguidas por um contrato social que mantém a reciprocidade ao longo do tempo (KAUFMAN e UHLENBERG, 1998; SILVERSTEIN et al., 2002; FINGERMAN et al., 2008).

Attias-Donfut (2001), analisando as dinâmicas dos padrões de solidariedade entre as gerações em estudo populacional da França, concluiu que a ajuda familiar é sujeita a normas sociais e cada familia interpreta-as de forma específica. Essas normas são expressas nos padrões de solidariedade $e$ se constituem como uma subcultura de valores de solidariedade que são transmitidos através da história familiar.

Gierveld e Dykstra (2006) sugeriram, em estudo realizado na Holanda, que a informação sobre o passado familiar contribui para entender as relações de troca de apoio entre os pais idosos e seus filhos. 
Tabela 9 - Mudança no apoio recebido pelos idosos nos dois momentos, segundo disponibilidade da rede de apoio domiciliar e extradomiciliar (filhos), Município de São Paulo, 2000 e 2006 ( $n=1115)$.

\begin{tabular}{|c|c|c|c|c|c|c|}
\hline \multirow{2}{*}{ Disponibilidade } & \multicolumn{2}{|c|}{ Ficou igual } & \multicolumn{2}{|c|}{ Aumentou } & \multicolumn{2}{|c|}{ Diminuiu } \\
\hline & 2000 & 2006 & 2000 & 2006 & 2000 & 2006 \\
\hline \multicolumn{7}{|l|}{ Domiciliar } \\
\hline \multirow[t]{2}{*}{$\mathrm{N}^{\circ}$ médio de co-residentes ${ }^{\S}$} & $2,9(1,8)$ & $2,3(1,2)$ & $3,2(1,6)$ & $3,0(1,6)$ & $3,3(1,9)$ & $2,6(1,5)$ \\
\hline & \multicolumn{2}{|c|}{$p=0,000^{* *}$} & \multicolumn{2}{|c|}{$p=0,059^{\star *}$} & \multicolumn{2}{|c|}{$\begin{aligned} 0,0(1,9) \\
p=0,000^{* \star}\end{aligned}$} \\
\hline \multirow[t]{2}{*}{$\mathrm{N}^{\circ}$ médio de filhos co-residentes ${ }^{\S}$} & $0,7(0,9)$ & $1,2(1,0)$ & $0,8(0,9)$ & $1,6(1,0)$ & $0,8(0,9)$ & $1,4(1,1)$ \\
\hline & \multicolumn{2}{|c|}{$p=0,000^{* *}$} & \multicolumn{2}{|c|}{$p=0,000^{\star \star}$} & \multicolumn{2}{|c|}{$p=0,000^{* *}$} \\
\hline \multicolumn{7}{|l|}{ Arranjo domiciliar (\%) } \\
\hline Sozinho & 19,7 & 27,6 & 10,5 & 10,4 & 9,7 & 21,7 \\
\hline Com cônjuge & 58,4 & 24,1 & 59,6 & 25,2 & 57,0 & 21,7 \\
\hline Com filho & 16,0 & 21,1 & 22,6 & 21,7 & 24,9 & 22,2 \\
\hline \multirow[t]{2}{*}{ Com outros } & 5,9 & 27,2 & 4,3 & 42,7 & 8,3 & 34,4 \\
\hline & \multicolumn{2}{|c|}{$p=0,007^{*}$} & \multicolumn{2}{|c|}{$p=0,000^{*}$} & \multicolumn{2}{|c|}{$p=0,000^{*}$} \\
\hline \multicolumn{7}{|l|}{ Extradomiciliar (filhos) } \\
\hline \multirow[t]{2}{*}{$N^{\circ}$ médio de filhos } & $2,3(2,0)$ & $2,4(2,0)$ & $2,8(2,4)$ & $2,8(2,2)$ & $2,6(2,4)$ & $2,8(2,3)$ \\
\hline & \multicolumn{2}{|c|}{$p=0,325^{\star *}$} & \multicolumn{2}{|c|}{$p=0,621^{\star *}$} & \multicolumn{2}{|c|}{$p=0,008^{* *}$} \\
\hline \multicolumn{7}{|l|}{ Local de residência dos filhos (\%) } \\
\hline Mesmo bairro & 22,1 & 17,5 & 16,2 & 16,3 & 16,2 & 16,2 \\
\hline Outro bairro & 40,7 & 39,8 & 34,7 & 36,1 & 42,0 & 38,8 \\
\hline Outra cidade & 29,5 & 36,2 & 45,1 & 42,1 & 37,0 & 38,8 \\
\hline \multirow{2}{*}{ Outro pais } & 7,7 & 6,5 & \multirow{2}{*}{\multicolumn{2}{|c|}{$p=0.734^{*, 0}$}} & 4,8 & 6,2 \\
\hline & \multicolumn{2}{|c|}{$p=0,357^{*}$} & & & \multicolumn{2}{|c|}{$p=0,049^{*}$} \\
\hline Média $(d p)^{(1)}$ & \multicolumn{2}{|c|}{$p=0,296^{\star \star}$} & \multicolumn{2}{|c|}{$p=0,735^{\star \star}$} & \multicolumn{2}{|c|}{$\begin{array}{c}\quad, 7(0,0) \\
p=0,048^{\star \star}\end{array}$} \\
\hline
\end{tabular}


Tabela 9 - Mudança no apoio recebido pelos idosos segundo disponibilidade da rede de apoio domiciliar e extradomiciliar (filhos), São Paulo, SP, 2000 e 2006 ( $n=1115)$.

"continuação"

\begin{tabular}{|c|c|c|c|c|c|c|}
\hline \multirow{2}{*}{ Disponibilidade } & \multicolumn{2}{|c|}{ Ficou igual } & \multicolumn{2}{|c|}{ Aumentou } & \multicolumn{2}{|c|}{ Diminuiu } \\
\hline & 2000 & 2006 & 2000 & 2006 & 2000 & 2006 \\
\hline \multicolumn{7}{|c|}{ Freqüência do contato com os filhos (\%) } \\
\hline Diário & 26,1 & 27,6 & 22,4 & 37,4 & 25,9 & 29,7 \\
\hline Semanal & 39,3 & 36,9 & 36,4 & 46,0 & 35,9 & 41,6 \\
\hline Mensal & 18,2 & 29,1 & 21,1 & 18,3 & 19,8 & 19,3 \\
\hline Anual & 12,5 & 4,9 & 17,4 & 5,8 & 12,7 & 7,4 \\
\hline \multirow[t]{2}{*}{ Nunca } & 3,9 & 1,5 & 2,7 & 1,9 & 5,8 & 2,0 \\
\hline & \multicolumn{2}{|c|}{$p=0,376^{\star}$} & \multicolumn{2}{|c|}{$p=0,000^{*}$} & \multicolumn{2}{|c|}{$p=0,009^{*}$} \\
\hline Média $(d p)^{(2)}$ & $\begin{array}{r}3,6(1,0 \\
p=\end{array}$ & $\begin{array}{l}3,8(0,9) \\
36^{\star *}\end{array}$ & $\begin{array}{r}3,6(1,1) \\
p=\end{array}$ & $\begin{array}{l}3,9(0,9) \\
0^{* *}\end{array}$ & $\begin{array}{r}3,6(1,1) \\
p=\end{array}$ & $\begin{array}{l}3,8(0,9) \\
8^{* *}\end{array}$ \\
\hline
\end{tabular}

§̧Variáveis expressas em média e desvio-padrão

(1) Escala de 1 a 4, conforme aumenta o valor, aumenta a proximidade da residência

${ }^{(2)}$ Escala de 1 a 5 , conforme aumenta o valor, aumenta a freqüência do contato

*Teste de McNemar

**Teste " $t$ " de Student 
As características estruturais da rede de apoio domiciliar e extradomiciliar, expressas pelo fluxo (dar e receber) de ajudas ocorridas, seguiram a tendência geral das mudanças no apoio recebido pelos idosos. $O$ fluxo de apoio dos idosos tem acontecido com toda a sua rede, as relações de troca sucederam mesmo quando os papéis de apoio são mais determinados, como no domicilio ou entre os filhos, como também, entre os outros familiares e amigos não co-residentes, indicando que os idosos continuam ativos em sua rede. (Tabela 10) 
Tabela 10 - Mudança no apoio recebido pelos idosos nos dois momentos, segundo características estruturais da rede de apoio domiciliar e extradomiciliar (filhos, outros familiares e amigos), Município de São Paulo, 2000 e 2006 ( $n=1115$ ).

\begin{tabular}{|c|c|c|c|}
\hline \multirow{2}{*}{ Características estruturais $^{\S}$} & Ficou igual & Aumentou & Diminuiu \\
\hline & $2000 \quad 2006$ & $2000 \quad 2006$ & $2000 \quad 2006$ \\
\hline Domiciliar & & & \\
\hline$N^{\circ}$ médio de ajudas recebidas & $\underset{p=0,195^{\star *}}{2,7(2,2)}$ & $\begin{array}{c}2,5(2,1) \quad 4,1(3,0) \\
p=0,000^{* *}\end{array}$ & $\begin{array}{c}4,1(3,4) \quad 2,2(2,2) \\
p=0,000^{* *}\end{array}$ \\
\hline$N^{\circ}$ médio de ajudas dadas & $\underset{p=0,026^{* \star}}{3,3(3,5)}$ & $\begin{array}{c}3,4(2,9) \quad 4,0(3,3) \\
p=0,001^{* \star}\end{array}$ & $\underset{p=0,000^{\star *}}{4,2(3,8)} \quad 2,4(2,4)$ \\
\hline $\begin{array}{l}\text { Extradomiciliar } \\
\text { Filhos }\end{array}$ & & & \\
\hline$N^{\circ}$ médio de ajudas recebidas & $\underset{p=0,236^{* \star}}{1,5(2,2)}$ & $\begin{array}{c}1,0(1,7) \quad 3,1(3,5) \\
p=0,000^{\star \star}\end{array}$ & $\begin{array}{c}2,8(3,7) \quad 1,5(2,5) \\
p=0,000^{* *}\end{array}$ \\
\hline$N^{\circ}$ médio de ajudas dadas & 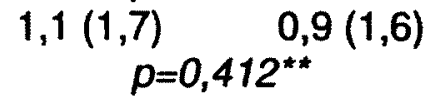 & $\begin{array}{c}0,8(1,5) \quad 1,4(2,5) \\
p=0,000^{* *}\end{array}$ & $\underset{p=0,000^{* *}}{1,5(2,3)} \quad 0,7(1,4)$ \\
\hline $\begin{array}{l}\text { Outros familiares/amigos } \\
N^{\circ} \text { médio de ajudas recebidas }\end{array}$ & 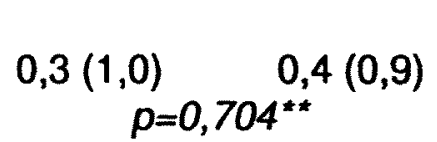 & $\begin{array}{c}0,1(0,5) \quad 1,1(2,1) \\
p=0,000^{* *}\end{array}$ & $\begin{array}{c}1,1(2,8) \underset{p=0,000^{* *}}{0,2}(0,8) \\
p^{*}\end{array}$ \\
\hline$N^{\circ}$ médio de ajudas dadas & $\begin{array}{c}0,4(0,9) \quad 0,3(0,9) \\
p=0,638^{\star \star}\end{array}$ & $\begin{array}{c}0,3(0,9) \quad 0,8(1,6) \\
p=0,000^{\star \star}\end{array}$ & $\begin{array}{c}1,2(2,8) \quad 0,3(0,9) \\
p=0,000^{* *}\end{array}$ \\
\hline
\end{tabular}


Entre as características funcionais da rede de apoio do idoso, o apoio instrumental foi o mais freqüente para as trocas com a rede domiciliar e extradomiciliar dos filhos e, de maneira geral, seguiu a tendência das mudanças no apoio recebido. (Tabela 11)

$\mathrm{Na}$ rede extradomiciliar dos filhos, mesmo os outros apoios não terem sido muito freqüentes, os filhos passaram a dar mais apoio de companhia e outro tipo de apoio, nas situações em que 0 idoso manteve ou passou a receber mais apoio da rede. Na relação de dar apoio aos filhos, o idoso passou a fornecer menos apoio instrumental, enquanto os outros tipos de apoio, mesmo não sendo muito presentes, seguiram a tendência geral das mudanças no apoio recebido pelo idoso. (Tabela 11)

A redução do apoio instrumental fornecido pelos idosos aos seus filhos foi também encontrada em estudo populacional realizado na Alemanha, em que conforme aumentava a idade dos idosos diminuía o apoio instrumental dado aos filhos (KOHLI, 1999).

$\mathrm{Na}$ rede extradomiciliar dos familiares e amigos do idoso, os apoios se distribuíram uniformemente entre instrumental, companhia e outro tipo de apoio, sendo a troca ocorrida de maneira bidirecional. Os tipos de apoio seguiram a tendência das mudanças no apoio recebido pelo idoso. (Tabela 11)

Os idosos reconhecem principalmente relações de troca instrumental com a rede domiciliar e com seus filhos, sendo evidenciados novamente que os aspectos emocionais que as trocas de apoio podem ocasionar não estão sendo identificados e alocados pelos idosos nessa rede de apoio. As relações criadas no domicílio e entre os filhos têm sido construídas no âmbito instrumental, sendo os recursos emocionais preenchidos por meio de trocas materiais e de serviços. Relação não tão evidente entre os laços criados pelos idosos e seus familiares e amigos, que mesmo não sendo tão presentes nas trocas de apoio, estas são distribuídas em componentes não só instrumentais. 
Tabela 11 - Mudança no apoio recebido pelos idosos nos dois momentos, segundo características funcionais da rede de apoio domiciliar e extradomiciliar (filhos, outros familiares e amigos), Município de São Paulo, 2000 e 2006 ( $n=1115$ ).

\begin{tabular}{|c|c|c|c|c|c|c|}
\hline \multirow{2}{*}{ Características funcionais $^{\S}$} & \multicolumn{2}{|c|}{ Ficou igual } & \multicolumn{2}{|c|}{ Aumentou } & \multicolumn{2}{|c|}{ Diminuiu } \\
\hline & 2000 & 2006 & 2000 & 2006 & 2000 & 2006 \\
\hline \multicolumn{7}{|l|}{$\begin{array}{l}\text { Domiciliar } \\
\text { Tipo de apoio recebido }\end{array}$} \\
\hline \multirow[t]{2}{*}{ Instrumental } & $2,4(2,2)$ & $1,8(1,7)$ & $2,2(1,9)$ & $2,7(2,3)$ & $3,5(3,2)$ & $1,8(1,9)$ \\
\hline & \multicolumn{2}{|c|}{$p=0,006^{* *}$} & \multicolumn{2}{|c|}{$p=0,000^{* *}$} & \multicolumn{2}{|c|}{$p=0,000^{* *}$} \\
\hline Outro tipo & \multicolumn{2}{|c|}{$p=0,720^{* *}$} & \multicolumn{2}{|c|}{$p=0,094^{* *}$} & \multicolumn{2}{|c|}{$p=0,000^{* *}$} \\
\hline \multirow{2}{*}{$\begin{array}{l}\text { Tipo de apoio dado } \\
\text { Instrumental }\end{array}$} & & & & & & \\
\hline & \multicolumn{2}{|c|}{$p=0,001^{* *}$} & \multicolumn{2}{|c|}{$p=0,047^{\star \star}$} & \multicolumn{2}{|c|}{$p=0,000^{\star \star}$} \\
\hline Outro tipo & \multicolumn{2}{|c|}{$p=0,328^{* *}$} & \multicolumn{2}{|c|}{$p=0,121^{\star \star}$} & \multicolumn{2}{|c|}{$p=0,000^{\star \star}$} \\
\hline \multicolumn{7}{|l|}{$\begin{array}{l}\text { Extradomiciliar } \\
\text { Filhos } \\
\text { Tipo de apoio recebido }\end{array}$} \\
\hline Instrumental & $1,2(1,9)$ & $1,0(1,9)$ & $0,7(1,4)$ & $1,6(2,2)$ & $1,6(2,4)$ & $1,0(2,0)$ \\
\hline Companhia & \multicolumn{2}{|c|}{$p=0,042^{\star \star}$} & \multicolumn{2}{|c|}{$p=0,000^{* \pm}$} & \multicolumn{2}{|c|}{$p=0,000^{* *}$} \\
\hline Outro tipo & \multicolumn{2}{|c|}{$p=0,002^{\star *}$} & \multicolumn{2}{|c|}{$p=0,000^{\star \star}$} & \multicolumn{2}{|c|}{$p=0,057^{\star \star}$} \\
\hline
\end{tabular}


Tabela 11 - Mudança no apoio recebido pelos idosos nos dois momentos, segundo características funcionais da rede de apoio domiciliar e extradomiciliar (filhos, outros familiares e amigos), Municipio de São Paulo, 2000 e 2006 ( $n=1115$ ).

"continuação"

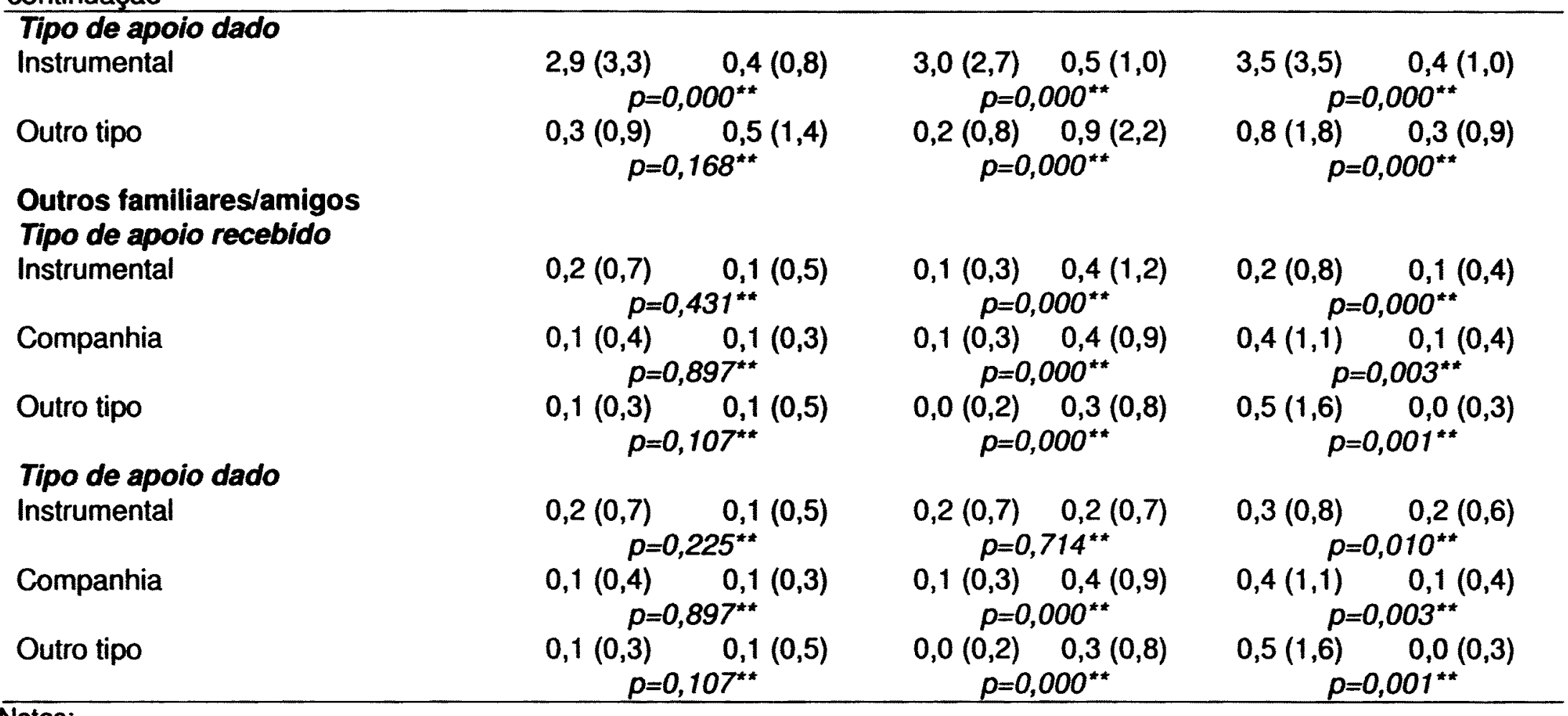

Notas:

\$Todas as variáveis foram expressas em média e desvio padrão

- Teste de McNemar

"*Teste " $\mathrm{t}$ " de Student 


\subsection{FATORES ASSOCIADOS ÀS MUDANÇAS NO APOIO RECEBIDO PELOS IDOSOS}

Para verificar os fatores que estão associados às mudanças no apoio recebido pelo idoso, foi analisado, em primeiro momento, o efeito isolado que as características sociodemográficas, de saúde e da rede de apoio social do idoso, em 2000, que predisseram essas mudanças e, em seguida, as alterações nessas variáveis, em 2006, que explicaram as mudanças nesse apoio social. (Tabelas 12 e 13)

Dessa forma, foi possível perceber se existiram comportamentos protetores que os idosos tinham, em 2000, que seriam importantes para manter a relação de apoio com a rede, ao longo do tempo. Como também, verificar que padrões de mudanças nos comportamentos dos idosos influenciam o recebimento de apoio da rede. (Tabelas 12 e 13)

As mudanças no recebimento de apoio pelos idosos procederam de maneira diferenciada entre os sexos, os homens estão mais sujeitos às mudanças no apoio recebido, verificadas tanto na probabilidade de $80 \%$ de receberem mais apoio, como também, na probabilidade de $20 \%$ de receberem menos apoio da rede. (Tabela 12)

Os dados trazem em evidência novamente que as mulheres estabelecem mais relações de troca com os membros da rede, enquanto os homens, que têm menos relações, tornam-se mais vulneráveis às mudanças no apoio recebido.

Os idosos que referiram menos doenças, em 2000, apresentaram efeito protetor para não precisarem receber mais apoio da rede, ao longo do tempo, sendo que, a piora nessas condições, em 2006, esteve acompanhada do aumento de apoio da rede. Merece atenção mencionar que a rede se manteve independente das condições de saúde do idoso, pois a melhora nessas condições, em 2006, não esteve relacionada com a diminuição do apoio recebido pela rede. (Tabela 12 )

O menor comprometimento funcional nas ABVDs, em 2000, também protege os idosos de não ter que receber mais apoio da rede, ao longo do 
tempo. Enquanto o aumento da dificuldade para executar as AIVDs, em 2006, passa a ativar mais apoio da rede. As atividades da vida diária não influenciaram na diminuição do apoio recebido pela rede, podendo-se dizer que - apoio que o idoso recebe se mantém independente da melhora nas condições funcionais. (Tabela 12)

Os dados apontam que a piora nos aspectos físicos do idoso tem sido identificados pela rede, entretanto, esta não tem identificado as questões emocionais, que são importantes para manter o bem-estar do idoso nessa fase da vida. Dado verificado no aumento da viuvez, em 2006, não ser acompanhado de mais apoio da rede, que viria a suprir os aspectos emocionais e instrumentais que a ausência do cônjuge deixou. (Tabela 12)

Os aspectos emocionais são fatores importantes para a reciprocidade estabelecida entre idoso e sua rede de apoio, para que consiga estabelecer melhores relações de troca com a rede, como também, demandar menos apoio desta. Mas a ausência de resposta da rede, na ocorrência de eventos da vida que podem abalar a saúde emocional do idoso, pode incidir em toda a rede de relações que estabelece, devido à piora nas condições de saúde física e mental que esses eventos podem ocasionar.

Isso pode ser visto na melhora da avaliação subjetiva da saúde do idoso, em 2006, ser componente importante para a manutenção e menor demanda de apoio da rede ao longo do tempo. (Tabela 12)

A disponibilidade de pessoas no domicilio e de filhos, tanto co-residentes como não co-residentes, apresentou ser importante para ambas as situações de mudanças no apoio recebido. Quanto maior essa disponibilidade, em 2000, mais provável as mudanças no apoio recebido ocorrerem. Porém, somente o aumento da disponibilidade no domicílio, em 2006, influenciou em mais apoio recebido pelo idoso, enquanto a diminuição nessa disponibilidade, em 2006, não incide em menos apoio recebido. Na rede extradomiciliar dos filhos, a sua reorganização, em 2006, influenciou somente na diminuição do apoio recebido. (Tabela 13)

Quanto mais relações de troca o idoso é capaz de estabelecer, mais a rede se mantém ao longo do tempo. A ajuda fornecida pelo idoso tem relação com melhores condições de saúde e bem-estar, dessa forma, menos ajuda vai passar a necessitar da rede ao longo do tempo. 
Esse dado é confirmado na ajuda fornecida pelo idoso no domicílio, quanto mais ajuda dava, em 2000, maior a probabilidade de ter o apoio recebido diminuído ao longo do tempo e, quanto mais ajuda passou a dar, em 2006, mais apoio é provável de receber. Enquanto a diminuição dessa relação de troca não influenciou no apoio recebido pelo idoso, mostrando que o apoio no domicílio se manteve independente da relação de troca. (Tabela 13)

Em relação às trocas de apoio com os filhos, quanto menos apoio o idoso dava, em 2000, menor a probabilidade de o apoio recebido aumentar ao longo do tempo. Conforme o aumento do apoio dado, em 2006, maior a probabilidade de receber mais apoio e, quanto menos o apoio diminuía menor a probabilidade de receber menos apoio. Mesma relação encontrada para os outros familiares e amigos não co-residentes. (Tabela 13)

A troca de apoio extradomiciliar foi elemento essencial para que 0 apoio fosse mantido ou aumentado, enquanto no domicilio não, entretanto, a manutenção ou aumento do apoio fornecido pelo idoso a sua rede foi elemento essencial para manter ou aumentar a troca.

Os idosos estabeleceram relações de troca com a sua rede que são independentes das condições funcionais e de saúde, no entanto, o componente emocional que essas relações podem disponibilizar não tem sido identificado ou alocado pelos idosos, como verificado pela mudança no estado civil não ser acompanhada de mais apoio recebido pela rede, ao contrário da piora nas condições de saúde e comprometimento funcional.

As condições de saúde física, comprometimento funcional e bem-estar dos idosos apresentaram serem fatores importantes para que os idosos continuem ativos na troca de apoio com a rede, representando que, quanto mais apoios trocam, mais protegidos estão pela rede. 
Tabela 12 - Resultados da análise de regressão logística multinomial univariada das mudanças no apoio recebido pelos idosos e características sociodemográficas e de saúde, Município de São Paulo, 2000 e 2006 ( $n=1115$ ).

\begin{tabular}{|c|c|c|c|c|c|c|}
\hline \multirow[b]{2}{*}{ Variáveis } & \multicolumn{3}{|c|}{ Mudanças no apolo recebido ${ }^{\text {(a) }}$} & \multicolumn{3}{|c|}{ Mudanças no apoio recebido ${ }^{\xi(b)}$} \\
\hline & $\begin{array}{l}\text { Aumentou } \\
\text { RR (IC95\%) }\end{array}$ & $\begin{array}{c}\text { Diminulu } \\
\text { RR (IC95\%) }\end{array}$ & $\mathbf{p}$ & $\begin{array}{l}\text { Aumentou } \\
\text { RR (IC95\%) }\end{array}$ & $\begin{array}{c}\text { Diminuilu } \\
\text { RR (IC95\%) }\end{array}$ & p \\
\hline \multicolumn{7}{|l|}{ Sociodemográficas } \\
\hline Feminino & 1,0 & 1,0 & & 1,0 & 1,0 & \\
\hline Masculino & $1,8(1,2-2,9)$ & $1,2(0,8-1,9)$ & & $1,8(1,2-2,9)$ & $1,2(0,8-1,9)$ & \\
\hline Idade & $1,0(0,9-1,1)$ & $1,0(0,9-1,1)$ & 0,547 & $1,2(0,7-1,3)$ & $1,1(0,8-1,5)$ & 0,590 \\
\hline Anos de estudo & $1,0(0,9-1,1)$ & $0,9(0,9-1,1)$ & 0,261 & $0,9(0,7-1,4)$ & $1,2(0,8-1,7)$ & $0,091^{*}$ \\
\hline Estado civil & & & 0,981 & & & - \\
\hline Casado/amasiado & 1,0 & 1,0 & & - & - & \\
\hline Divorciado/separado & $1,3(0,5-2,9)$ & $1,4(0,5-3,7)$ & & - & - & \\
\hline Viúvo & $0,9(0,5-1,6)$ & $1,0(0,6-1,6)$ & & - & - & \\
\hline Solteiro & $0,8(0,3-1,8)$ & $1,0(0,4-2,3)$ & & - & - & \\
\hline Mudança no estado civil & & & - & & & $0,001^{*}$ \\
\hline Não & - & - & & 1,0 & 1,0 & \\
\hline Sim & - & - & & $0,5(0,2-0,9)$ & $1,2(0,6-2,2)$ & \\
\hline \multicolumn{7}{|l|}{ Características de saúde } \\
\hline Auto-avaliação da saúde ${ }^{(1)}$ & $0,9(0,7-1,2)$ & $1,0(0,8-1,4)$ & 0,489 & $0,7(0,5-1,0)$ & $0,7(0,5-1,0)$ & $0,145^{\star}$ \\
\hline$N^{\circ}$ de ABVDs & $0,8(0,7-1,1)$ & $1,0(0,8-1,3)$ & $0,062^{*}$ & $1,0(0,8-1,1)$ & $0,9(0,8-1,1)$ & 0,252 \\
\hline$N^{\circ}$ de AIVDs & $1,0(0,8-1,2)$ & $1,0(0,8-1,2)$ & 0,720 & $1,1(0,9-1,3)$ & $0,9(0,7-1,1)$ & $0,034^{*}$ \\
\hline $\mathrm{N}^{\circ}$ de doenças referidas & $0,8(0,7-1,0)$ & $1,0(0,8-1,2)$ & $0,011^{*}$ & $1,3(0,9-1,8)$ & $0,9(0,6-1,4)$ & $0,029^{*}$ \\
\hline $\begin{array}{l}\text { Notas: } \\
\text { SA categoria "ficou igual" foi co } \\
\text { (a) Análise com as variáveis } \\
\text { (D)Análise com as variáveis } \\
\text { (1) Escala de } 1 \text { a 4, conforme } \\
\text { " } 0<0,200\end{array}$ & $\begin{array}{l}\text { mo referênci } \\
\text { tes referente } \\
\text { tes referente } \\
\text { valor, piora }\end{array}$ & $\begin{array}{l}\text { no } 2000 \\
\text { erença pro } \\
\text {-avaliaçãc }\end{array}$ & le en & e 2006 & & \\
\hline
\end{tabular}


Tabela 13 - Resultados da análise de regressão logística multinomial univariada das mudanças no apoio recebido pelos idosos e características da rede de apoio domiciliar e extradomiciliar (filhos, outros familiares e amigos), Município de São Paulo, 2000 e 2006 ( $n=1115)$.

\begin{tabular}{|c|c|c|c|c|c|c|}
\hline \multirow[b]{2}{*}{ Variáveis } & \multicolumn{3}{|c|}{ Mudancas no apoio recebido ${ }^{\text {s(a) }}$} & \multicolumn{3}{|c|}{ Mudanças no apoio recebido $^{\$(D)}$} \\
\hline & $\begin{array}{l}\text { Aumentou } \\
\text { RR (IC95\%) }\end{array}$ & $\begin{array}{c}\text { Diminuiu } \\
\text { RR (IC95\%) }\end{array}$ & $p$ & $\begin{array}{c}\text { Aumentou } \\
\text { RR (IC95\%) }\end{array}$ & $\begin{array}{c}\text { Diminuiu } \\
\text { RR (IC95\%) }\end{array}$ & $p$ \\
\hline \multicolumn{7}{|l|}{ Domiciliar } \\
\hline$N^{\circ}$ de co-residentes & $1,1(0,9-1,2)$ & $1,1(0,9-1,3)$ & 0,344 & $2,0(1,0-4,0)$ & $0,8(0,4-2,0)$ & $0,001^{*}$ \\
\hline $\mathrm{N}^{\circ}$ de filhos co-residentes & $1,2(0,9-1,5)$ & $1,2(0,9-1,7)$ & 0,336 & $1,3(0,8-2,1)$ & $0,8(0,5-1,3)$ & $0,000^{*}$ \\
\hline $\mathrm{N}^{\circ}$ de ajudas recebidas & $0,9(0,9-1,1)$ & $1,2(1,1-1,3)$ & $0,000^{\star}$ & $2,4(1,3-4,1)$ & $0,2(0,1-0,4)$ & $0,000^{*}$ \\
\hline$N^{\circ}$ de ajudas dadas & $1,0(0,9-1,1)$ & $1,1(1,0-1,2)$ & $0,008^{*}$ & $1,3(1,1-1,6)$ & $0,7(0,5-1,0)$ & $0,000^{*}$ \\
\hline \multicolumn{7}{|l|}{$\begin{array}{l}\text { Extradomiciliar } \\
\text { Filhos }\end{array}$} \\
\hline$N^{\circ}$ de filhos & $1,1(1,0-1,2)$ & $1,1(0,9-1,2)$ & $0,145^{\star}$ & $0,7(0,4-1,4)$ & $1,2(0,7-2,2)$ & $0,039^{*}$ \\
\hline Local de residência dos filhos ${ }^{(1)}$ & $0,8(0,6-1,1)$ & $0,9(0,6-1,2)$ & 0,391 & $1,1(0,4-3,2)$ & $0,8(0,3-2,0)$ & 0,490 \\
\hline Freq. contato com os filhos ${ }^{(2)}$ & $0,9(0,7-1,1)$ & $0,9(0,7-1,2)$ & 0,536 & $1,4(0,8-2,4)$ & $1,5(0,9-2,6)$ & 0,291 \\
\hline$N^{\circ}$ de ajudas recebidas & $0,9(0,8-1,0)$ & $1,2(1,0-1,3)$ & $0,000^{*}$ & $1,9(1,5-2,4)$ & $0,5(0,4-0,8)$ & $0,000^{*}$ \\
\hline $\begin{array}{l}N^{\circ} \text { de ajudas dadas } \\
\text { Outros familiares/amigos }\end{array}$ & $0,9(0,8-1,0)$ & $1,1(0,9-1,3)$ & $0,000^{*}$ & $1,3(1,1-1,5)$ & $0,8(0,6-1,1)$ & $0,000^{*}$ \\
\hline$N^{\circ}$ de ajudas recebidas & $0,7(0,5-0,9)$ & $1,3(1,1-1,6)$ & $0,000^{*}$ & $1,8(1,4-2,4)$ & $0,3(0,2-0,6)$ & $0,000^{*}$ \\
\hline$N^{\circ}$ de ajudas dadas & $0,9(0,8-1,1)$ & $1,3(1,1-1,5)$ & $0,000^{*}$ & $1,5(1,2-1,9)$ & $0,7(0,5-1,0)$ & $0,000^{*}$ \\
\hline
\end{tabular}
Notas:

${ }^{\$} \mathrm{~A}$ categoria "ficou igual" foi considerada como referência

(a) Análise com as variáveis independentes referentes ao ano 2000

(b)Análise com as variáveis independentes referentes à diferença proporcional entre 2000 e 2006

(1)Escala de 1 a 4, conforme aumenta o valor, aumenta a proximidade da residência

${ }^{(2)}$ Escala de 1 a 5 , conforme aumenta o valor, aumenta a freqüência do contato * $p<0,200$ 
Para investigar a influência que as variáveis referentes às características sociodemográficas, de saúde e da rede de apoio social dos idosos teriam entre si, foi feita a análise multivariada com o conjunto dessas variáveis que apresentaram associação com as mudanças no apoio recebido pelos idosos. (Tabelas 14 e 15)

Para comparar como a relação entre os gêneros atuaria no comportamento das variáveis foram feitas análises multivariadas sem e com o ajuste do sexo. (Tabelas 14 e 15)

As melhores condições de saúde e menor comprometimento funcional nas ABVDs dos idosos, em 2000, continuaram a ter influência preditora para não precisarem de mais apoio ao longo do tempo. Contudo, o comprometimento funcional nas ABVDs passou a predizer também a diminuição do apoio recebido. Somente as doenças referidas apresentaram comportamento diferenciado entre os sexos, tendo diminuída sua importância na manutenção da relação de apoio entre o idoso e a rede. (Tabela 14)

As variáveis em seu conjunto continuam mostrando que as condições de saúde são fatores importantes para manter a relação de apoio entre o idoso e a rede, por representar ao idoso maior autonomia da necessidade de apoio, como também, melhor possibilidade de manter relação de troca de apoio.

A disponibilidade da rede extradomiciliar dos filhos, em 2000, permaneceu predizendo as duas situações de mudanças no apoio recebido pelos idosos e não teve comportamento diferenciado entre os sexos. (Tabela 14)

As relações de troca de apoio que o idoso e sua rede estabeleciam em 2000 , exibiram diferenças somente na rede extradomiciliar, verificada pelo aumento da importância do apoio fornecido aos filhos manter o apoio recebido ao longo do tempo. Enquanto o apoio dado aos familiares e amigos não mais predisseram a manutenção do apoio, e sim, a diminuição deste, ou seja, quanto mais apoio os idosos davam a esses membros da rede, em 2000, menor a probabilidade de receberem apoio ao longo do tempo. Não houve comportamento diferenciado entre os sexos para a rede de apoio dos idosos. (Tabela 14) 
Os dados trouxeram a questão dos laços de apoio, mantidos entre os idosos e seus familiares e amigos dependerem das circunstâncias em que ambos estão vivendo, sendo menos estabelecidos e presentes que os vínculos de apoio criados no domicílio e nas relações filiais.

A questão da viuvez continua enfatizando não ter sido acompanhada de suporte da rede dos idosos, que atuariam como mecanismos de proteção da piora da saúde física e emocional nesse momento da vida dos idosos. (Tabela 15)

As melhores percepções de saúde do idoso e menor comprometimento nas AIVDs, em 2006, continuaram a ter importância na manutenção do apoio recebido ao longo do tempo, evidenciando, novamente, a questão do bemestar e autonomia do idoso ser componente essencial para que estabeleça mais relações de troca e, assim, mantém o apoio recebido ao longo do tempo. (Tabela 15)

Os dados apontam também que o aumento da dificuldade na execução das AIVDs, em 2006, demanda mais apoio recebido pela rede dos idosos, enquanto a melhora na percepção de saúde, em 2006, passa a requerer menos apoio recebido. A influência do sexo tornou mais clara à questão do bem-estar dos idosos serem importantes para manterem suas relações de apoio ao longo do tempo. (Tabela 15)

A piora na condição de saúde do idoso, verificada pelo aumento das doenças referidas, em 2006, permanece influenciando o aumento do apoio recebido pela rede ao longo do tempo. Contudo, o apoio recebido se manteve independente das condições de saúde e das outras características da rede de apoio dos idosos. A relação entre os sexos revelou as mulheres referirem mais doenças, dado confirmado na literatura. (Tabela 15)

As alterações na disponibilidade de apoio no domicílio, em 2006, quando analisadas em conjunto com as outras variáveis, apresentaram diminuição do efeito protetor para o aumento no apoio recebido pelos idosos. $O$ número de co-residentes modificou seu efeito sobre a manutenção do apoio recebido, que pode ser verificado pelo aumento do número de pessoas no domicílio, em 2006, estarem associados com a diminuição do apoio recebido pelos idosos. Enquanto as alterações no número de filhos co-residentes, em 2006, não tiveram associação com as mudanças desse apoio. (Tabela 15) 
A reorganização domiciliar, verificada pelas alterações na disponibilidade de pessoas e de filhos que residem com o idoso, em 2006, tornou mais evidente a influência que pode ocasionar no apoio recebido pelo idoso, podendo disponibilizar mais apoio quando necessita, mas também, pode diminuir o apoio requerido pelo idoso. $O$ sexo apresentou efeito modificador sobre o arranjo domiciliar do idoso, mas o comportamento das mudanças se manteve. (Tabela 15)

Mesmo fato encontrado na rede extradomiciliar dos filhos, em que a diminuição na disponibilidade de filhos não co-residentes, em 2006, pode manter o apoio recebido pelo idoso ao longo do tempo, mas o aumento dessa disponibilidade pode não refletir em mais apoio recebido pelos idosos. (Tabela 15)

Os filhos continuam a representar em apoio não utilizado ou reconhecido pelo idoso, podendo corresponder também a uma fonte de apoio que não distribui as funções entre si, sendo o apoio trocado somente com determinados filhos e não apresentou alterações evidentes nesse comportamento ao longo do tempo do estudo.

A importância da relação de troca entre o idoso e a rede domiciliar e extradomiciliar dos filhos diminuiu em $10 \%$ a probabilidade de aumentar 0 apoio recebido ao longo do tempo, enquanto para a rede extradomiciliar dos familiares e amigos, não houve alterações do ajuste pelas outras variáveis, mantendo a importância da troca de apoio entre o idoso e essa rede aumentar o apoio que recebe. (Tabela 15)

Merece destacar que 0 apoio recebido pelo idoso se manteve independente da troca estabelecida com a rede de apoio como um todo. Não houve comportamento diferenciado entre os sexos para as trocas de apoio entre o idoso e a rede. (Tabela 15)

A reciprocidade de apoio entre os idosos e sua rede, tanto na análise univariada quanto multivariada, foi importante para aumentar a relação de troca, mais evidente entre os familiares e amigos não co-residentes, porém os idosos recebem apoio da rede mesmo diminuindo o apoio que fornecem. Os dados revelaram claramente mecanismos de reciprocidade diferentes para as relações estabelecidas no domicílio e as relações filiais, em relação aos outros 
familiares e amigos fora do âmbito domiciliar, mas os idosos continuam a receber apoio de toda a rede, mesmo quando trocam menos apoio. 
Tabela 14 - Modelo de regressão logística multinomial multivariada dos fatores associados às mudanças no apoio recebido pelos idosos, Município de São Paulo, 2000 e 2006 ( $n=1115)$.

\begin{tabular}{|c|c|c|c|c|}
\hline \multirow[b]{2}{*}{ Variáveis" } & \multicolumn{2}{|c|}{ Mudancas no apoio recebido ${ }^{5}$} & \multicolumn{2}{|c|}{ Mudanças no apoio recebido ${ }^{\text {gh }}$} \\
\hline & $\begin{array}{c}\text { Aumentou } \\
\text { RR (IC95\%) }\end{array}$ & $\begin{array}{c}\text { Diminuiu } \\
\text { RR (IC95\%) }\end{array}$ & $\begin{array}{c}\text { Aumentou } \\
\text { RR (IC95\%) }\end{array}$ & $\begin{array}{c}\text { Diminuiu } \\
\text { RR (IC95\%) }\end{array}$ \\
\hline \multicolumn{5}{|l|}{ Caracteristicas de saúde } \\
\hline $\begin{array}{l}N^{\circ} \text { de ABVDs } \\
N^{\circ} \text { de doenças referidas } \\
\text { Rede de apoio }\end{array}$ & $\begin{array}{l}0,9(0,7-1,1) \\
0,8(0,7-1,1)\end{array}$ & $\begin{array}{l}1,1(0,8-1,3) \\
0,9(0,7-1,2)\end{array}$ & $\begin{array}{l}0,9(0,7-1,1) \\
0,9(0,7-1,1)\end{array}$ & $\begin{array}{l}1,1(0,8-1,3) \\
1,0(0,8-1,2)\end{array}$ \\
\hline Domiciliar & & & & \\
\hline Ajudas dadas & $1,0(0,9-1,1)$ & $1,1(1,0-1,2)$ & $1,0(0,9-1,1)$ & $1,1(1,0-1,2)$ \\
\hline \multicolumn{5}{|l|}{ Extradomiciliar } \\
\hline Filhos & & & & \\
\hline$N^{\circ}$ de filhos & $1,1(1,0-1,2)$ & $1,1(0,9-1,2)$ & $1,1(1,0-1,2)$ & $1,1(0,9-1,2)$ \\
\hline Ajudas dadas & $0,8(0,7-1,0)$ & $1,0(0,8-1,3)$ & $0,8(0,7-1,0)$ & $1,0(0,8-1,3)$ \\
\hline Outros familiares/amigos & & & & \\
\hline Ajudas dadas & $1,0(0,8-1,1)$ & $1,3(1,1-1,5)$ & $1,0(0,8-1,2)$ & $1,3(1,1-1,5)$ \\
\hline
\end{tabular}


Tabela 15 - Modelo de regressão logística multinomial multivariada dos fatores associados às mudanças no apoio recebido pelos idosos, Município de São Paulo, 2000 e $2006(n=1115)$.

\begin{tabular}{|c|c|c|c|c|}
\hline \multirow[b]{2}{*}{ Variáveis" } & \multicolumn{2}{|c|}{ Mudanças no apoio recebido ${ }^{\$}$} & \multicolumn{2}{|c|}{ Mudanças no apoio recebido } \\
\hline & $\begin{array}{c}\text { Aumentou } \\
\text { RR (IC95\%) }\end{array}$ & $\begin{array}{c}\text { Diminuiu } \\
\text { RR (IC95\%) }\end{array}$ & $\begin{array}{c}\text { Aumentou } \\
\text { RR (IC95\%) }\end{array}$ & $\begin{array}{c}\text { Diminuiu } \\
\text { RR (IC95\%) }\end{array}$ \\
\hline \multicolumn{5}{|l|}{$\begin{array}{l}\text { Sociodemográficas } \\
\text { Mudanç no estado civil }\end{array}$} \\
\hline Não & 1,0 & 1,0 & 1,0 & 1,0 \\
\hline Sim & $0,5(0,2-0,9)$ & $1,2(0,7-2,1)$ & $0,5(0,3-0,9)$ & $1,2(0,7-2,2)$ \\
\hline \multicolumn{5}{|l|}{ Características de saúde } \\
\hline Auto-avaliação da saúde ${ }^{(1)}$ & $0,7(0,4-1,0)$ & $0,7(0,5-1,1)$ & $0,6(0,4-1,0)$ & $0,7(0,5-1,1)$ \\
\hline$N^{\circ}$ de AIVDs & $1,1(0,9-1,3)$ & $0,9(0,7-1,1)$ & $1,1(0,9-1,4)$ & $0,9(0,7-1,1)$ \\
\hline$N^{\circ}$ de doenças referidas & $1,3(0,9-1,8)$ & $1,0(0,7-1,5)$ & $1,2(0,9-1,8)$ & $1,0(0,7-1,4)$ \\
\hline \multicolumn{5}{|l|}{ Rede de apoio } \\
\hline$N^{\circ}$ de co-residentes & $1,7(0,8-3,5)$ & $1,4(0,6-3,1)$ & $1,8(0,9-3,8)$ & $1,4(0,6-3,2)$ \\
\hline$N^{\circ}$ de filhos co-residentes & $1,0(0,6-1,7)$ & $0,9(0,5-1,5)$ & $0,9(0,5-1,6)$ & $0,9(0,5-1,5)$ \\
\hline Ajudas dadas & $1,2(1,0-1,4)$ & $0,7(0,5-0,9)$ & $1,2(1,0-1,4)$ & $0,7(0,5-1,0)$ \\
\hline \multicolumn{5}{|l|}{ Extradomiciliar } \\
\hline \multicolumn{5}{|l|}{ Filhos } \\
\hline$N^{\circ}$ de filhos & $0,8(0,4-1,4)$ & $1,3(0,7-2,3)$ & $0,7(0,4-1,2)$ & $1,3(0,8-2,2)$ \\
\hline Ajudas dadas & $1,2(1,0-1,4)$ & $0,8(0,6-1,1)$ & $1,2(1,1-1,5)$ & $0,8(0,6-1,1)$ \\
\hline \multicolumn{5}{|l|}{ Outros familiares/amigos } \\
\hline Ajudas dadas & $1,5(1,2-1,9)$ & $0,7(0,5-1,0)$ & $1,5(1,2-2,0)$ & $0,8(0,5-1,0)$ \\
\hline
\end{tabular}

Notas:

${ }^{5} \mathrm{~A}$ categoria "ficou igual" foi considerada como referência

*Ajustado por sexo

"Variáveis independentes referentes à diferença proporcional entre 2000 e 2006

("Escala de 1 a 4, conforme aumenta o valor, piora a auto-avaliação da saúde 


\section{CONCLUSÕES}

Os dados trazem em evidência a importância de o sistema formal estar atuando na manutenção da capacidade funcional e das condições de saúde física e bem-estar dos idosos, em vista de serem componentes essenciais para que os idosos sintam-se com autonomia e independência para estabelecerem mais relações de troca com a rede de apoio.

A rede informal demonstrou atuante quando ocorre piora na saúde física do idoso, entretanto, está sendo disponibilizada primordialmente para as questōes instrumentais, sendo o conjunto de fatores emocionais, enfrentados nesse período de vida pelo idoso, como a maior perda de familiares e amigos, a saída do mercado de trabalho, poder levar a piora desses agravos e isolamento social, se não acompanhados de apoio devido. Esses fatores não são supridos somente da maneira instrumental.

Os resultados sugerem que o padrão de relacionamento ocorrido entre o idoso e a rede mais próxima, como a domiciliar e dos filhos, pode não oferecer o mesmo tipo de proteção em torno do apoio social recebido ao longo do tempo. Devido a essa rede sofrer reorganizações que envolvem fatores contextuais, como as mudanças no direcionamento das políticas públicas, questões econômicas que influenciam no mercado de trabalho e renda dos idosos e a rede, fatores culturais estabelecidos no âmbito familiar etc. Esse conjunto de fatores incide em como a rede se organiza com as novas demandas trazidas com o processo de envelhecimento, tornando o idoso mais protegido ou vulnerável.

Não foi possivel investigar aprofundadamente as relações filiais, pois o estudo não foi direcionado somente para a rede de apoio do idoso, e sim, para as suas condições de vida como um todo, que envolveu características de saúde, de acesso e utilização de serviços, entre outros. No entanto, foi possível identificar que o idoso prioriza ou não pode utilizar da ampla disponibilidade de filhos que têm, sendo a resposta de apoio ocorrida somente com determinados filhos. Fato esse que não possibilita ao idoso utilizar dos outros recursos, não só instrumentais, que essa rede poderia disponibilizar como companhia, 
informações etc. Esses outros recursos poderiam atuar como protetores para as sensações de bem-estar do idoso e enfrentamento das situações mais freqüentes nesse período da vida.

As relações de troca com a rede de apoio foram reconhecidas primordialmente na forma material, isso demonstra um componente cultural, não explorado nesse trabalho, em que a palavras apoio e ajuda, trazem ao imaginário do idoso somente componente de necessidade material. Os fatores emocionais, trazidos nas relações de amizade e amor, que permeiam as relações sociais, não são reconhecidos como apoio ou ajuda pelo idoso.

O que a teoria de apoio social tem enfatizado sobre a importância da troca de apoio para que o idoso se sinta ativo na troca, e assim, passa a receber e reconhecer mais apoio, foi comprovado nesse estudo. Os comportamentos que previamente seriam protetores para a manutenção da troca de apoio, ao longo do tempo, mostraram a importância das condições físicas do idoso para se sentir apto a trocar mais apoio com a rede. Quanto mais apoio trocava, mais apoio continuou trocando e, dessa forma, mais a rede se manteve fortalecida ao longo do tempo.

Os dados longitudinais fornecem uma importante confirmação empírica para verificar como a rede de apoio do idoso se dispõe, conforme o avanço da idade, como também, perceber as mudanças nos comportamentos de apoio entre o idoso e a rede e verificar as condições que envolvem essas mudanças. Como também, foi possível perceber como as relações de apoio foram se estabelecendo na disposição da rede, com o aumento do apoio requerido pelo idoso.

Em nenhuma outra época da existência, as famílias conviveram tanto tempo com várias gerações, como também, as mudanças sociais ocorridas nas estruturas familiares, como a entrada da mulher no mercado de trabalho, os recasamentos, a diminuição da fecundidade, a imigração dos membros das famílias, trouxeram mudanças drásticas na cultura familiar, tornando-as mais vulneráveis para lidarem com as demandas do processo de envelhecimento.

$O$ processo de envelhecimento não envolve somente o convívio e acúmulo de doenças crônicas, como também, a diminuição da capacidade funcional. A necessidade da família e dos amigos, que compõem a rede de apoio do idoso, vai se tornando maior, conforme o avanço da idade. Porém, 
essa rede precisa de suporte da rede formal, principalmente por meio de serviços e informação.

Envelhecer não é uma fase da vida como outra qualquer, envolve sentimentos de perda da independência física, diminuição da renda, saída do mercado de trabalho, mudança no corpo físico, perda de familiares e amigos, entre outros. Esse conjunto de condições tem que ser sensibilizado na cultura, envelhecer faz parte da vida, mas tem que se tornar cultural, se a população não olhar para esses fatores, cada vez mais, o idoso estará desprotegido de apoio emocional, que tanto influencia na perda de autonomia e sentido da vida. 


\section{REFERÊNCIAS BIBLIOGRÁFICAS}

ANTONUCCI, T. C.; AKIYAMA, H. Social networks in adult life and a preliminary examination of the convoy model. Journal of Gerontology, v. 42, n. 5, p. 519-527, 1987.

; LANSFORD, J. E. Negative effects of close social relations. Family Relations, v. 47, n. 4, p. 379-384, oct. 1998.

; OKORODUDU, C.; AKIYAMA, H. Well-being among older adults on different continents. Journal of Social Issues, v. 58, n. 4, p. 617-626, 2002

ATTIAS-DONFUT, C. The dynamics of elderly support: the transmission of solidarity patterns between generations. Z Gerontol Geriat, v. 34, n. 1, p. 9-15, 2001.

; OGG, J.; WOLFF, F. C. European patterns of intergenerational financial and time transfers. European Journal of Ageing, $v$. 2, p. 161-173, 2005.

BENGTSON, V. L.; ROBERTS, R. E. L. Intergenerational solidarity in aging families: an example of formal theory construction. Journal of Marriage and Family, v. 53, n. 4, p. 856-870, nov. 1991.

; MARTIN, P. Families and intergenerational relationships in aging societies: comparing the United States with German-speaking countries. Z Gerontol Geriat, v. 34, n. 3, p. 207-217, 2001.

BERKMAN, L. F. The relationship of social networks and social support to morbidity and mortality. In: COHEN, S.; SYME, S. L. (Eds.) Social support and health. Orlando: Academic Press, 1985. p. 241-262.

BLAU, P. M. The structure of social associations. In: Exchange and power in social life. New Jersey: Transaction Publishers, 2006. 10th ed. p.1332.

Social integration. In: Exchange and power in social life. New Jersey: Transaction Publishers, 2006. 10th ed. p. 33-59.

Social support. In:

Exchange and power in social life. New Jersey: Transaction Publishers, 2006. 10th ed.p. 60-87.

Social exchange. In: Exchange and power in social life. New Jersey: Transaction Publishers, 2006. 10th ed.p. 88-114.

BONSANG, E. How do middle-age children allocate time and money transfers to their older parents in Europe. Working Paper, n. 2. Liège: University of 
Liège, 2006. 18p. (CREEP Working Papers). Disponivel em: <http://www.shareproject.org/>. Acesso em: 15 maio 2007.

BORGLIN, G. et al. Older people in Sweden with various degress of present quality of life: their health, social support, everyday activities and sense of coherence. Health and Social Care in the Community, v. 14, n. 2, p. 136-146, 2006.

BOWLING, A. et al. Do perceptions of neighbourhood environment influence health: baseline findings from a british survey of aging. Journal of Epidemiology and Community Health, v. 60, p. 476-483, 2006.

BRISSETTE, I.; COHEN, S.; SEEMAN, T. Measuring social integration and social networks. In: COHEN, S.; UNDERWOOD, L. G.; GOTTLIEB, B. H. Social support measurement and intervention: a guide for health and social scientists. New York: Oxford University Press, 2000. p. 53-85.

BUBER, I.; ENGELHARDT, H. Children and mental health of elderly. Research Paper, n.3, 2006. 50p. (European Demographic Research Paper). Disponível em: <http://www.oeaw.ac.at/vid/download/edrp_3_06.pdf>. Acesso em: 20 jul. 2007.

Ageing in Austria: an overview of "Survey of Health, Ageing and Retirement in Europe" (SHARE) with special focus on aspects of health. In: Vienna Yearbook of Population Research, 2007. p. 309-326.

; ENGELHARDT, H. Children's impact on the mental health of their older mothers and fathers: findings from the Survey of Health, Ageing and Retirement in Europe. European Journal of Ageing, v. 5, p. 31-45, 2008a.

. The relation between depressive symptoms and age among older Europeans. Findings from SHARE. Working Paper, n. 1. Vienna: Institute of Demography, 2008. 19p. Disponivel vem: <http://www.share-project.com>. Acesso em: 12 dez. 2008.

CAMARANO, A. A.; KANSO, S.; LEITÃo E MELLO, J. Como vive o idoso brasileiro. In: (Org.) Muito além dos 60: os novos idosos brasileiros. Rio de Janeiro: IPEA, 2004. p.25-73.

; PASINATO, M. T. O envelhecimento populacional na agenda das políticas públicas brasileiras. In: (Org.) Muito além dos 60: os novos idosos brasileiros. Rio de Janeiro: IPEA, 2004. p. 253-292.

vulnerabilidades. In: et al. Famílias: espaço de compartilhamento de recursos e idosos brasileiros. Rio de Janeiro: IPEA, 2004. p. 137-168.

COBB, S. Social support as a moderator of life stress. Psychosomatic Medicine, v. 38, n. 5, p. 300-314, 1976. 
COHEN, S.; MCKAY, G. Social support, stress and the buffering hypothesis: a theoretical analysis. In: BAUM, A.; TAYLOR, S. E.; SINGER, J. E. (Eds.) Handbook of Psychology and Health. Hillsdale, NJ: Lawrence Erlbaum Associates, 1984. p. 253-267.

; SYME, S. L. Issues in the study and application of social support. In: (Eds.) Social support and health. Orlando: Academic Press, 1985. p. 3-22.

; WILLS, T. A. Stress, social support, and the buffering hypothesis. Psychological Bulletin, v. 98, n. 2, p. 310-357, 1985.

et al. Measuring the functional components of social support. In: SARASON, I. G.; SARASON, B. R. (Eds.) Social support: theory, research and applications. Dordrecht, Netherlands: Martinus Nijhoff, 1985. p. 73-94.

Stress, social support, and disorder. In: VEIEL, H. O. F.; BAUMANN, U. (Eds.) The meaning and measurement of social support. New York: Hemisphere Press, 1992. p. 109-124.

; GOTTLIEB, B. H.; UNDERWOOD, L. G. Social relationships and health. In: COHEN, S.; UNDERWOOD, L. G.; GOTTLIEB, B. H. Social support measurement and intervention: a guide for health and social scientists. New York: Oxford University Press, 2000. p. 03-25.

8, p. 676-684, 2004.

COMISIÓN ECONÓMICA PARA AMÉRICA LATINA Y EL CARIBE. Recomendaciones para politicas sobre redes de apoyo social de personas adultas mayores. In: REUNIÓN DE EXPERTOS EN REDES DE APOYO SOCIAL A PERSONAS ADULTAS MAYORES: EL ROL DEL ESTADO, LA FAMILIA Y LA COMUNIDAD, 2002, Santiago, Chile. Documento eletrônico. Chile: CEPAL, 2002. Disponivel em: <http://www.eclac.cl/cgibin/getProd.asp? $\mathrm{xml}=/$ celade/noticias/paginas/7/11497/P11497.xml\&xsl=/celade/tpl/p18f.xsl\&bas e=/celade/tpl/topbottom_env.xslt>. Acesso em:16 jul. 2007.

DYKSTRA, P. A. Aging and social support. In: RITZER, G. (Ed.) The Blackwell encyclopedia of sociology. Oxford: Blackwell, 2006. p. 88-93.

; TILBURG, T. G.; GIERVELD, J. J. Changes in older adult loneliness: results from a seven-year longitudinal study. Research on Aging, $v$. 27, n. 6, p. 725-747, nov. 2005.

FINGERMAN, K. L. et al. Ambivalent relationship qualities between adults and their parents: implications for the well-being of both parties. Journal of Gerontology: Psychological Sciences, v. 63B, n. 6, p. 362-271, 2008. 
FURSTENBERG, F. F. Banking on families: how families generate and distribute social capital. Journal of Marriage and Family, v. 67, n.4 p. 809-821, 2005.

GIERVELD, J. J.; DYKSTRA, P. A. Impact of longer life on care giving from children. In: ZENG, Y. et al. (Eds.) Longer life on health aging. Dordrecht, Netherlands: Springer, 2006. p. 239-259.

GIRONDA, M.; LUBBEN, J. Preventing loneliness and isolation in older adulthood. In: GULLOTTA, T; BLOOM, M (Orgs.) Encyclopedia of Primary Prevention and Health Promotion. Nova York: Kluwer Academic/Plenum Publishers, 2002. p. 20-34.

GLASER, K.; TOMASSINI, C.; GRUNDY, E. Revisting convergence and divergence: support for older people in Europe. European Journal of Ageing, v. 1, p. 64-72, 2004.

GOTTLIEB, B. H. Social support and community mental health. In: COHEN, S.; SYME, S. L. (Eds.) Social support and health. Orlando: Academic Press, 1985. p. 303-326.

GRUNDY, E.; TOMASSINI, C. The family support of older people in Europe: contrasts and implications. In: REUNIÓN DE EXPERTOS EN REDES DE APOYO SOCIAL A PERSONAS ADULTAS MAYORES: EL ROL DEL ESTADO, LA FAMILIA Y LA COMUNIDAD, 2002, Santiago, Chile. Documento eletrônico. Chile: CEPAL, $2002 . \quad$ Disponível em: <http://www.eclac.cl/cgibin/getProd.asp?xml=/celade/noticias/paginas/7/11497/ P11497.xml\&xsl=/celade/tpl/p18f.xsl\&base=/celade/tpl/topbottom_env.xslt $>$. Acesso em:16 jul. 2007.

GUZMÁN, J.M.; HUENCHUAN, S.; MONTES DE OCA, V. Redes de apoyo social a las personas mayores: marco conceptual. In: REUNIÓN DE EXPERTOS EN REDES DE APOYO SOCIAL A PERSONAS ADULTAS MAYORES: EL ROL DEL ESTADO, LA FAMILIA Y LA COMUNIDAD, 2002, Santiago, Chile. Documento eletrônico. Chile: CEPAL, 2002. Disponivel em:<http://www.eclac.cl/cgibin/getProd.asp?xml=/celade/noticias/paginas/7/114 97/P11497.xml\&xsl=/celade/tpl/p18f.xsl\&base=/celade/tpl/topbottom_env.xslt>. Acesso em: 16 jul. 2007.

Políticas hacia las familias con adultos mayores: el desafio del derecho al cuidado en la edad avanzada. In: REUNIÓN DE EXPERTOS "POLÍTICAS HACIA LAS FAMLIAS, PROTECCIÓN E INCLUSIÓN SOCIALES", 2005, Santiago, Chile. Documento eletrônico. Chile: CEPAL, 2005. (CEPAL serie seminarios y conferencias, 46) Disponível em: $<$ http://www.eclac.org/cgi-bin/getProd.asp?

$\mathrm{xml}=/$ publicaciones/xml/2/22672/P22672.xml\&xsl=/dds/tpl/p9f.xsl\&base=/tpl/topbottom.xslt >. Acesso em:10 dez. 2008. 
HALL, A.; WELLMAN, B. Social networks and social support. In: COHEN, S.; SYME, S. L. (Eds.) Social support and health. Orlando: Academic Press, 1985. p. 23-39.

HAMMARSTRÖM, G. The construct of intergenerational solidarity in a lineage perspective: a discussion on underlying theoretical assumptions. Journal of Aging Studies, v. 19, n. 1, p. 33-51, 2004.

HANK, K. Proximity and contacts between older parents and their children: a european comparison. Journal of Marriage and Family, v. 69, p. 157-173, feb. 2007.

HILLCOAT-NALLÉTAMBY, S.; DHARMALINGAM, A. Mid-life parental support for adult children in New Zealand. Journal of Sociology, v. 39, n. 3, p. 271$290,2003$.

HOSMER, D. H.; LEMESHOW, S. Applied logistic regression. New York: John Willey and Sons, 2000. 2nd ed. 392p.

HOUSE, J. S.; KAHN, R. L. Measures and concepts of social support. In: COHEN, S.; SYME, S. L. (Eds.) Social support and health. Orlando: Academic Press, 1985. p. 83-108.

HUENCHUAN, S. Pobreza y redes de apoyo en la vejez: acercamiento desde las diferencias de género. In: Congresso da Associação Latino Americana de População, ALAP, 1., 2004, Caxambú, Minas Gerais. Anais eletrônicos do I Congresso da Associação Latino Americana de População - ALAP. Campinas: ABEP, 2004. Disponivel em: <http://www.abep.nepo.unicamp.br/site_eventos_alap/PDF/ALAP2004_410.PD F>. Acesso em: 10 dez. 2008.

ISRAEL, B. A. et al. Health education and community empowerment: conceptualizing and measuring perceptions of individual, organizational, and community control. Health Education Quarterly, v. 21, n. 2, p. 149-170, 1994.

KALACHE, A. O mundo envelhece: é imperativo criar um pacto de solidariedade social. Ciência \& Saúde Coletiva, v. 13, n. 4, p. 1107-1111, 2008.

KARSCH, U. M. Idosos dependentes: famílias e cuidadores. Cadernos de Saúde Pública, v. 19, n. 3, p. 861-866, jun. 2003.

KAUFMAN, G.; UHLENBERG, P. Effects of life course transitions on the quality of relationships between adult children and their parents. Journal of Marriage and the Family, v. 60, n. 4, p. 924-938, 1998.

KIM, I. K.; KIM, C. Patterns of family support and the quality of life of the elderly. Social Indicators Research, v. 62-63, p. 437-454, 2003. 
KLEINBAUM, D. G. et al. Applied regression analysis and other multivariable methods. Boston: Brooks/Cole Pub Co, 1997. 3rd ed. 816p.

$\mathrm{KOHLI}, \mathrm{M}$. Private and public transfers between generations: linking the family and the state. European Societies, v. 1, n. 1, p. 81-104, 1999.

; KÜNEMUND, H.; LÜDICKE J. Family structure, proximity and contact. In: BÖRSCH-SUPAN, A. et al. (Eds.) Health, ageing and retirement in Europe: first results from the Survey of Health, Ageing and Retirement in Europe. Mannheim: MEA, 2005. Disponivel em: <http://www.eui.eu/SPS/People/Faculty/CurrentProfessors/PDFFiles/FamilyStru cture.pdf/>. Acesso em: 12 jul. 2007.

KOMTER, A. E.; VOLLEBERGH, W. A. M. Solidarity in dutch families: family ties under strain. Journal of Family Issues, v. 23, n. 2, p. 171-188, mar. 2002.

LABONTE, R. Health promotion and empowerment: reflections on professional practice. Health Education Quarterly, v. 21, n. 2, p. 253-268, 1994.

LAKEY, B.; COHEN, S. Social support theory and measurement. In: COHEN, S.; UNDERWOOD, L. G.; GOTTLIEB, B. H. Social support measurement and intervention: a guide for health and social scientists. New York: Oxford University Press, 2000. p. 29-53.

LAWTON, L.; SILVERSTEIN, M.; BENGTSON, V. Affection, social contact, and geographic distance between adult children and their parents. Journal of Marriage and the Family, v. 56, n. 1, p. 57-68, 1994.

LEBRÃO, M. L.; DUARTE, Y. A. O. SABE - Saúde, Bem-Estar e Envelhecimento - O Projeto Sabe no município de São Paulo: uma abordagem inicial. Brasília: OPAS, 2003. 255p.

Estudo SABE: estudo longitudinal das condições de vida e saúde das pessoas idosas do Município de São Paulo. Cd-Rom. 2008

LITWIN, H. Social networks and self-rated health: a cross-cultural examination among older israelis. Journal of Aging and Health, v. 18, n. 3, p. 335-358, june 2006.

LOWENSTEIN, A. Intergerational family relations and social support. Z Gerontol Geriat, v. 32, p. 398-406, 1999.

MARTINEZ, I. Recomendaciones sobre metodos y instrumentos para estudios sobre redes de apoyo y calidad de vida. In: REUNIÓN DE EXPERTOS EN REDES DE APOYO SOCIAL A PERSONAS ADULTAS MAYORES: EL ROL DEL ESTADO, LA FAMILIA Y LA COMUNIDAD, 2002, Santiago, Chile. Documento eletrônico. Chile: CEPAL, 2002. Disponível em:<http://www.eclac.cl/cgibin/getProd.asp?xml=/celade/noticias/paginas/7/114 
97/P11497.xml\&xsl=/celade/tpl/p18f.xsl\&base=/celade/tpl/topbottom_env.xslt $>$. Acesso em: 16 jul. 2007.

MINKLER, M. Social support and health of the elderly. In: COHEN, S.; SYME, S. L. (Eds.) Social support and health. Orlando: Academic Press, 1985. p. 199-216.

Community organizing among the elderly poor in the United States: a case study. International Journal of Health Services, v. 22, n. 2, p. 303-316, 1992.

MONTES DE OCA, V. Participación, organización y significado de las redes de apoyo comunitario entre hombres y mujeres adultas mayores: la experiencia de la Colonia Aragón en la delegación Gustavo A. Madero, CD. de México. In: REUNIÓN DE EXPERTOS EN REDES DE APOYO SOCIAL A PERSONAS ADULTAS MAYORES: EL ROL DEL ESTADO, LA FAMILIA Y LA COMUNIDAD, 2002, Santiago, Chile. Documento eletrônico. Chile: CEPAL, 2002. Disponível em: <http://www.eclac.cl/cgibin/getProd.asp?xml=/ celade/noticias/paginas/7/11497/P11497.xml\&xsl=/celade/tpl/p18f $. x s \mid \& b a s e=/ c e$ lade/tpl/topbottom_env.xsit>. Acesso em:16 jul. 2007.

ORGANIZAÇĀO MUNDIAL DA SAÚDE. Envelhecimento ativo: uma política de saúde. Tradução de Suzana Contijo. Brasília: OPAS, 2005. 60 p.

PEARLIN, L. I. Social structure and processes of social support. In: COHEN, S.; SYME, S. L. (Eds.) Social support and health. Orlando: Academic Press, 1985. p. 43-59.

ROOK, K. S.; UNDERWOOD, L. G. Social support measurement and interventions: coments and future directions. In: COHEN, S.; UNDERWOOD, L. G.; GOTTLIEB, B. H. Social support measurement and intervention: a guide for health and social scientists. New York: Oxford University Press, 2000. p. 311-334.

SCHULZ, R.; RAU, M. T. Social support through the life course. In: COHEN, S.; SYME, S. L. (Eds.) Social support and health. Orlando: Academic Press, 1985. p. 129-198.

SHÜTZE, Y.; HOLLSTEIN, B. Support-exchange between adult children and their old and very old parents. Research Report, n. 46. Berlin, Germany Freie Universität, 1994. Disponível em: < http://fall-berlin.de/>. Acesso em: 17 jul. 2007.

SCHWARZ, B. Adult daughters family structure and the association between reciprocity and relationship quality. Journal of Family Issues, v. 27, n. 2, p. 208-228, feb. 2006.

SILVERSTEIN, M.; PARROTT, T. M.; BENGTSON, V. L. Factors that predispose middle-aged sons and daughters to provide social support to older 
parents. Journal of Marriage and the Family, v. 57 , n. 2, p. $465-475$, may 1995.

; BENGTSON, V. L. Intergenerational solidarity and the structure of adult-child relationships in american families. American Journal of Sociology, v. 103, n. 2, p. 429-460, sept. 1997.

. et al. Reciprocity in parent-child relations over the adult life course. Journal of Gerontology: Social Sciences, v. 57B, n. 1, p. 3-13, 2002.

; GANS, D.; YANG, F. M. Intergenerational support to aging parents: the role of norms and needs. Journal of Family Issues, v. 27, n. 8, p. 1068-1084, aug. 2006.

SHEIKH, J. I.; YESAVAGE, J. A. Geriatric Depression Scale (GDS): recent evidence and development of a short version. Reviews in Clinical Gerontology, v. 5, p. 165-173, 1986.

SOARES, L. T. Os custos sociais do ajuste neoliberal na América Latina. Coleção Questões da Nossa Época, n. 78. São Paulo: Cortez, 2000. 118 p.

SLUZKI, C. E. Rede social: proposições gerais. In: A rede social na prática sistêmica: alternativas terapêuticas. São Paulo: Casa do Psicólogo, 1997. p. 37-60.

SOSA, Z.; HUENCHUAN, S. Redes de apoyo social de personas mayores en Chile. In: REUNIÓN DE EXPERTOS EN REDES DE APOYO SOCIAL A PERSONAS ADULTAS MAYORES: EL ROL DEL ESTADO, LA FAMILIA Y LA COMUNIDAD, 2002, Santiago, Chile. Documento eletrônico. Chile: CEPAL, 2002. Disponível em: <http://www.eclac.cl/cgibin/getProd.asp?xml=/celade/ noticias/paginas/7/11497/P11497.xml\&xsl=/celade/tpl/p18f $. x s \mid \& b a s e=/ c e l a d e / t p l$ /topbottom_env.xslt>. Acesso em: 16 jul. 2007.

SZKLO, M.; JAVIER-NIETO, F. Epidemiology: beyond the basics. Baltimore: Aspen Publication, 2007. 2nd ed. 518p.

TORNEL, I. El tema de las redes de apoyo y calidad de vida en el plan de Madrid y estrategias regionales. In: REUNIÓN DE EXPERTOS EN REDES DE APOYO SOCIAL A PERSONAS ADULTAS MAYORES: EL ROL DEL ESTADO, LA FAMILIA Y LA COMUNIDAD, 2002, Santiago, Chile. Documento eletrônico. Chile: CEPAL, 2002. Disponivel em: $<$ http://www.eclac.cl/cgibin/getProd.asp?xml=/celade/noticias/paginas/7/114971 497.xml\&xsl=/celade/tpl/p18f.xsl\&base=/celade/tpl/topbottom_env.xslt $>$. Acesso em: 16 jul. 2007.

VALLA, V. V. Sobre participação popular: uma questão de perspectiva. Cadernos de Saúde Pública, v. 14, n. 2, p. 7-18, 1998. 
Educação popular, saúde comunitária e apoio social numa conjuntura de globalização. Cadernos de Saúde Pública, v. 15, n. 2, p. 7-14, abr.jun. 1999.

VERAS, R. P. A longevidade da população: desafios e conquistas. Revista Serviço Social e Sociedade, v. 24, n. 75, p. 5-18, out. 2003.

WELLMAN, B. Network analysis: some basic principles. Sociological Theory, v. 1, p. 155-200, 1983.

WILLS, T. A. Supportive functions of interpersonal relationships. In: COHEN, S.; SYME, S. L. (Eds.) Social support and health. Orlando: Academic Press, 1985. p. $61-79$.

; SHINAR, O. Measuring perceived and received social support. In: COHEN, S.; UNDERWOOD, L. G.; GOTTLIEB, B. H. Social support measurement and intervention: a guide for health and social scientists. New York: Oxford University Press, 2000. p. 86-135.

WONG, R.; ESPINOZA, M. Bienestar económico de población de edad media y avanzada en México: primeros resultados del estudio nacional de salud y envejecimiento en México. In: REUNIÓN DE EXPERTOS EN REDES DE APOYO SOCIAL A PERSONAS ADULTAS MAYORES: EL ROL DEL ESTADO, LA FAMILIA Y LA COMUNIDAD, 2002, Santiago, Chile. Documento eletrônico. Chile: CEPAL, 2002. Disponível em: $<$ http://www.eclac.cl/cgibin/getProd.asp?xml=/celade/noticias/paginas/7/11497/ P11497.xml\&xsl=/celade/tpl/p18f.xsl\&base=/celade/tpl/topbottom_env.xslt $>$. Acesso em: 16 jul. 2007.

WORLD HEALTH ORGANIZATION. Ottawa charter for health promotion, 1986. Disponivel em: <http://www.who.int/hpr/NPH/docs/ottawa_charter_hp.pdf>. Acesso em: 16 jul. 2007

ZIMMER, Z.; KWONG, J. Family size and support of older adults in urban and rural China: current effects and future implications. Demography, v. 40, n. 1, p. 23-44, feb. 2003. 


\section{ANEXOS}

ANEXO 1 TERMO DE APROVAÇÃO DO COMITÊ DE ÉTICA EM PESQUISA DA FACULDADE DE SAÚDE PÚBLICA 


\section{UNIVRSIDADE DE SÃO PAULO}

FACULDADE DE SAÚDE PÚBLICA

COMITẺ DE ÉTICA EM PESQUISA DA FSP/USP - COEP

Av. Dr. Amaldo, 715 - CEP 01246-904 - São Paulo - Brasil

Telefones: (55-11) 3066 7742 - fax (55-11) 30647314

\section{Or.COEP/67/99}

24 de maio de 1999

Pelo presente, informo que o Comitê de Ética em Pesquisa, aprovou, em sua 3.\%/99, Sessão Ordinária, de 19.05.99, de acordo com os requisitos da Resolução CNS/196/96, o Projeto de Pesquisa “AS CONDIÇÕES DE SAÚdE DOS IDOSOS NA AMÉRICA DO SUL E CARIBE", apresentado pelo pesquisador Ruy Laurenti, devendo ser remetido à CONEP conforme as normas da Resolução 196/96.

Atenciosamente,

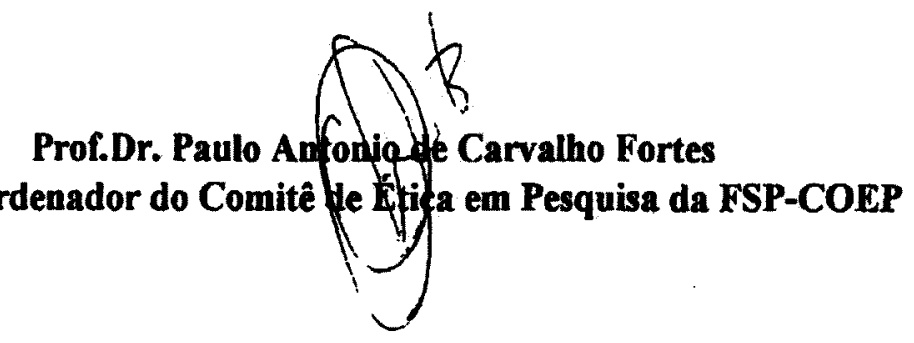


ANEXO 2 TERMO DE APROVAÇÃO DA COMISSÃO NACIONAL DE ÉTICA EM PESQUISA 


\section{MINISTERIO DA SAULDE}

Conselho Nacional de Soude

Comiss o Nacinnal de Elica em Pesquisa - CONEF

\section{PARECER N J1SH9O}

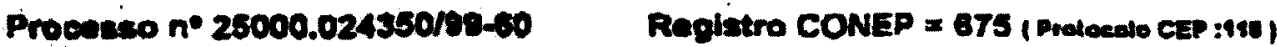

Projeto de Pesquisa:"As condicós de savide dos idosos na America do Sul Canibo:.

Pesquilador Responsival: Dr. Ruy Laurenti

Inattulctio: Faculdade de Saúde Pública / USP

Ares Temstica Especiut Pesquisa com coopersecho estrangeirs.

Ao se proceder à análıse do protocolo em quesiăo, cabem as seguintes consideragóes:

a) as informą̧⿸尸es enviades atandem aos aspectos fundamentais das Res CNS 196/96 e 231/97. sobre Diretrizes e Normas Regulamentadoras de Pesquiass Envolvendo Seres Humanos:

b) o projeto tol aprovado pelo Comité de Ética em Pesquisa - CEP da instituigato.

Diante do exposto, a Comissăo Nacional de Etica em Pesquilas CONEP, de acordo com as atribuiçoes da Res. CNS 198/96, manifeste - se pele aprovagaso do projeto de pesquisa proposto, com a seguinte recomendaçlo a ser acompanhada pelo CEP:

1) Orçamento financeiro datalhado, especificando a remuneraçlo do pesquisador (Res. CNS 196/96. VI:J") ).

Situaclio : Projeto aprovado com recomendaçăb.

Brasilia, 17 de junho de 1999.

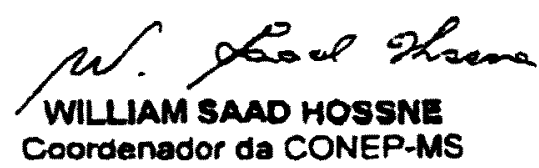


ANEXO 3 TERMO DE APROVAÇÃO DO COMITÊ DE ÉTICA EM PESQUISA DA FACULDADE DE SAÚDE PÚBLICA 


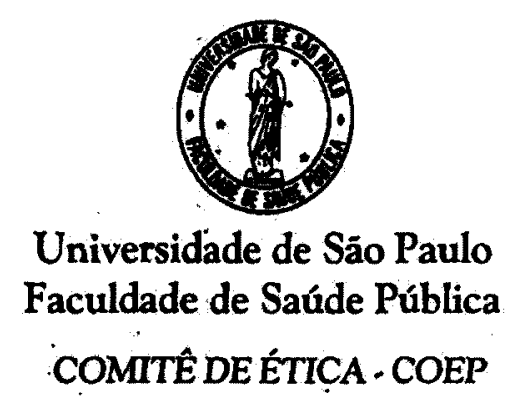

Av. Dr. Arnaldo, 715 - Assessoria Acadêmica - CEP 01246-904 - São Paulı - Brasil Telefones: (55-11) 3066-7779-e-mail: cocporifso.usn.hr

\section{Of.COEP/83/06}

14 de março de 2006

Pelo presente, informo que o Comitê de Ética em Pesquisa da Faculdade de Saúde Pública da Universidade de São Paulo-COEP, aprovou o Protocolo de Pesquisa n. ${ }^{\circ}$ 1345, intitulado: "PROJETO SABE-2005 - SAÚDE, BEM-ESTAR E ENVELHECIMENTO. AS CONDIÇŌES DE SAÚdE E DE VIDA DOS IDOSOS NO MUNICÍPIO DE SĀO PAULO", apresentado pela pesquisadora Maria Lúcia Lebrăo.

Atenciosamente,

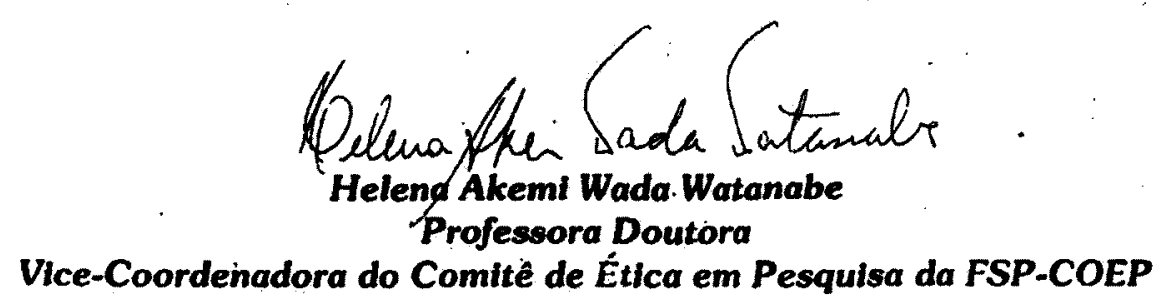


ANEXO 4 QUESTIONÁRIOS DO ESTUDO SABE 2000 E 2006 
MARIA LUCIA LEBRAO CONCLUIU O DOUTORADO EM SAUDE PUBLICA PELA UNIVERSIDADE DE SAO PAULO EM 1982. ATUALMENTE E PROFESSOR TITULAR DA UNIVERSIDADE DE SAO PAULOO. PUBLICOU 23 ARTIGOS EM PERIODICOS ESPECIALIZADOS E 26 TRABALHOS EM ANAIS DE EVENTOS. POSSUI 5 CAPITULOS DE LIVROS E 5 LIVROS PUBLICADOS. POSSUI 104 ITENS DE PRODUCAO TECNICA. PARTICIPOU DE 13 EVENTOS NO BRASIL. ORIENTOU 9 DISSERTACOES DE MESTRADO E 3 TESES DE DOUTORADO NA AREA DE MEDICINA. RECEBEU 9 PREMIOS E/OU HOMENAGENS. ATUA NA AREA DE SAUDE COLETIVA, COM ENFASE EM EPIDEMIOLOGIA. EM SUAS ATIVIDADES PROFISSIONAIS INTERAGIU COM 49 COLABORADORES EM COAUTORIAS DE TRABALHOS CIENTIFICOS. EM SEU CURRICULO LATTES OS TERMOS MAIS FREQUENTES NA CONTEXTUALIZACAO DA PRODUCAO CIENTIFICA. TECNOLOGICA E ARTISTICO-CULTURAL SAO: MORBIDADE, DADOS HOSPITALARES, MORBIDADE HOSPITALAR, CID, CID PARA A PRATICA, CLASSIFICACAO INTERNACIONAL DE DOENCAS, CLASSIFICACAO INTERNACIONAL DE DONCAS, DEMANDA HOSPITALAR, ENSINO MEDICO E ESTATISTICA EM SAUDE, ESTUDOS DE ENVELHECIMENTO.

(Texto informado pelo autor)

\section{Outras Bases:}

Diretório de grupos de pesquisa

SCiELO - artigos em texto

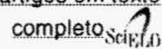

Última atualização do currículo em 26/05/2009

Endereço para acessar este CV:

http://lattes.cnpq.br/5317708343061802
Certificado

pelo autor em

$26 / 05 / 09$

Dados pessoais

Nome Maria Lucia Lebrao

Nome em citações LEBRAO, M. L.

bibliográficas

Sexo Feminino

Endereço profissional Universidade de São Paulo, Faculdade de Saúde Pública, Departamento de Epidemiologia.

Av Dr. Arnaldo, 715 - Pinheiros

01246-904 - Sao Paulo, SP - Brasil

Telefone: (11) 30667724 Fax: (11) 30823886

URL da Homepage: http:ll

Formação acadêmica/Titulação

1994 Livre-docência

Universidade de São Paulo, USP, Brasil.

Título: , Ano de obtenção: 1994.

1977 - 1982 Doutorado em Saúde Pública .

Universidade de São Paulo, USP, Brasil.

Título: Morbidade Hospitalar no Vale do Paraíba, 1975, Ano de Obtençâo: 1982.

Orientador: Ruy Laurenti.

Bolsista do(a): Fundaçăo de Amparo à Pesquisa do Estado de São Paulo, .

Palavras-chave: Morbidade Hospitalar.

Grande área: Ciências da Saúde / Área: Saúde Coletiva / Subárea: Epidemiologia.

Setores de atividade: Saúde humana.

1974 - 1977 Mestrado em Faculdade de Saúde Pública.

Universidade de São Paulo, USP, Brasil.

Título: Análise da Fidedignidade dos Dados Estatísticos Hospitalares Disponiveis na Secretaria de Estado da Saúde de São Paulo, em 1974, Ano de Obtenção: 1977.

Orientador: Ruy Laurenti.

Bolsista do(a): Fundação de Amparo à Pesquisa do Estado de São Paulo, . .

Palavras-chave: DADOS HOSPITALARES.

Grande área: Ciências da Saúde / Área: Saúde Coletiva / Subárea: Epidemiologia.

Setores de atividade: Saúde humana.

1972 - 1973 Especialização-Residência médica

Faculdade de Ciências Médicas e Biológicas de Botucatu. Residência médica em: Medicina Preventiva Número do registro:

1979 - 1979 Especialização em Didática do Ensino Superior

Núcleo de Tecnologia Educacional Para a Saúde Centro Latino Americano de Te.

1976 - 1976 Especialização em Curso Procedimentos da Pesquisa Científica

Faculdade de Saúde Pública.

1975 - 1975 Especialização em Uso da Classificaçăo Internacional de Doenças Em M 


\title{
Soraya Martins de Alencar
}

Curriculum Vitae

\section{Dados Pessoais}

\author{
Nome Soraya Martins de Alencar \\ Nascimento 28/07/1981 - Rio Branco/AC - Brasil \\ Endereço eletrônico \\ e-mail para contato : soraya @ usp.br \\ e-mail alternativo : soraya_alencar@hotmail.com
}

\section{Formação Acadêmica/Titulação}

2007

Mestrado em Saúde Pública.

Universidade de São Paulo, USP, São Paulo, Brasil

Título: Rede de apoio social dos idosos residentes no Município de São

Paulo

Orientador: Maria Lúcia Lebrão

Bolsista do(a): Fundação de Amparo à Pesquisa do Estado de São Paulo

2000 - 2004 Graduação em Serviço Social.

Pontifícia Universidade Católica de São Paulo, PUC/SP, São Paulo, Brasil

Título: Envelhecimento no Mundo e no Brasil: Desafios para a prática do assistente social

Orientador: Mercedes Cywinski

Bolsista do(a): Conselho Nacional de Desenvolvimento Científico e Tecnológico

\section{Formação complementar}

2008 - 2008 Modelos de multinível.

Universidade de São Paulo, USP, São Paulo, Brasil

2008 - 2008 Pacote estatístico STATA.

Universidade de São Paulo, USP, São Paulo, Brasil

2008 - 2008 Modelagem Hierarquizada e Equações Estruturais.

Fundação Oswaldo Cruz, FIOCRUZ, Rio De Janeiro, Brasil

2008 - 2008 Monitoria em curso Pacote Estatístico STATA.

Universidade de São Paulo, USP, São Paulo, Brasil

$2009-2009 \quad$ Análise de Sobrevida.

Universidade de São Paulo, USP, São Paulo, Brasil

2009 - 2009 Monitoria em curso Análise de Tabelas 2x2.

Universidade de São Paulo, USP, São Paulo, Brasil

2009-2009 Monitoria em curso Pacote Estatístico STATA.

Universidade de São Paulo, USP, São Paulo, Brasil 